Florida International University

FIU Digital Commons

\title{
The Promise and (Im)Possibility of the Debt-Free Student: A Qualitative Analysis
}

\author{
Michael W. Ward \\ Florida International University, mward030@fiu.edu
}

Follow this and additional works at: https://digitalcommons.fiu.edu/etd

Part of the Higher Education Commons

\section{Recommended Citation}

Ward, Michael W., "The Promise and (Im)Possibility of the Debt-Free Student: A Qualitative Analysis" (2020). FIU Electronic Theses and Dissertations. 4390.

https://digitalcommons.fiu.edu/etd/4390

This work is brought to you for free and open access by the University Graduate School at FIU Digital Commons. It has been accepted for inclusion in FIU Electronic Theses and Dissertations by an authorized administrator of FIU Digital Commons. For more information, please contact dcc@fiu.edu. 


\title{
FLORIDA INTERNATIONAL UNIVERSITY
}

Miami, Florida

THE PROMISE AND (IM)POSSIBILITY OF THE DEBT-FREE STUDENT: A QUALITATIVE ANALYSIS

\author{
A dissertation submitted in partial fulfillment of \\ the requirements for the degree of \\ DOCTOR OF PHILOSOPHY \\ in \\ HIGHER EDUCATION
}

By

Michael W. Ward 
To: Dean Michael Heithaus

College of Arts, Sciences and Education

This dissertation, written by Michael W. Ward, and entitled The Promise and

(Im)Possibility of the Debt-Free Student: A Qualitative Analysis, having been approved in respect to style and intellectual content, is referred to you for judgement.

We have read this dissertation and recommend that it be approved.

$\begin{array}{r}\text { Benjamin Baez } \\ \hline \text { James Burns } \\ \hline \text { Rebekah Schulze } \\ \hline \text { Daniel Saunders, Major Professor }\end{array}$

Date of Defense: March 26, 2020

The dissertation of Michael W. Ward is approved.

Dean Michael Heithaus

College of Arts, Sciences and Education

Andrés G. Gil

Vice President for Research and Economic Development and Dean of the University Graduate School

Florida International University, 2020 


\section{DEDICATION}

For Grandpa Mike, Grandma Lily, Mom, and Dad

Without your support my academic journey would not have been possible. 


\section{ACKNOWLEDGMENTS}

This dissertation project would not have been possible without the support of my wonderful fiancée, Amanda. Without her encouragement, especially during the drafting and editing phase, this project would never have been completed. Thank you for guiding me through the ups and downs of this endeavor.

I would also like to thank the members of my dissertation committee, Dr. Benjamin Baez, Dr. James Burns, Dr. Rebekah Schulze, and my Chair, Dr. Daniel Saunders. Your guidance, support, feedback, and encouragement were critical to my success throughout this process.

To my friends/colleagues both inside the higher education program and out, including, but not limited to, Almi, Eric, Gerson, Justin, Kristina, Matt, Robbert, and Susy - thank you for the laughs and support along the way.

To Jungle and Slinky, thank you for sitting with me on the couch as I read, thought, and wrote over the past several years.

Finally, I would like to thank the New York Knicks for being so terrible over the past six years that I was able to fully focus on this project. 


\title{
ABSTRACT OF THE DISSERTATION \\ THE PROMISE AND (IM)POSSIBILITY OF THE DEBT-FREE STUDENT: \\ A QUALITATIVE ANALYSIS
}

\author{
by \\ Michael W. Ward \\ Florida International University, 2020 \\ Miami, Florida \\ Professor Daniel Saunders, Major Professor
}

As economic inequality in higher education continues to increase, many states and universities have started to introduce financial promise programs meant to eliminate college costs for eligible students. Further, many lawmakers and politicians have also brought debt-free college to the forefront of their campaigns, creating a discourse of the allegedly debt-free student. While debt is most commonly associated with financial liability, scholars have also started to consider other, non-financial ways debt can manifest Financial debts require repayment in dollars, while non-financial debts might require repayment not in money, but in feeling, conduct, attitude, or sense of obligation, for example. When more than the association of money is considered, it is possible to contemplate the other ways that debt, both financial and non-financial, might work to affect individual decision making across multiple temporalities. Much has been written about the foreclosing aspects of debt theoretically, but little empirical research has been conducted in this area. This study highlights how low-income students in a promise program understand and make meaning of their present and future decision making in relation to perceptions of their own debt. Semi-structured interviews were conducted with 
thirteen low-income college students who qualified for a need-based promise program. Transcripts of each interview were analyzed to identify themes relevant to each research question. The results of this study suggest that the participants in this sample experienced not only financial debts with attending college, but non-financial debts as well. Specifically, students discussed their experiences navigating non-financial emotional, social, and racial/ethnic debts, among others, as they paid for the opportunity to attend college. Additionally, many of the students in this sample experienced the foreclosing aspects of these non-financial debts as they navigated the college decision making process including where they felt they could attend and what major to pursue. Importantly however, these non-financial debts were not only foreclosing. In fact, many of the students expressed the opportunities they were able to pursue as a result of the commitments and non-financial debts they felt they owed their families, highlighting the both the foreclosing and opportunity creating nature of these non-financial debts. 


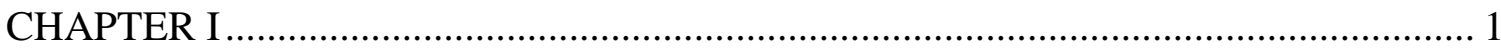

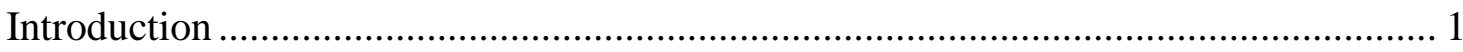

Background and Statement of the Problem............................................................... 4

Purpose and Research Questions........................................................................... 7

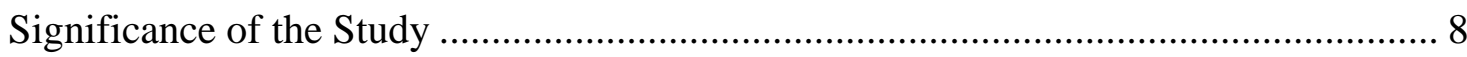

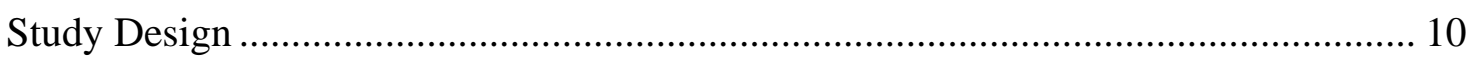

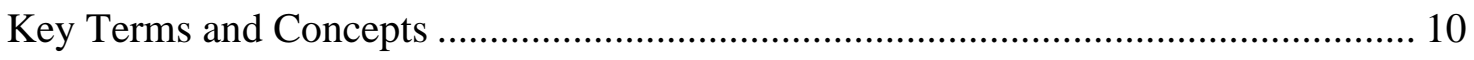

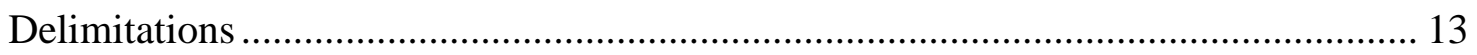

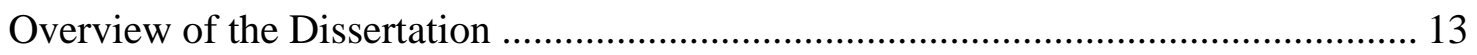

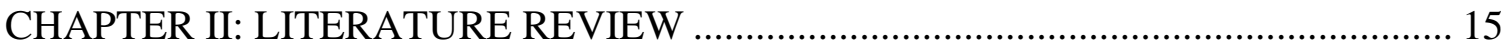

Neoliberal Ideology in the United States ............................................................... 15

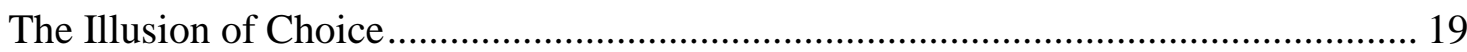

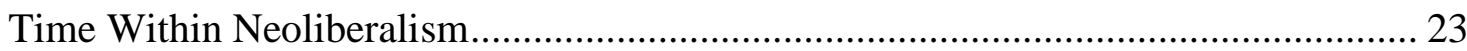

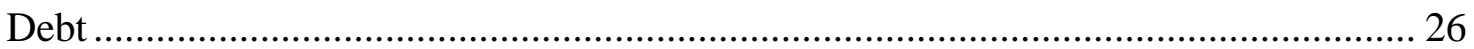

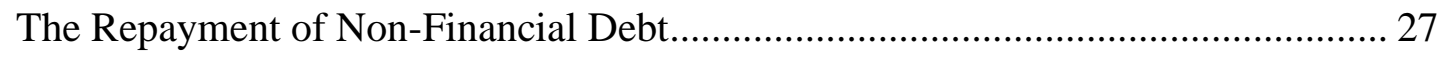

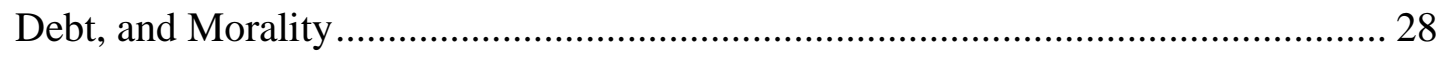

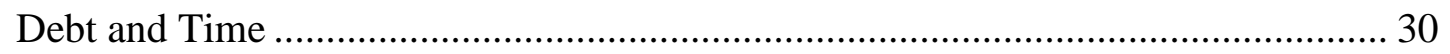

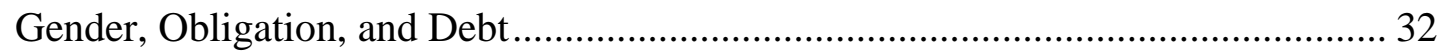

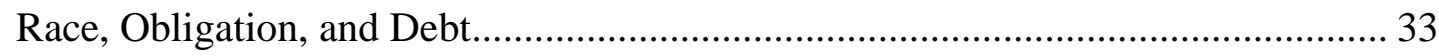

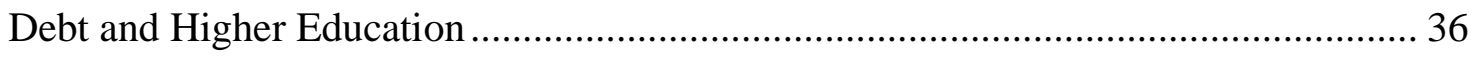

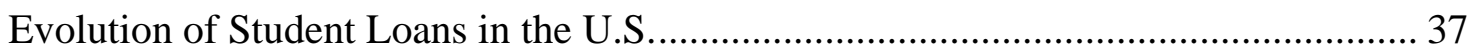

The Beginning of Student Loans in America ……………………………….......... 37

The 1960's: The Beginning of Public/Private Partnerships ....................................... 38

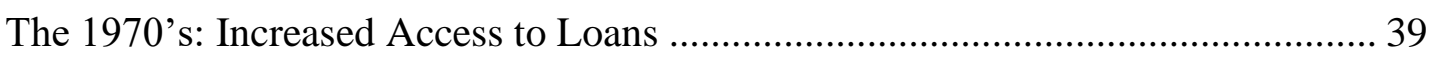

The 1980's: Amid the Neoliberal Turn, Loan Use Skyrockets .................................... 41

The 1990's: Neoliberal Student Loans Policy is Bipartisan........................................ 45

The New Millennium: A Student Loan Crisis? ......................................................... 46

The Student Loan Crisis by the Numbers.................................................................. 50

What Makes Today's Crisis Different? ………………….................................... 52

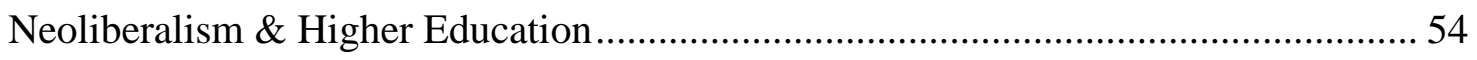

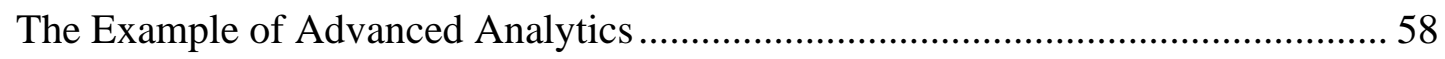




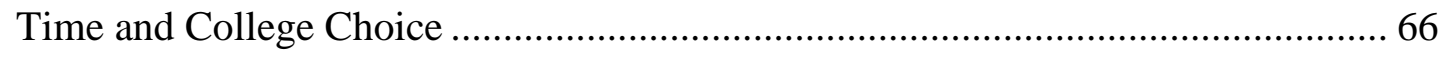

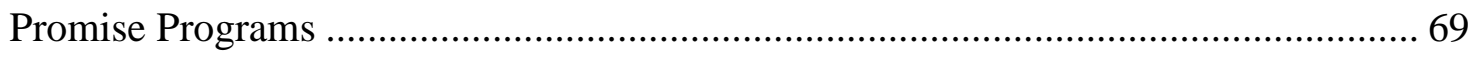

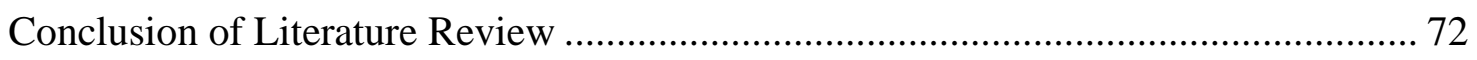

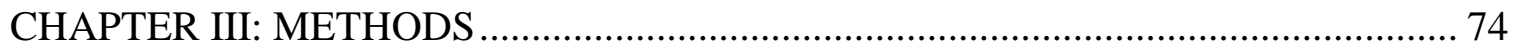

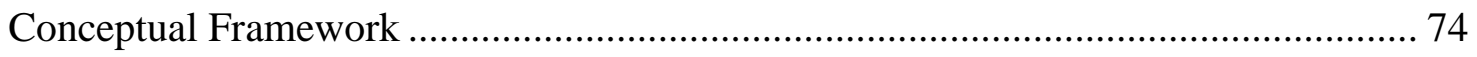

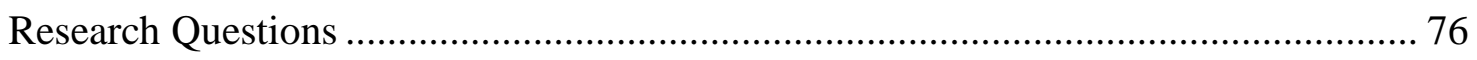

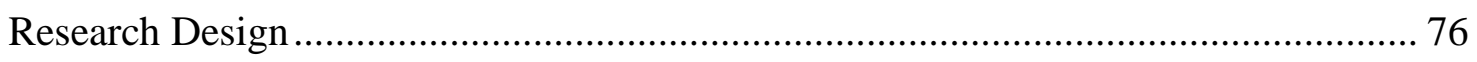

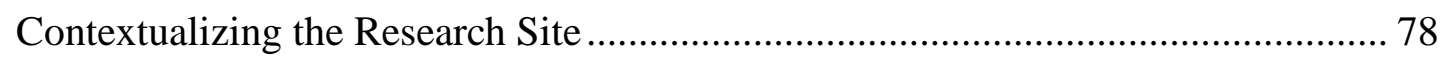

Sampling Universe: The Golden Promise Program ................................................. 79

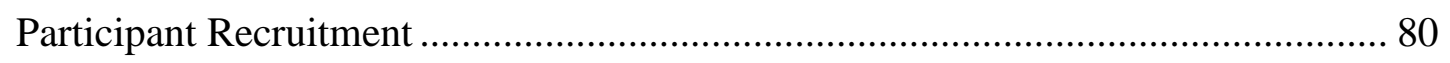

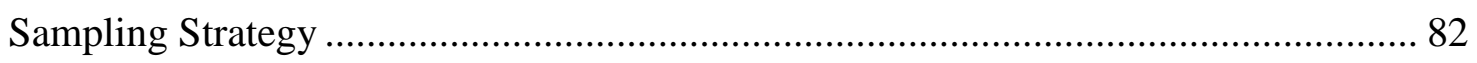

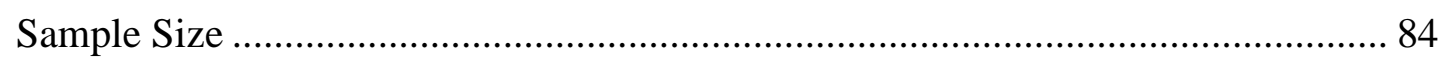

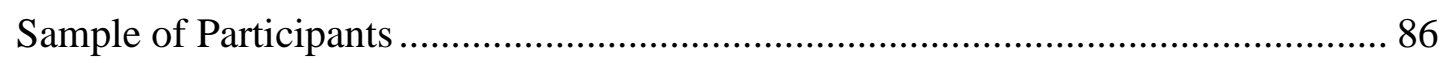

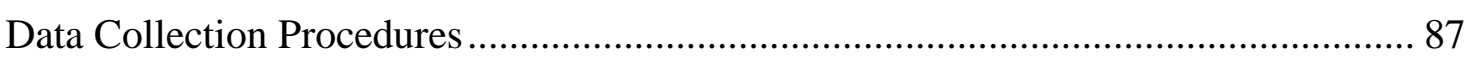

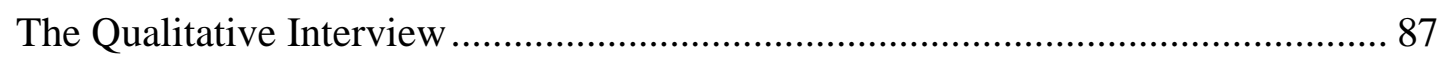

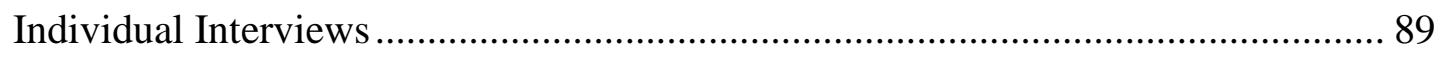

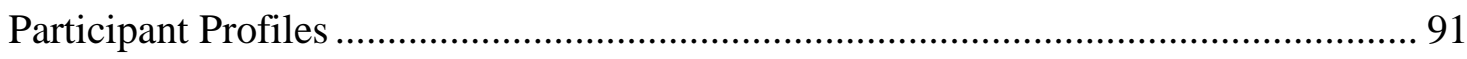

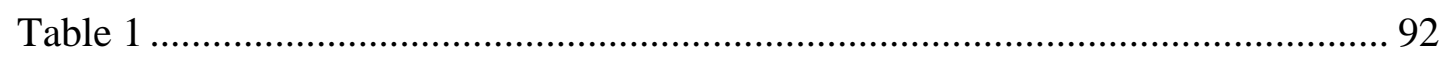

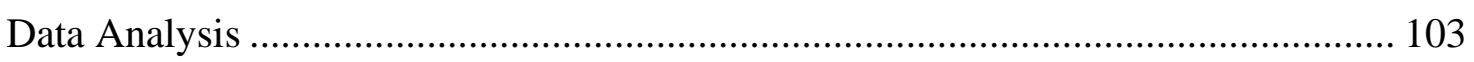

Code Choices and Their Operational Definitions.................................................... 104

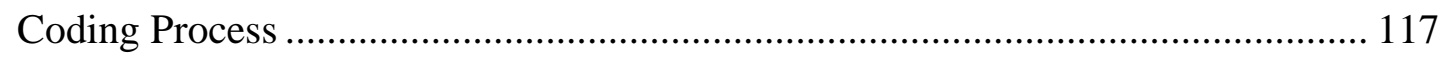

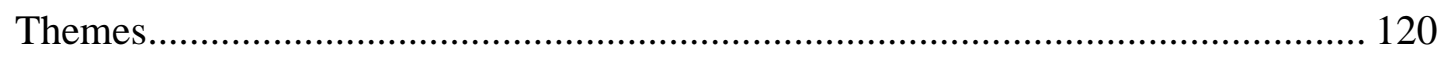

Computer Assisted Qualitative Data Analysis Software ………………................. 121

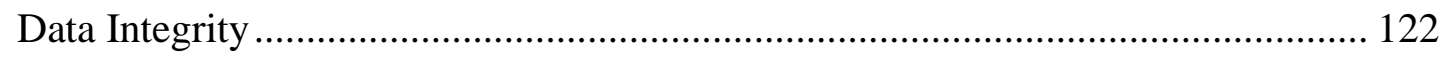

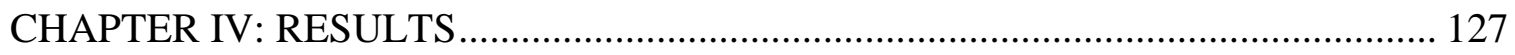

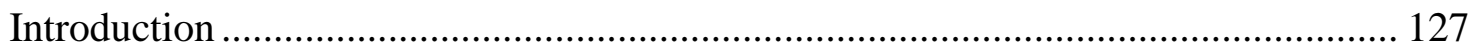

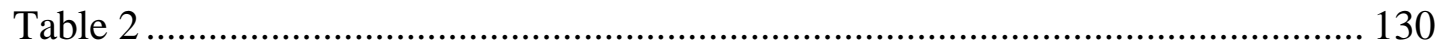

The Meaning of a Promise ............................................................................ 130

It Can Be a Little Rough; Sometimes I Have to Take Out Loans ............................ 131

I've Heard of It, But I Did Not Know They Had Me Under That ............................. 134

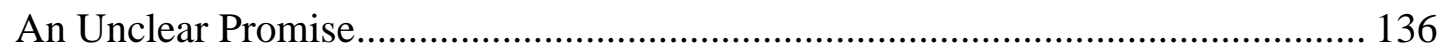

Non-Financial Debt and Its Repayment ............................................................... 141 


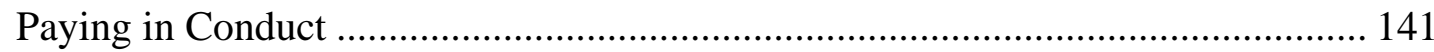

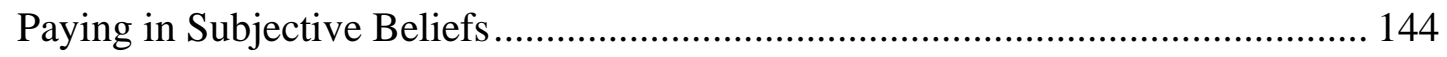

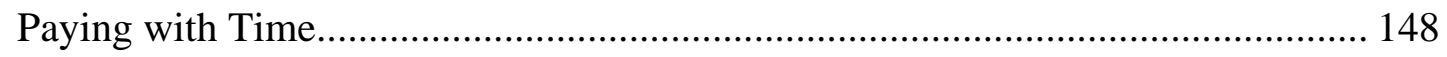

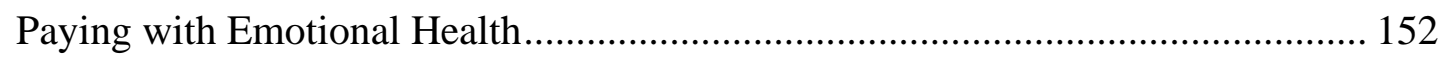

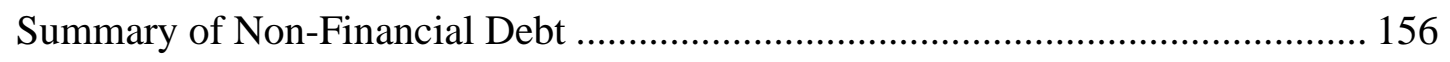

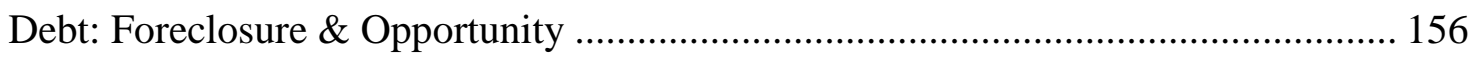

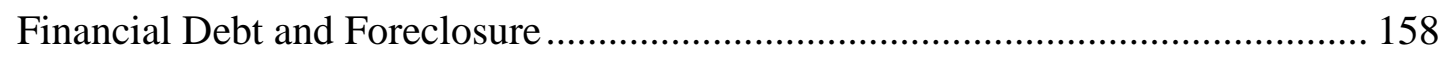

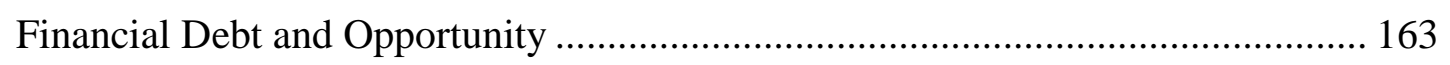

Non-Financial Debt and Foreclosure................................................................. 165

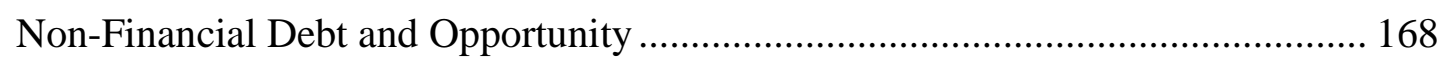

The Difficulty in Separating the Financial and Non-Financial ............................... 170

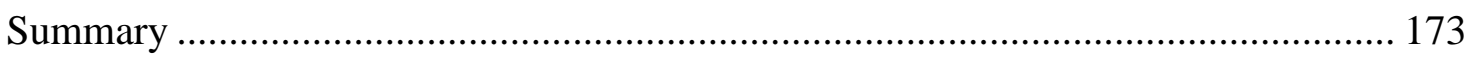

CHAPTER V: DISCUSSION AND FUTURE DIRECTIONS ..................................... 176

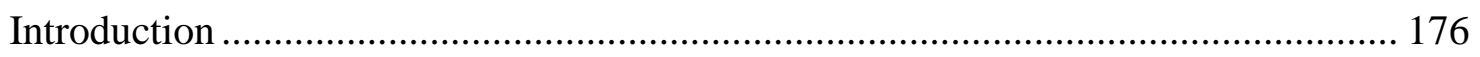

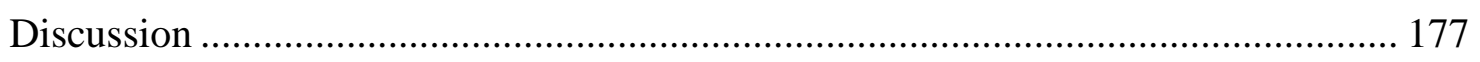

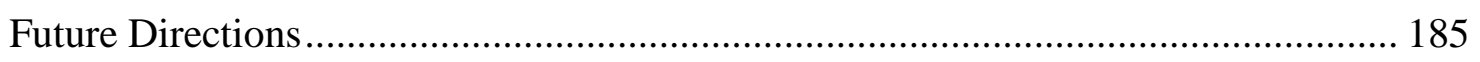

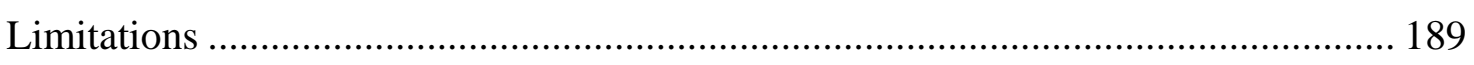

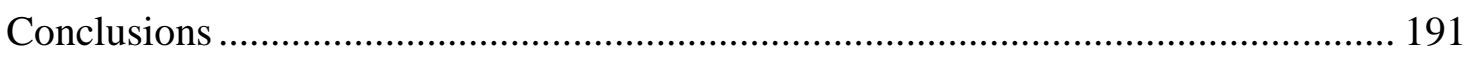

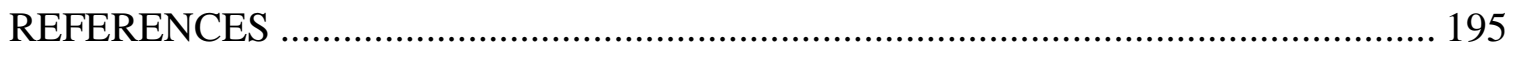

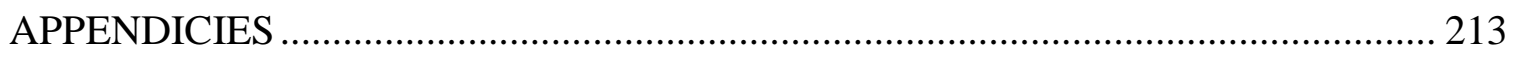

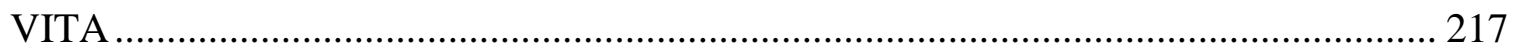




\section{LIST OF TABLES}

TABLE

PAGE

1. Participant Demographic Information........................................92

2. Super-Ordinate and Sub-Themes................................................. 130 


\section{CHAPTER I}

\section{Introduction}

In the epic novel East of Eden by John Steinbeck (1952; 1992), many of the characters experience struggles that center around the concepts of free-will and choice. At one point in the novel, a character posits that is in fact humankind's free-will and the ability to make their own choices that differentiates humankind from the rest of life on earth; "think of the glory of the choice! That makes a man, a man" (Steinbeck, 1952; 1992, p. 304). East of Eden, however, was written during the post-World War II years of progress and excitement in the United States (for some); an era years before neoliberalism would take hold of global social, economic, and fiscal policy during the 1970’s (Lazzarato, 2015).

According to Brown (2015), "neoliberalism is best understood not simply as economic policy, but as a governing rationality that disseminates market values and metrics to every sphere of life" (p. 176). One of the key tenets of neoliberalism is the notion that by enhancing the marketization of everyday life and eliminating regulation, individuals will be able to live in a world ripe with choices and freedoms (Lissovoy, 2015). However, under the current neoliberal landscape that surrounds almost every aspect of life, freedoms and choices are rapidly deteriorating (Brown, 2015), leaving "the glory of the choice" a distant memory for all but a select group of elites. Brown argues that under neoliberal rationality "freedom... as self-rule... and participation in rule by the demos gives way to comportment with a market instrumental rationality that radically constrains both choices and ambitions" (p. 41). As a result of this neoliberal order 
individuals are stripped of their freedom and autonomy; "we no longer choose our ends or the means to them" (Brown, p. 42).

In many cases, these limits on freedom and choice are a result of individuals needing to take on debt in order to survive (Lazzarato, 2011; 2015). Neoliberal policies have slashed taxes and social spending alike creating wealth disparities benefiting large corporations and the wealthiest individuals in the world (Lazzarato, 2011). By the end of 2019, the richest 500 individuals across the globe added $\$ 1.2$ trillion to their fortunes and the wealthiest $0.1 \%$ of Americans control an astounding piece of the economy in the US (Metcalf and Witzig, 2019). In 2017, the income earners in the $10 \%$ earned over $50 \%$ of generated income and between the years of 1993 and 2017 earners in the top 1\% received $51 \%$ of total income growth (Saez, 2019). Over the past 40 years, CEO compensation has increased 1000\% and CEOs on average make 278 times more than the average worker in their companies (Cox, 2019).

As world-wide wealth disparities have increased and middle- and working-class families have faced deepening economic insecurity, debt and credit have become an integral part of everyday life (Lazzarato, 2015). Debt is an implicit and explicit part of everyday life - credit cards, student loans, mortgages. The average American household carries $\$ 6,849$ of credit card debt each month, adding up to a total of $\$ 444$ billion annually; the average American learner carries $\$ 46,822$ worth of student loan debt, totaling over \$1.6 trillion owed in the U.S. (El Issa, 2019). Neoliberalism has "ushered in the substitution of social rights (the right to education, health care, retirement, etc.) for access to credit, in other words, for the right to contract debt" (Lazzarato, 2015, p. 66). For many families and individuals, taking on debt is a critical part of their ability to send 
their child to college or attend themselves (Hsu and Fisher, 2016). Ultimately, neoliberalism has ushered in the era of the indebted student (Gildersleeve, 2017).

In response to the student debt crisis created by neoliberal policy where the dollar value of outstanding student loans in the US is over \$1.5 trillion, many states and institutions have started to introduce financial aid programs aimed at eliminating debt for students who qualify. One example of aid programs meant to help students pay for college are promise programs. Often, these programs are scholarships funded by state governments or individual institutions that hope to eliminate the full cost of tuition and in some cases, additional educational costs (Perna and Leigh, 2018). Further, these scholarships are usually place-based, meaning the student must be a resident of their state in order to qualify for funding (Perna and Leigh, 2018). There are many examples of these programs throughout the United States and they vary greatly in terms of eligibility requirements, how/when aid is awarded, and the types of costs covered (Perna and Leigh, 2018). Ultimately, the rise in frequency of promise programs has created a discourse on the elimination of debt or the creation of a "debt-free student" who can leave the university clear and free of financial burden (e.g. Nilsen, 2018).

This study examines the experiences of students in one promise program, the Golden Promise program at Florida International University (FIU). The Golden Promise covers the cost of tuition and fees at FIU for in-state residents who have an expected family contribution (EFC) of zero dollars and is completely need-based. According to representatives in the university's financial aid office (via personal communication), around $50 \%$ of the student body at FIU has an EFC of zero. The amount awarded to each student is calculated to cover any gaps after federal and state aid have been awarded, 
typically known as a last dollar scholarship. In discussing the Golden Promise program at FIU, one administrator noted that one of the goals of the program was to ensure that students in the program who graduate from FIU would "be debt-free" (Lacayo, 2017).

\section{Background and Statement of the Problem}

Akers and Chingos (2016) define debt as "a tool that enables an individual to consume more today by taking money from her future self" (p. 5). While this definition may seem simple, it highlights the temporal aspect to debt that is important to consider when evaluating the wide reach debt has in modern society. According to Lazzarato (2015), "control through debt...is exercised within an open space and an unlimited time, that is, the space and time of life itself...The question of time, or duration is at the heart of debt...[T]ime as possibility, as future" (Lazzarato, 2015, 69-70). Returning to freedom and choice, debt can act to narrow one's choices; instead of money, students are expected to repay their debts "in conduct, attitudes, ways of behaving, plans, subjective commitments...etc" (Lazzarato, 2011, p. 104). This is especially true for many students as they navigate paying for their postsecondary educational expenses.

The dollar amount of student debt in the US has surpassed $\$ 1,600,000,000,000$, an almost incomprehensible number. In response to neoliberal economic policies that have increased individuals' reliance on debt, policymakers, states, colleges, and universities have created a discourse around the "debt-free" student (e.g. Bernie 2020, 2020; Lacayo, 2017, The Office of Hillary Rodham Clinton, 2017). In fact, “debt-free” college has become a critical piece of 2020 Democratic primary campaigns. Bernie Sanders' campaign wants to abolish all existing student loan debt in the US and make public colleges and universities tuition free for all Americans (not tied to EFC or need) 
(Bernie 2020, 2020). While she was still in the campaign, Elizabeth Warren proposed eliminating up to $\$ 50,000$ of existing student debt for Americans making less than $\$ 250,000$ per year while also introducing a plan to make public colleges and universities tuition free for all Americans (Warren for President, 2020). In terms of making future educational attainment "debt-free", both the Sanders and Warren campaigns established the idea of education as a public good that should be accessible to all Americans, without income qualifiers. Both campaigns however solely describe "debt-freeness" as the nonexistence of tuition and fees, without going into further detail. The Biden campaign only proposes free two-year college, but steeps its "freeness" in the idea that only "hardworking individuals" should qualify for free community college without explicitly defining what "hard-working" means (Biden for President, 2020). Pete Buttigieg's campaign actually discussed the idea that there may be costs associated with college that are not covered with tuition and fees and discussed living expenses as part of his proposal to increase the maximum value of federal Pell grants (Pete for America, 2020). The postsecondary and higher education policies championed by these Democratic presidential candidates exemplify the lack of nuance within the current mainstream conversation about debt-freeness within higher education.

As such, while a student may not face any financial debts associated with attending college, authors question whether or not an individual can truly be debt-free (e.g. Gildersleeve, 2017; Gillespie, 2018; Lazzarato, 2011; 2015). According to Peters (2016), "students and the young...go into debt earlier and never emerge from the circle of debt and self-investment that surrounds their existence" (p. 12). The present study highlights the links between student debt, students' experiences, and their obligations. 
Muir and Weinstein (1962) write, "the notion of being indebted to someone for a given some of money is a familiar concept in many cultures... Yet most of us, in our daily routines, become the witting and unwitting debtors and creditors of others" (p. 532-533). The purpose here is to expand and elaborate upon conventional notions of debt as a financial relationship between creditor and debtor. For Gildersleeve (2017), "debt...includes but also expands beyond the common association with money" (p. 55). In fact, in addition to debt's common association with money, it is possible to contemplate the other ways that debt might work to affect individual decision making in multiple temporalities as a result of neoliberal rationale. This is important because of the ebbs and flows that indebtedness has through time and across generations.

Debt exists in these multiple temporalities because it creates a connection for students between their present and future selves (Lazzarato, 2015). Nowotny (1994) has termed this connection between present and future - the extended present. Essentially, the concept of the extended present acts as a way to understand time from the perspective that even in the present we are always planning for the future; in the future there exist problems that have not yet occurred, yet in the present we are obliged to plan for them even before they've happened. Lazzarato (2011) writes that "the debt economy is an economy of time and subjectivation...Indeed, neoliberalism is an economy turned toward the future, since finance is a promise of future wealth (p. 46). This idea of a promise in the future is critical because it establishes that a person's decision making capability today has already been turned towards the future without acknowledging (or caring about) the circumstances the individual is in today. Lazzarato continues, "debt appropriates not only the present labor time of wage-earners and of the population in 
general, it preempts non-chronological time, each person's future, as well as the future of society as a whole (p. 46-47). The creation of the extended present is a symptom of neoliberalism's reach into domains of temporality that have blurred lines between present and future. The idea of debt rests in this extended present wherein the neoliberal subject may need to forfeit future decision making to make choices today. As highlighted above, much has been written about the foreclosing aspects of debt theoretically, but little empirical research has been conducted on how individuals understand and make meaning of their past, present, and future decision making in relation to perceptions of their own debt.

\section{Purpose and Research Questions}

As a result of neoliberal policy affecting institutions of higher education, the student debt crisis has continued to worsen, with an additional \$20 billion of student loan debt added to the ledger of dollars owed by American learners by the end of 2019 (Federal Reserve Bank of New York Research and Statistics Group, 2019; Sollenberger, 2019). As more students have had to consider taking on debt to pay for their education, some states and institutions have begun to introduce methods of eliminating debt for students (Perna and Leigh, 2018; Poutre and Voight, 2018). As the ubiquity of promise programs increases, more research is needed to understand their impacts for low-income students. While much of the current research focuses on the outcomes for students in these programs (Carlson and Laderman, 2018; Perna and Leigh, 2018; Poutre and Voight, 2018), more information is needed that explores experiences of students in the early stages of their promise program. Specifically, Perna and Leigh (2018) call for a better understanding of "whether particular program types achieve intended goals and 
outcomes...and further research...to determine the most useful operationalization of variables to measure conceptually important characteristics" (p. 164). Ultimately, through an examination on non-financial debt, this exploratory study contributes to the research literature by providing an additional framework with which to assess promise programs and the discourse around the debt-free student with the purpose of exploring debt's effect on decision making.

By better understanding the experiences of the "debt-free" student in higher education it is possible to more clearly understand notions of freedom and debt under neoliberalism. For Lazzarato (2011), the futures of neoliberal subjects are foreclosed due to debt; by exploring the experiences of "debt-free" students, I empirically examine how such students are impacted by debt as it relates to past, present, and future decision making.

Ultimately, this project explores various forms of indebtedness through the experiences of students who, at least discursively, have no debts through the following research questions.

1. Do "debt-free" low-income students in a promise program express non-financial debts within their educational experiences?

2. Does debt, both financial and non-financial, act as a foreclosing agent in student decision making for students in a need-based promise program?

\section{Significance of the Study}

As I will discuss in Chapter II, there has been little empirical, qualitative research exploring the non-financial debts of low-income students in a promise program. Research literature on student debt most commonly focuses on how the financial aspects of debt 
impact students' lives (e.g. Despard et al., 2016; Houle and Warner, 2017; Hsu and Fisher, 2016; Perna, Kvall, and Ruiz, 2017). On the other hand, theorists, writers, and researchers have started to examine the non-financial debts that individuals may encounter in their daily lives and interactions (e.g. Biss, 2015; Gildersleeve, 2017; Lazzarato, 2011; 2015; Padgett Walsh, 2018; Peters, 2016). By engaging with allegedly debt-free students and exploring different types of indebtedness, this study explores debts that exist outside of financial commitments, the temporalities in which indebtedness operates (i.e. present and future), and how indebtedness impacts freedom and choice. Further, this study contextualizes the multidimensional roles that debt plays in neoliberal society. Specifically, neoliberalism's focus on all things economic has dominated the conversation, shaping discourse around debt that has relegated non-financial debts to the periphery.

Graeber (2014) catalogues a history of debt that existed well before modern financial markets and even modern concepts of money. However, since the rise of neoliberalism, which, according to Graeber, has forced us to "think of ourselves as tiny corporations, organized around [the] relationship of investor and executive: between the cold, calculating math of the banker, and the warrior who, indebted, has abandoned any sense of personal honor and turned himself into a kind of disgraced machine," (p. 376) there is little room left in the conversation for an analysis of the non-financial components of debt.

Lastly, this study has implications for the discourse on access and success in higher education. Seeking to understand the experiences of students with an EFC of zero in regard to debt provides useful insights into the decision making processes of students 
from economically disadvantaged backgrounds. This study contributes to the existing literature on debt and student choice by examining an understudied phenomenon that benefits from empirical research, non-financial debt and freedom.

\section{Study Design}

For this qualitative interview study, I conducted interviews with thirteen students participating in the Golden Promise scholarship program at Florida International University. I analyzed the interview data I collected to identify themes relevant to students' experiences with debt and alleged “debt-freeness." My study was informed and guided through my use of Gildersleeve's (2017) and Lazzarato’s $(2011 ; 2015)$ scholarship on debt, foreclosure, and choice.

This study was guided by my desire to conduct a study that critically examined students' debs from both a financial and non-financial standing. Further, I wanted to examine how students' debts enabled and/or foreclosed their decision making capabilities within the context of neoliberalism. According to Lissovoy (2015), "the first task for a pedagogy against neoliberalism — and against neoliberal freedom — is to challenge the prevailing definition of freedom itself" (p. 51). This study examines students "freedoms" within neoliberal higher education and questions the systems that have led students to certain "choices" in the first place.

\section{Key Terms and Concepts}

The following section explores the key terms, concepts, and programs that will be explored throughout this manuscript. The first concept necessary to define is promise programs. Promise programs are grant or scholarship programs that states or institutions offer to reduce the amount of money that low- and middle-income students must pay for 
college. One of the most common components of promise programs is the "promise of a financial aid award to traditional-age students living in a particular place" (Perna and Leigh, 2018, p. 164). There are a variety of differences between programs across institutions and states. Some programs are more restrictive than others in terms of postsecondary the post-secondary options provided recipients. Programs also differ in the criteria for students to qualify; some are need-based, while others are merit-based (Perna and Leigh, 2018).

Often, a critical part of qualifying for a promise program is the completion of the Free Application for Federal Student Aid (FAFSA). The FAFSA is an application required by the federal government to determine what students qualify for federal student aid (U.S. Department of Education, Federal Student Aid, 2019). Further, many state and institutional grants are also contingent upon the completion of the FAFSA (U.S. Department of Education, Federal Student Aid, 2019). The FAFSA requires that students and their families complete over 100 questions where students are required to know: their social security number or alien registration number; federal tax return information (their own or parents); records of untaxed income; cash, savings, and checking account balances; and investments (Bettinger, Terry Long, Oreopoulos, and Sanbomatsu, 2012; US Department of Education, Federal Student Aid, 2019).

Once a student has completed the FAFSA, their Expected Family Contribution $(E F C)$ is calculated. EFC is the minimum amount of money that the federal government calculates a students' family can contribute to the cost of their higher education based on their income and wealth. According to the U.S. Department of Education, EFC "is a number that determines students' eligibility for federal student aid" (US Department of 
Education, Federal Student Aid, 2019). This EFC calculation is based off the income and other assets of the student and their parent(s) or spouse (Kelchen, 2015). Generally, there are 3 distinct ways a student can qualify for an EFC of zero: completing the entire FAFSA, completing the simplified version of the FAFSA (excludes assets), or being automatically assigned an EFC of zero through participation in "certain means-tested program[s] and income requirements, depending on individual circumstances" (Kelchen, 2015, p. 180). In all cases, students need to demonstrate substantial financial need. EFC is a problematic concept in practice because it does not consider the cost of living in certain locations and penalizes families for having children whose college years overlap (Auer Jones, 2009). Even considering this, it is currently the way federal financial aid payments and qualification for specific promise programs are calculated.

In addition to the important higher education systems highlighted above, this manuscript will frequently refer to financial debt and non-financial debt. Financial debts are those where repayment in the form of money is expected. Often, these take the form of student loans (e.g. Minicozzi, 2005), credit card debt, mortgages, or car loans, for example (Gillespie, 2018). Non-financial debt is more abstract than financial debt and varies based on individual experience. Non-financial debts require "repayment" not in money, but in feelings, conduct, attitudes, or sense of obligation for example (e.g. Gildersleeve, 2017; Lazzarato, 2011; Lazzarato 2015). Other types of debts explored in this study are: emotional debts, conduct debts, commitment debts, and time debts (these concepts are all explored in Chapters 4 and 5). Each of these debts extends into both the financial and non-financial realms of debt, due to the difficulty of completely separating the two categories; the extension of neoliberalism into modern society has inextricably 
linked the financial and non-financial impacts of debt in modern society. Returning to Graeber (2014), neoliberalism has ushered in a “world [where] paying one's debts can well come to seem the very definition of morality;" TV shows, advertisements, and other media enterprises blur these lines by both covertly and overtly insinuating that "personal debt is ultimately a matter of self-indulgence, a sin against one's loved ones” (p. 376378). A financial choice becomes a moral one, and a moral choice, in some ways, can become a financial one.

\section{Delimitations}

This is an exploratory study meant to examine the experiences of students in one promise program at a large, urban, four-year university. I aim to begin to understand how one specific population of students in a promise program makes meaning of debt in their lives. The results are not meant to be generalized to students in all promise programs, but instead highlight the experiences of students in one specific program at this point in time.

As such, there may be other examples of students who could be considered debtfree, e.g. students whose families are able to afford their tuition outright, or students that qualify for any of the merit-based scholarships that FIU offers covering the full cost of tuition and fees. While these students may have their own experiences in relation to debt, obligation, and the foreclosure of choices, this study focuses specifically on students with demonstrated financial need that have qualified for the Golden Promise Program at FIU.

\section{Overview of the Dissertation}

This dissertation consists of five chapters. Chapter I is an introduction to the study and provides relevant background information on the research problem. Chapter II is a review of selected literature that expands upon the background literature presented in 
Chapter I. In Chapter II, I discuss conceptualizations of debt, freedom, and choice within a framework of neoliberal ideology and highlight some of the non-financial ways individuals are burdened, specifically focusing on class, race, and gender. I also explore neoliberalism's impact on higher education finance and present historical information about financial student debt in America.

Chapter III discusses the methods and methodology of the present study, including why I chose to conduct a qualitative interview study, data collection techniques, participant biographies, and data analysis and coding techniques.

Chapter IV includes the results of the present student, with a focus on student quotations that highlight all relevant themes. The first super-ordinate theme is "Nonfinancial debt and its repayment." This theme features four sub-themes: (1) paying in conduct, (2) paying in subjective commitment, (3) paying with time, and (4) paying with emotional health. These four sub-themes represent the ways in which the students in this sample were indebted non-financially. The second super-ordinate theme is "debt: foreclosure and opportunity." The sub-themes within this super-ordinate theme center on the ways debt, both financial and non-financial, had foreclosing and opportunity creating aspects for the students in this sample.

Chapter V summarizes my findings, provides suggestions for future research, limitations, and conclusions made from this study. 


\section{CHAPTER II: LITERATURE REVIEW}

\section{Neoliberal Ideology in the United States}

As a global ideology and governing principle, neoliberalism has augmented the ways in which societal institutions operate (Brown, 2015). According to Rowlands and Rawolle (2013), “neoliberalism has been discussed as a range of objects, from discourse, theories and programs of research to the practices and actions of activist think tanks, policy and political positions and global approaches to economic development" (p. 262). The advance of neoliberalism in the 1990's is summed up succinctly by McDonald (2017):

In the Clinton years of the 1990s, this insidious ideology truly got its sea legs, and marched triumphant across the globe, capturing the minds of both liberal and conservative elites, university administrations, and think tanks...to media talking heads on down, ad nauseam (p. 131).

Despite the range of ideas, neoliberalism most often features two key points: "increased competition - achieved through deregulation and the opening up of domestic markets, including financial markets to foreign competition [and] a smaller role for the state, achieved through privatization and limits on the ability of governments to run fiscal deficits and accumulate debt" (Ostry, Loungani, and Furceri, 2017, p. 38). Aviram (2014) defines neoliberal policies as those that reduce government support for social expenditures, such as appropriations for health care or education. Often such policies are linked with tax cuts for the wealthiest individuals and corporations under the guise of economic stimulation that often have consequences for working-class and low-income individuals (Soos, 2016). For Wacquant (2012), the practice of neoliberalism is much different than the one presented by governments, politicians, and the media; "in practice, 
states deviate from the doctrinal template of 'small government' only to foster a businessfriendly climate for capitalistic endeavors, to safe-guard financial institutions and to repress popular resistance to the neoliberal drive toward 'accumulation by dispossession" (p. 69).

Essentially, neoliberal policies and agendas have infiltrated "almost all states...sometimes voluntarily and in other instances in response to coercive pressure" (Harvey, 2005, p. 470). While certainly a global phenomenon, the present study focuses on and examines neoliberalism's impact on governance in the United States. A prime example of neoliberalism's reach has been the privatization of services that were once funded and operated by the federal government. From partnerships between the former Immigration and Naturalization Service (INS) and the Corrections Corporation of America (CCA), to the Lockheed Martin Corporation delivering social services in Los Angeles County, to the US federal government essentially outsourcing the War in Iraq, the privatization of once publicly run entities has been happening for decades (Bernstein and Blitt, 1986; Fifield, 1997; Hayes, 2004). Now, "the state's role is not to provide an alternative realm apart from the market, but to grease the wheels of the market, subsidizing citizens to participate in it and businesses to provide social services" (William, 2006, p. 91). Asylum seekers, the incarcerated, soldiers, and civilians of wartorn nations are all seen as malleable subjects ripe to produce capital.

Writing in the 1960s, almost a decade and a half before neoliberal ideology would become central to American and Western European policy, Gary Becker expanded upon the notion of human capital theory, which would become one of the foundational inspirations for modern neoliberal policy. For Becker (1962) the main idea of human 
capital theory is steeped in crass economic logic; "activities that influence future real income through the embedding of resources in people. This is called investing in human capital" (p. 9). In other terms, the individual is born and raised to be homo oeconomicus. The notion of homo oeconomicus has been relevant in social and political theory since the 1800's, when the concept of an abstract economic subject was created for an analysis of political economy by John Stuart Mill, however even as an abstraction, Mill's notion of the economic man would go on to have great influence in future works on social and political economy, and is oft cited (Persky, 1995). In fact, some of the first academic discussions of homo economics, or the economic man, were written specifically in response to Mill's idea that the goals of humankind were more than the simple desire to increase wealth, luxury, and leisure and to procreate (Persky, 1995). Interestingly, this idea of the economic individual would become widely regarded in circles that would advance neoliberal policies in the future, such as Reagan and Thatcher in the 1980's (Metcalf, 2017). Metcalf (2017), writes "peer through the lens of neoliberalism and you see more clearly how the political thinkers helped shape the ideal of society as a kind of universal market (and not, for example, a polis, a civil sphere or a kind of family) and of human beings as profit-and-loss calculators (and not bearers of grace, or of inalienable rights and duties)" (n.p.).

For Foucault (2008a), homo oeconomicus is a rational being that predictably responds to variables in his/her environment. The behavior of homo oeconomicus has become increasingly more governable through mechanisms of biopolitical control (Foucault, 2008) and the institutions, practices, traditions, ideologies, and relations put in place over centuries by those in power (Foucault 2007); "homo oeconomicus...responds 
in a non-random way, a systematic way...to modifications in the variables of the environment...[and] is eminently governable" (Foucault, 2008a, p. 271). For Brown (2015), "we are everywhere homo oeconomicus and only homo oeconomicus" - the economic (wo)man (p. 33). This presentation of governmentality is not meant to demean the individual or present people as puppets with no autonomy, instead it aims to highlight the ways in which neoliberal policies have worked to shape the decisions individuals are able to make by creating guardrails around what "choices" they have in the first place. Instead of being free to make his/her own decisions, the individual is then left with what presents as a choice, but is actually a decision left to be made as a result of the societal conditions created in the aftermath of neoliberal policies. Ideas of personal freedom have been so entrenched in American society, via neoliberal think-tanks, newsmedia, and policy makers, that they almost become impossible to question (Harvey, 2007). Further, "neoliberal institutions are committed to reducing the role of government, and empowering market functioning irrespective of public desires" (Thompson and Coghlan, 2015, p. 64), creating a world in which the profits of major corporations are put ahead of sick individuals who are, essentially, forced to figure out ways to eke out an existence. For Harvey, "neoliberalism confers rights and freedoms on those "whose income, leisure and security need no enhancing', leaving a pittance for the rest of us" (p. 38). The responsible neoliberal subject acts through the appearance of choice, with all roads leading to the production of capital. Under this logic, economic success and struggle/failure is solely the responsibility of the individual, whose economic status becomes the foundation for their moral and social status. Ultimately under neoliberal rule "the powers of the state are thus directed at empowering entrepreneurial subjects in their 
quest for self-expression, freedom and prosperity. Freedom, then, is an economics shaped by what the state desires, demands and enables" (Davies and Bansel, 2007, p. 249-250); in this case the state being not only the U.S. federal government but the global corporations and elite that help guide federal policy.

\section{The Illusion of Choice}

Neoliberal actors, such as politicians, policy makers, and think-tanks, among others, have created a world where almost exclusively economic and market-oriented approaches have reshaped society and created an atmosphere where freedom and choice are limited in ways that individuals may not even recognize. According to Shirazi and Johnson (2019), the language of choice itself is:

profoundly deceitful. The notion of "choice" as a gateway to freedom and a sign of societal success isn't a neutral call for people to exercise some abstract civic power; it's free-market capitalist ideology manufactured by libertarian and neoliberal think tanks and their mercenary economists and media messaging nodes. Its purpose: to convince people that they have a choice while obscuring the economic factors that ensure they really don't: People can't "choose" to keep their employer-provided insurance if they're fired from their jobs or "choose" to enroll their kids in private school if they can't afford the tuition (n.p.).

Neoliberalism has overtly and covertly worked to limit individual freedoms and choices despite claims of the opposite. Chen (2013) discusses the idea that neoliberal ideologies have shifted understandings of freedom from a more 'humanist' oriented definition of "unlimited, universalized and absolute freedom" to one of the "ability to choose maximum material gain and profit in order to construct one's own self, and agency now means the ability to be active in this materialistic, profitable self-actualizing project" (p.

443). She summarizes:

instead of being coerced by direct disciplinary surveillance by the state, individuals now willingly and actively self-govern in a climate enabled by the 
state. Traditional calls for resistance to dominant power and norms presuppose an opposition or tension between the individual and the state, but such opposition is now collapsed and defused in the neoliberal atmosphere, for out of self-interest, now the individual as homo economicus can self-serve best by choosing to follow the normative line" (Chen, 2013, p. 444).

The normative line of life can take many forms for different individuals, but one of the most common assumptions made of individuals, especially today, is one's educational pathway - high school followed by attending some form of post-secondary education; almost $70 \%$ of students who graduated from high school in 2018 were enrolled in colleges or universities as of April 2019 (Bureau of Labor Statistics, 2019). In today's educational landscape, many students are left with the "choice" between navigating the American job market without some form of post-secondary education or going into debt to finance their education. Strikingly, this was not always the case; over the past $\sim 80$ years lawmakers and politicians, shaped by neoliberal ideology, have worked to make this "choice" a reality for millions of American learners (Best and Best, 2014; Lumina Foundation, 2017; Zumeta, Breneman, Callan, and Finney, 2012). Specifically, the history of student loan policy in America, explore later in this manuscript, shows the evolution from policies meant to increase access and opportunity to those that, both purposely and inadvertently, work to limit the choices students have in the first place.

For McDonald (2017), neoliberalism is "a worldwide gospel canon within which few of us can see out to an entirely other way forward through the caged bars of a failing doctrine" (p. 131). One of the key components of neoliberalism is the illusion of freedom that is imparted upon subjects by governments, think-tanks, and mass media organizations to name a few. Elliott (2018) writes that the one of the goals of neoliberalism is to introduce workers to a market based existence "in a manner that does 
not view it as commoditized or alienated but rather as chosen and self-activated" (p.

1280).

Chen (2013) critiques neoliberalism through women's popular media, specifically its portrayal of freedoms for women that may not exist in reality; the idealized version of freedom portrayed in popular media actually serves to covertly and overtly influence individuals towards specific choices and predetermined ideals. Chen (2013) writes:

The promise of freedom, which should mean the elimination of all prohibitions and restrictions on the individual's exercise of choice, has turned into a new form of restriction and pressure which urges women to follow and not deviate, and to constantly live up to its promise by actively choosing and enjoying. Sexual liberation and freedom, in particular, have become the new imperative, the new obligation from which one is not free. This is a mentality that the neoliberal selfgovernance contributes to, whereby to be empowered, free and actively choosing becomes the normative ideal to which one must aspire through ceaseless self-care and perfection, and for which one must bear full responsibility and take risks.

Similarly, allegedly, "class-blind" and "race-blind" policies supported and championed by politicians aligned with neoliberal ideologies, especially those labeled as "choice" programs, have actually worked (often by design) to limit individual freedoms and opportunities (Burt and Baber, 2018; Camp, 2016). Often these veiled “choice" programs theoretically meant to provide the individual with more options, but as Shure (2019) argues, "choice" is more often than not an attempt by neoliberal and conservative lawmakers to further privatize services and reduce government spending by alleging that the free-market will work its alleged magic and create affordable, dependable programs that give individuals a choice of what college to attend or what health insurance provider to select.

In the United States alone, one can see the negative consequences of neoliberal policies through the example of the healthcare system. The primarily employer based, 
free-market system of health insurance currently dominating American health care is allegedly ripe with choices for consumers to make, presenting a facade of choice among insurance plans. However, prior to the passage of the Affordable Care Act (ACA) in 2010, Americans trying to purchase insurance plans directly from companies faced many hurdles including price and needing to be screened for pre-existing conditions and "risks," for example (Field, 2014). Even after the passage of the ACA in 2010, which attempted to reduce some of the barriers to gaining affordable insurance coverage outside of an employer plan, according to Collins, Gunja, Doty, and Bhupal (2018), 57\% of Americans remain uninsured or underinsured (12.4 uninsured and 45\% underinsured, respectively). The key point here is that decisions about the health care coverage of millions of Americans (and they choices they have to "decide" their coverage) are the result of decades of lobbying and policy decisions made by American leaders to maintain the status-quo of employer-based health coverage in the US (Field, 2014). As it stands, however, the choices of market-based health insurance plans often leave millions of Americans without coverage, leading to choices that in fact limit freedoms and decisionmaking capacities. Further, as several of the politicians currently running for the Democratic presidential nomination will contend, how free are individuals when the choices they are left with are food and/or housing and medical care and medications they need to survive (e.g. Sanders, 2019).

Racialized language by politicians during the 1980's and 1990's led to the passage of laws by the federal government that additionally worked to limit individual freedoms and choices in the United States in another area - the criminal justice system (DuVernay, 2016). This eventually culminated in "regimes of mass incarceration" that 
have continued to exist to this day. Given the impacts on personal freedoms that mass incarceration has had on millions of Americans, especially those from communities of color (Alexander, 2010), this is another example of a direction connection between neoliberal policies and the erosion of individual personal freedoms for the masses, not the select few privileged in neoliberal society (Harvey, 2007). The example of mass incarceration highlights the intentional disconnect between the words of neoliberally aligned lawmakers and the actual impacts of policies rhetorically meant to increase individuals' ability to exist and make decisions freely.

By creating a world dominated by the illusion of choice, neoliberally aligned think-tanks, policy makers, and politicians have created a world controlled by the "ideology of choice" (Lowenberg, 1995), where "poor" decisions can be used against individuals who are simply trying to navigate the societal conditions created through deregulation and the promise of free-market, trickle-down economics. Control over resources is (and the choices about how to utilize them) are stripped from the masses and instead controlled by the few. Perhaps one of the most valuable of these resources is time; a resource managed both by an individual's employer and/or the State and proper/mainstream society.

\section{Time Within Neoliberalism}

One of the ways neoliberalism has worked to limit freedom and choice is through the evolution of values around time spearheaded by many organizational leaders and policy think-tanks. According to Nowotny (1994), increased economic integration into daily life (i.e. neoliberalism, although Nowotny does not use the term specifically) has led to changes in the relationship between the individual and time; individuals are now required to respond almost simultaneously to the events that occur around them, there is a 
"constant temporal presence, real or virtual, of others" that did not previously exist (p. 31). Anyone who does not take part in the simultaneity of daily life is deemed an outsider, which can have negative social and, perhaps most important to the neoliberal subject, negative economic consequences (Nowotny, 1994). Under neoliberalism, even time has been commodified; more colloquially, it brings to mind the phrase "time is money" or "the scarcity of time." Under the parameters of neoliberalism, the commodification of time is coupled with the extended present and homo oeconomicus.

Homo oeconomics, under neoliberalism, must not only endure the condition of the extended present, but the experience of the destabilization and "flexibilization" of how time is perceived (Martineau, 2017). What was once known as 8-8-8 time, or 8 hours for work, 8 hours for leisure, and 8 hours for sleep, has been destabilized for in modern society there is almost no way to escape the marketization of leisure time given that "leisure time in many ways has been absorbed into the logic of global market time" (Martineau, 2017, p. 221). The flexibilization of time comes as a result of the integration of technology into everyday life (Martineau, 2017; Robinson and Godbey, 2005). The lines between work and home become blurred as individuals feel the need to answer emails in the era of bringing work home (Martineau, 2017). Today, individuals do not solely bring home "concerns about work, but actual work, or search for work. In this sense also, economic (work) considerations infiltrate non-work time and can therefore be seen as a further way in which market time makes itself felt in people's everyday extraeconomic activities" (Martineau, 2017, p. 224). In this way, the homo oeconomics of neoliberalism exists in the extended present in their present at work extends in perpetuity as they are never far removed from having to answer a work call or answer a work email. 
Now that humankind is eternally connected, there is no time in which they cannot be striving to be productive. Further, this drive for productivity is passed down through generations; children see their parents working around the clock and come to see it as a normal part of everyday life without question. As Harvey (2007) discusses, one of the key components of neoliberal control is the way that neoliberal think-tanks, news media, and policy makers have linked self-worth with productivity. Instead of asking why we have internalized this idea of working around the clock, we are asking what more we can do from home. For Elliott (2018), one of the great achievements of neoliberal governance is the "process of folding work into socially passive consumption" (p. 1290). The ideology of neoliberalism, through language of choice, has successfully blurred the line between work and leisure, creating a temporal reality that stretches on in perpetuity due to the lack of boundaries around each segment of an individual's day.

Further, given the commodification of leisure activities under neoliberalism, the need and drive to continue working, even off hours, becomes almost second nature. Martineau (2017) argues, “consumption practices during leisure time are of course not new historical phenomena, but the extent to which leisure time nowadays has become market dependent certainly is. Work time and leisure time therefore share the common characteristic of being under market-time hegemony. The historical tradition of leisure as an extra-economic time has therefore been under serious challenge" (p. 224). When thinking about the notion of time is money, in modern society that becomes true as a result of the increased marketization of leisure time; as a result of the increased inequality created as a result of neoliberal policies, the joys of consumerism exist to distract from the bleak reality facing millions of Americans who work long hours for not enough pay. 
One of the ways that neoliberal ideology has advanced this idea is through the language of choice and freedom as discussed by Shirazi and Johnson (2019) and Shure (2019). Workers are now trapped in a time-cycle of endless work because they feel the drive to be productive as a result of the things they have witnessed and experienced across their lifespan; their time is no longer their own. An additional way that workers and homo oeconomics is trapped in the extended present is through indebtedness.

\section{Debt}

The uneven development of neoliberalism has also created an environment where the use of debt has worked to individuals' advantage or disadvantage depending on one's race, class, and/or, gender. Debt has been used as a mechanism of control in the United States well before the rise of neoliberal ideology, since the days of Westward Expansion following the Revolutionary War (Biewin, 2012). Colonizers would use financial debt to coerce indigenous peoples to sell off their land at a price well below its value (Biewin, 2012). In an 1803 letter to William Henry Harrison, Thomas Jefferson wrote:

to promote this disposition to exchange lands, which they have to spare and we want, for necessaries, which we have to spare and they want, we shall push our trading uses, and be glad to see the good and influential individuals among them run in debt, because we observe that when these debts get beyond what the individuals can pay, they become willing to lop them off by a cession of lands (n.p.).

This use of debt to force the sale of lands was critical to America's westward expansion and is a prime example of how the State can use debt as a way to intimidate and control its subjects and foreclose futures. As neoliberal policies have taken hold around the world, wages have stagnated and inequality between classes has increased (Brown, 2015). Overall, the global use of debt has expanded since the rise of global neoliberalism 
as highlighted by the rise of use in credit cards, mortgages, and student loans over the last 40-50 years. In fact, the amount of non-real estate debt held per person increased from $\$ 1,186$ in 1948 to $\$ 10,168$ in 2010 (adjusted for inflation) (Indiviglio, 2010).

Debt inequality between classes however does not solely exist in a financial realm. The introduction to this study established the existence of both financial and nonfinancial debt. The idea of debt as a non-financial burden is not meant to replace the dominant understanding of debt as a financial mechanism, but instead make room in the conversation for broadening our understanding of how debt can inhabit both financial and nonfinancial spaces. Presently, this is an underexplored area in research on higher education. Researchers are examining the emotional, social, familial, financial, moral, and decision making aspects of having financial debt (e.g., Archuleta, Dale, and Spann, 2013; Callender and Jackson, 2005; Elliott and Lewis, 2017; Polletta and Tufail, 2014; Sweet, Nandi, Adam, and McDade, 2013), however, often fail to explore the debts one might experience outside of the common financial association, such as obligation, debt of gratitude, or burden, for example. Studies on non-financial debt seem most likely to be located in research and writing on philosophy, religion, and ethics (e.g., Ahn, 2010; Berger, 1975; Card, 1988). A critical piece of expanding upon the solely financial understanding of debt is redefining what it means to be indebted and how this indebtedness is conceptualized for individuals in everyday life.

\section{The Repayment of Non-Financial Debt}

Ultimately, the indebted person is "deprived of the possibility of evaluating risks and taking them; they are prohibited from challenging themselves in unexpected situations, working things out, and coming up with solutions" (Lazzarato, 2011, p. 143). 
For Peters (2016), debt is essentially taking out a lease on one's future. Or, in reality, an extended present where decisions are made in the present because a future where one's debts must be repaid is always approaching; a state where the present does not become the past or the future - it is constantly with us, shaping our decisions and foreclosing our possibility for change. In this way, debt "repayment" comes in many forms, for example a sense of obligation (Mitchall and Jaeger, 2018), one's health (Sweet, 2018), or future choices and decisions (Padgett Walsh, 2018; Lazzarato, 2011).

For example, Card (1988) discusses the idea that individuals can feel "indebted" to family and friends for "benefits received" (p. 116), and based on her interpretation of Kantian ethics writes "even after expressing appreciation... one could never pay such a debt...off" (p. 117). Lazzarato (2015) discusses the idea of a "life debt" as proposed by other theorists. The idea of a life debt proposes that "the living are obligated to repay their debt, a repayment that has no end because, ultimately, the debt of life is an infinite debt. Debt functions in the same way as original sin" (p. 76).

\section{Debt, and Morality}

There is a moral component to how one utilizes and accounts for their time under neoliberal regimes, just as one's morality can come into question based on how they choose to spend their money. Sweet (2018) argues, "while neoliberalism operates formally as an economic and policy agenda supported by an underlying ideology, it's more insidious effects may be as a widely diffused cultural orientation that shapes the way people view themselves and others" (p. XX). Even speaking in fully financial terms, Polletta and Tufail (2014) found that, among the participants in their sample, 
to repay one's debt in full was a moral obligation, even if the debt was high and even if it was owed to a creditor whom one neither knew nor likely would have any contact with, if the debt was incurred for an important purpose and if the creditor provided in good faith the service that was paid for (p. 25).

Peebles (2010), discusses the idea that in most research on credit/debt, that the creditor has the moral high ground, while the debtor is left being seen as being a "burdensome and imprision[ed]" individual (p. 226). This is illustrated clearly throughout the evolution on federal student loan policy throughout the past several decades. Through questioning the merits of grant and scholarship aid and choosing to offer more loan based aid, the Reagan administration sought to cut funding for need-based aid as a way to ease the alleged financial burden on the government. This in turn, with the assistance of policies passed during the Clinton, Bush, and Obama administrations, led to the unintended consequence of creating the problem of indebted students that were seen as an alternative burden on the State - the freeloading borrower defaulting on their loan payments, who did not make a responsible choice about where to go to college or how to spend their (or the government's) money.

This moral argument is steeped in neoliberal ideas about personal responsibility and individual moral failings. Lowenberg (1995) discusses such ideas as the "ideology of choice," where individuals' choices are used as leverage to eliminate or reduce social services, especially if they are "judged guilty of life-style lapses" (p. 321). Neoliberalism guides individuals to act within certain norms, including how individuals spend their time, recalling Brown (2015) and Foucault (2008a) in their discussion of homo oeconomicus. 
Even from a young age, children are taught ways in which they can become profitable; "all the activities and time spent on the formation of a child as a kind of capital-ability machine...constitute practices of investment that are expected to yield future returns" (Tadair, 2013, p. 20). For Nowotny (1994), there are consequences for a lack of involvement within dominant temporal systems. Certain occupations, lifestyles, and decisions are valued over others; differences can be translated into "temporal inequalities [where] society runs the risk of moving at two speeds [and] the fast group are doing it right" (Nowotny, 1994, p. 32). No longer does the 8-8-8 time clock exist; instead individuals are always on the clock, expected to be productive regardless of when they are being asked to produce (Martineau, 2017; Nowotny, 1994).As a result of neoliberalism's influence on temporality and the "proper" way individuals are obliged to utilize the twenty four hours in a day, "the so-called 'passive' citizen of the welfare state becomes the autonomous 'active' citizen with rights, duties, obligations and expectations - the citizen as active entrepreneur of the self; the citizen as morally superior" (Davies and Bansel, 2007, p. 252).

\section{Debt and Time}

The notion of morality and time is also critical when understanding debt in terms of temporality. Padgett Walsh (2018) writes, "all debts are temporal in nature, extended through time...In each case...debt is ascribed based upon an interpretation of what occurred in the past. The debtor's choices and actions in the present and future are constrained by earlier circumstances of debt creation" (p. 48-49). Ultimately, as a result of the temporal nature of debt, moral judgements are made of debtors; "debt is administered by evaluating morality...Each individual is a particular case which must be 
studied carefully because...it is the debtor's future plans, his style of life, his solvency that guarantees reimbursement of the social debt he owes" (Lazzarato, 2011, p. 131).

When making the "choice" to take on debt, individuals are evaluated based on past, present, and expected future behaviors. For Di Feliciantonio (2016), "the new subject shaped by indebtedness is the "responsible" debtor always feeling guilty for their own condition, as well as anxious for not being able to fully perform the "selfentrepreneur" or the "financial subject" evoked by the neoliberal faith" (p. XX); the debtor is not only impacted in the past, but the future. In this way debt works to "appropriate not only the physical and intellectual abilities the poor man employs in his labor, but also his social and existential forces" (Lazzarato, 2011, p. 59). Ultimately, debt limits a person's "power of self-affirmation...[and] the choices that [find] and bear with them modes and styles of life" (Lazzarato, 2011, p. 60).

Debt under neoliberalism requires individuals to account for their future selves and future decisions in the present; "the debt economy is an economy that requires a subject capable of accounting for himself as a future subject, a subject capable of promising and keeping a promise" (Lazzarato, 2011, p. 88). One example of this is the credit score; an individual's entire history is reduced to a number that impacts how they conduct themselves and make decisions in the present and future (Montgomerie, 2008). Of course, the idea of spending time in and of itself has different moral valuations by race, class, and gender, and is emblematic of the ways neoliberal ideology has developed differently for those in power and those forced to the margins of society (Lowenberg, 1995; Rowlands and Rawolle, 2013). 


\section{Gender, Obligation, and Debt}

In an analysis of women, money, and debt, Federici (2018) discusses the idea

that:

The simultaneous dismantlement of the 'welfare state' - a pillar of the neoliberalisation of the world political economy - leading to the practical elimination, in 1996, of Aid to Families with Dependent Children and the defunding of the public services that most affect women's work and income levels (daycare centres, services in support of elderly and the chronically ill, healthcare and educational services) have further eroded the gains access to a wage may provide. As a result, many women today in the United States, while being directly affected by the cuts in state budgets, also carry most of the burden of individual debt.

These financial debts also have non-economic consequences for women. Federici (2018) continues:

Debt and the daily preoccupation with money deeply affects also women's relations to others, producing a tendency to calculate the monetary implications and possibilities of daily interactions. There is also some evidence that debt as well as the marketing of one's services make women more vulnerable to physical violence at the hands of spouses as well as strangers. Debt and worrying about money problems exacerbate family tensions and bring women to work in areas where they are more vulnerable to male violence.

In addition to these troubling situations that arise as a result of having to take on financial debt, women are also more likely to face burdens of non-economic debt as well. Female participants in Mitchall and Jaeger's study discussed family members encouraging students to stay home because "going to college was often not expected of the women in their families" (Mitchall and Jaeger, 2018). This was because participants felt a sense of obligation to stay home and care for family members and siblings based off of familial pressure to do so (Mitchall and Jaeger, 2018). Further, Stein et al., (1998) report that women scored higher than men on several dimensions of felt family obligations. Their study suggests that overall "women reported feeling more obligated to parents and 
reported providing more care" than their male counterparts (Stein et al., 1998, p. 620). These differences were also strongly correlated by generation; young adults rated significantly higher than older generations on the same measures of felt familial obligation (Stein et al., 1998).

There are also gender differences in concerns about one's ability to pay for college. According to Eagen, Bara Stolzenberg, Bates, Aragon, Ramirez Suchard, and Rios-Aguiar, (2015) female students were $10 \%$ more likely to report concerns about their ability to pay for college than males. Also, among women who report having some or major concerns about paying for college are $13 \%$ more likely to state there is "a very good chance" they will seek outside employment to help with college related expenses (Eagen et al., 2015, p. 13). Haultain, Kemp, and Chernyshenko (2010) found that female students were more likely than male students to be afraid of going into debt and less likely to find the idea of taking on educational financial debt useful.

\section{Race, Obligation, and Debt}

In terms of educational attainment, "of the 16.9 million undergraduate students in fall 2016, some 9.1 million were White, 3.2 million were Hispanic, [and] 2.2 million were Black" (US Department of Education, 2018, p. 159). Clearly, what it means to be a "debt-free" student may look different for students from black and Latinx backgrounds versus those from white backgrounds. Research also suggests that there are also differences in obligation and family influence by race and ethnicity. Fuligni (2001) writes that among Latinx families, "the needs of the family usually have priority, and individual members often are asked to downplay their own needs and desires if they conflict with those of the larger group" (p. 61). In terms of the sense of future obligation felt towards 
family, Latin American youth "held significantly stronger values regarding respect and future obligations to their families than those from European backgrounds" (Fuligni, Tseng, and Lam, 1999, p. 1035). According to the authors, these differences were consistent across many sociodemographic characteristics including: "generation, gender, family composition, and socioeconomic background" (Fuligni, Tseng, and Lam, 1999, p. 1040). Lastly, for students from African- and Afro-Caribbean American backgrounds, there are higher reported rates of family interdependence, meaning students from these backgrounds come from families where the family dynamic is a critical part of daily life (Tseng, 2004).

Sometimes this obligation extends towards the responsibility to fellow community members. In an opinion piece written for The Undefeated, Rhoden (2019) argues that elite black student athletes should negotiate with their colleges and universities to get a four-year scholarship for a qualified student from an underserved community. He writes, "If a Power 5 school pines for a Zion Williamson, it should be compelled by the elite athlete to take a student from their community who will stay the full four years at that school" (n.p.). While elite black athletes attending schools in athletic power conferences make up a very small percentage of college students nationwide, this argument provides insight into the sense of debt individuals from communities of color might feel towards the community they came from. Rhoden's (2019) argument highlights the idea that if someone has the opportunity to attend college, they are then obliged to represent their community's interests; “[Zion] Williamson could have created a rich academic opportunity for someone in his community to attend Duke; at an early age, he could have created a legacy" (n.p.). Similarly, Perkins (1983) discusses this idea in the context of 
women's education in the nineteenth century. During the 1800's, education for white women was seen as a way towards the improvement of their homemaking skills and the creation of social standards that would help them in the pursuit of a husband; alternatively, for black women, education was seen as a necessity to "aid in the improvement of their race" (Perkins, 1983, p. 19). This thinking extended well into the twentieth century, eventually becoming a "burden" for black women in leadership roles (Perkins, 1983).

This idea is discussed as racial uplift, where the actions of individuals are expected to "uplift" the standing of the broader population and individuals must consider the impact their actions will have not only on themselves, but on their race/ethnicity as a whole (Perkins, 1983). For Malcom (2015), "given that individuals are viewed as representatives of a category...the limitations and obligations this categorization places on individuals is stressful for both the individual and the group to which he or she is said to belong" (p. 123). Aside from racial uplift, there is the risk of being labeled a sellout that can have negative impacts on mental health for individuals from communities of color. Malcom (2015) discusses the use of the term sellout as a "means in which individuals who violate group norms are stigmatized. Stigmatization functions to eliminate threats to group cohesion by rhetorically excommunicating "heretics'”' (p. 121). For Pettus (2007),

in the hazardous waters of American race politics, a particular danger shadows the successful black American who achieves status and acclaim in mainstream society. Too much approval from "white" society quickly yields suspicions of racial treachery. The black "sellout" suffers a form of cultural banishment-a cruel psychic punishment for an ill-defined crime...Too often, feelings of group pride in an individual's achievements go hand in hand with questions of racial loyalty that can quickly lead to the unsubstantiated branding of a "sellout." (n.p.). 
Essentially, people from communities of color seeking higher education are often caught between the two worlds of racial uplift and being labeled a "sellout."

In addition to family obligations and social stressors, for low-income individuals in black and Latinx communities, there are often a variety of negative social and psychological outcomes associated with living with poverty (Elliott and Sims, 2001). Black and Latinx students are almost 6 times as likely to attend a high poverty school as their white counterparts (US Department of Education, 2018) and black families living in poverty face greater risk of partner violence than other demographic groups living in poverty (Cunradi, Caetano, Clark, and Schafer, 2000).

\section{Debt and Higher Education}

The sections above established the need for expanding the discourse on debt to include the non-financial costs associated with attending an institution of higher learning. Additionally, the financial debts associated with attending college often reduce students to the balance on their student loan bill and have impacts on the very credit score that can impact future decision making capabilities of students in the future (Farrington, 2019). The reality of student loans impacting students' present and future decision making is a relatively new phenomenon in higher education and was brought about by decades of changes in the value of education in the United States as a result of neoliberal ideology and the passage federal student loan policies by leaders who took to heart those values as such policies were constructed. 


\section{Evolution of Student Loans in the U.S.}

\section{The Beginning of Student Loans in America}

One of the defining moments in the history of American higher education was the passage of the Servicemen's Readjustment Act of 1944, which included the GI Bill; one of the first pieces of American legislation that increased access to higher education beyond solely the children of the wealthy (Labaree, 2018). The GI Bill is significant is because it was one of the first instances of the federal subsidy of individual higher education and established the federal government as "financier and coordinator of higher education for millions of Americans" (Fuller, 2014, p. 49; Zhou and Mendoza, 2017). Further, according to Fuller (2014), the GI Bill also established the future model for lowinterest educational loans with the introduction of low-interest housing loans for returning veterans. The federal government's role in higher education continued to expand during the 1950's, when the first federal student loan program for low-income students was introduced as part of the National Defense and Education Act (NDEA) of 1958 (Best and Best, 2014). The passage of the NDEA created the National Defense Student Loan (NDSL) program that provided loan funds directly to institutions of higher education on behalf of students (Elliott and Lewis, 2017). These loans ranged in value from $\$ 1000-\$ 5000$ and required repayment within 10 years at a fixed 3\% interest rate (Elliott and Lewis, 2017). The US federal government created this program during the rise of the Cold War between the USSR and the United States in order to boost the numbers of students attending college and advance scientific (and military) power within the United States (Loss, 2012). The creation of the NDSL program was critical in the history of student loans because it established the federal government's role in student 
lending and was the beginning of the growing financial commitment the US government would make to students and their families.

\section{The 1960's: The Beginning of Public/Private Partnerships}

The U.S. federal government, under President Lyndon Johnson, expanded the use of loans (as well as other types of grant aid) with the passage of the Higher Education Act (HEA) in 1965 (Best and Best, 2014). Specifically, it allowed students who did not qualify for income related grants the ability to take out low-interest loans that did not need to be repaid while they were still taking classes (Zhou and Mendoza, 2017). As highlighted above, under the NDSL program, federal loans were paid directly to institutions on behalf of students; one of the most impactful changes to student loan policy under the HEA of 1965 was the introduction of the Guaranteed Student Loan (GSL) program, which redistributed federal loan dollars from institutions to individuals by having private banks and lenders pay the upfront costs and the federal government cover the cost of interest (Best and Best, 2014).

Also, under the GSL program the private sector financial institutions lending money to students were given a guarantee from the federal government that they would be able to recoup their investment if a student defaulted on their loan payment; in fact, in the event of a default, the debt would be transferred to the federal government so that private lenders would not take a financial loss (Elliott and Lewis, 2017). Zhou and Mendoza (2017) discuss the shift in loan dollars being paid directly to institutions to private loans guaranteed by the federal government as a policy shift in American higher education ideologically aligned with future neoliberal policies; "this approach to loans is essentially neoliberal in that the private sector earns interest from the ransomed future 
earning power of indebted collegians who for years pay that interest and eventually that principle too" (p. 5). While these changes in federal financial aid policy occurred before the widespread global reach of neoliberalism, the public-private partnership created by the HEA of 1965 would be emblematic of the government's reliance on and use of the private sector as part of neoliberal policy in the decades to come.

\section{The 1970's: Increased Access to Loans}

Even as early as the 1970's the federal government recognized that there were problems associated with the burgeoning reliance on student loan debt to finance higher education. In their history of student loans in America, Best and Best (2014) highlight that "policymakers' attention focused on...the frequent need to adjust federal payments to make student loans more attractive to lenders...[who] disliked student loans because...it might be several years before students who borrowed...began to repay their loans" (p. 38). In addition to the historical documents reviewed in their text, this claim is supported by researchers at the time who questioned the viability and longevity of student loans as a method for funding higher education (Campbell \& Boyd, 1970; Carlsson, 1970; McNamara, 1974).

Writing in 1970, Carlsson argues that lenders at the time were wary of offering student loans because of the long repayment period and the pressure from the public to keep interest rates on student loans lower than interest rates on other types of loans they might provide. In addition to fears over private lenders supporting the GSL program, the merits of a grant vs. loan model were also being debated among researchers in higher education. A 1970 article by Campbell and Boyd highlights one example of the concerns researchers had about the impacts student loan programs would have on low- and middle- 
class students attempting to access institutions of higher learning focusing on the idea that shifting towards a primarily loan based model of funding would cause tuition costs to drastically rise thus potentially limiting college access to those solely interested in taking on debt and children of the wealthy.

Ultimately, debates about the merits of the federal government's increasingly expanded role in higher education finance led the federal government to create the Student Loan Marketing Association (Sallie Mae) as part of a reauthorization of the HEA in 1972 under President Richard Nixon (Best and Best, 2014; Lumina Foundation, 2017). Sallie Mae was created in order to increase the commercial and institutional lending to college students where:

banks would lend money to students but then sell their loans to Sallie Mae rather than having to wait years for their loans to be repaid. In turn, Sallie Mae would issue its own government-guaranteed debt in the capital markets, creating a secondary market where investors could purchase bundles of student loans as long-term investments (Best and Best, 2014, p. 39).

Ultimately, the creation of Sallie Mae allowed the federal government to sponsor an increased flow of money into the Guaranteed Student Loan program (Lumina Foundation, 2017). Similar to the analysis provided by Zhou and Mendoza (2017) previously, the creation of a secondary market for student loans was another step towards future neoliberal-type policy for higher education further allowing banks and lenders to profit off of students and their families who needed to go into debt to finance the cost of their higher education. 
In addition, the reauthorization of the HEA of 1972 also established the creation of the Basic Education Opportunity Grant (BEOG) program (later renamed for Senator Claiborne Pell), which provided grants which did not require repayment to students from low-income backgrounds (Loss, 2012). During the first year of the BEOG program student payments were capped at $\$ 1400$ per year, or enough to cover about one-half of the cost at public colleges and universities (Loss, 2012). Given that the cost of federal Pell grants were not enough to cover the full cost of tuition and fees at colleges and universities, students were required to seek out alternative ways to fund their pursuit of higher education. Access to and use of student loans drastically expanded during the 1970 's, which at the time was presented as the extension of choice and opportunity in the college choice process for students (Burt and Baber, 2018).

\section{The 1980's: Amid the Neoliberal Turn, Loan Use Skyrockets}

The expansion of access to student loans was signed into law in 1978 when the federal government passed the Middle Income Student Assistance Act (MISAA), which raised the income ceiling required to qualify for guaranteed student loans and reduced regulations on where students could spend student loan dollars (e.g., for-profit colleges) (Lumina Foundation, 2017; Zhou and Mendoza, 2017). In addition, the MISAA and following reauthorizations increased the maximum payout for Pell grants from $\$ 1,400$ to $\$ 1,800$ to $\$ 2,600$ and introduced a guaranteed loan program for parents (PLUS loans, later renamed the Auxiliary Loans to Assist Students program) (Akers and Chingos, 2016; Lumina Foundation, 2017; Zumeta, Breneman, Callan, and Finney, 2012). This increase in federal Pell grant payouts was not enough to keep up with rising tuition costs; between the years of 1977 and 1981, the dollar value of federal student loans exploded, 
increasing from $\$ 2.2$ billion to $\$ 6.2$ billion (Zumeta et. al, 2012). This increase in student debt was a result of increased loan eligibility and borrowing limits, the rising costs of tuition, and increases in federal financial aid dollars entering the private sector lending market through Sallie Mae (Lumina Foundation, 2017).

Additionally, the MISAA marked a transition from a federal financial aid policy focused on need to one focused on merit; Burt and Baber (2018) write, "the MISAA in particular was an attempt to camouflage the ideological shift from financial aid being need-based for Black and low-income students to being a right to which White and other middle-income students were entitled" (p. 150). Further, based on their analysis of congressional testimony leading up to the passage of the MISAA, Burt and Baber (2018) highlight one of the ways neoliberal ideology worked to shape the discourse around student financial aid - utilizing language focused on choice and freedom. Their analysis which was conducted through the textual analysis of primary source documents shows how those testifying in favor of the MISAA worked to redefine the stated purpose of federal financial aid, shifting the focus from need based to merit based aid (Burt and Baber, 2018). For example, they argue that:

the omission of race [from several of the analyzed testimonies] was strategic in shifting ideology with regard to who deserved aid. Avoiding the mention of "race" or specific races in the context of the MISAA made race no longer central to the discussion of who should receive financial aid. While race was not explicitly mentioned, it was implicitly discussed; race was masked in the usage of words that described socioeconomic status (low-income and middle-income), "access" (generally used to describe Black students' opportunities to go to college), "all" (used to suggest that financial aid should be available to everyone, not just low-income Black students), "diversity" and "poverty (poor)" (p. 149150). 
This ideological shift in language was one of the first steps towards a more neoliberally oriented federal financial aid policy that focused on higher education as an individual investment in human capital, one that would require students, even those from low- and middle-income backgrounds, to shoulder most of the burden of paying for their postsecondary educational opportunities, something that would continue into the Reagan administration of the 1980's. As discussed earlier, the co-opting of ideas around personal freedom and choice, were critical to the advancement of neoliberal policies (Harvey, 2007).

In fact, the election of Ronald Reagan in 1980 was a turning point in the financing of higher education, as loans started to become the dominant way to finance college for students and their families, replacing grants and self-funding (Elliott and Lewis, 2017; Zhou and Mendoza, 2017; Zumeta et al., 2012). The federal government's interest in subsidizing the cost of higher education began to diminish as a result of small government and free-market oriented policies that viewed higher education as a private good meant for the individual (Loss, 2012; Marginson, 2011); "as [the emphasis on human capital theory] gained popularity, questions arose as to why the beneficiary of higher education (that is, the student), should not pay more, or most, of the cost" (Zumeta et al., 2012, p. 72).

As a result of the lingering concerns among law-makers and the public over the costs of the Vietnam War, increases in oil prices, and the general costs of Great Society programs created under Lyndon Johnson lawmakers, led by President Reagan, sought to limit spending during a period of stagnation and inflation in the American economy (Burt and Baber, 2018; Zumeta et al., 2012). In fact, the Reagan government, using the very 
real economic concerns of many Americans at the time as a boogeyman, sought to cease federal funding for higher education completely (with the exception of the neediest students), claiming that it was the responsibility of individual States and the individual student (Saunders, 1982; Zumeta et al., 2012). Writing at the time, Saunders (1982) notes that as a result of the perceived need to increase military spending and boost the American economy, the Reagan administration took aim at federal student aid programs; "the administration is moving toward outright rejection of a federal responsibility for access to higher education," cutting over $\$ 1$ billion in federal funding for student aid between 1981 and 1982 (Saunders, 1982, p. 7).

The 1980's saw some of the lowest increases in federal appropriations for higher education in decades, leading to a $\$ 600$ million gap between appropriated funds and the funds required to maintain federal aid programs (Saunders, 1982; Zumeta et al., 2012). Reagan's early budgets effectively repealed the MISAA, lowering the minimum income needed to qualify for federal grants from $\$ 25,000$ to $\$ 15,000$, leading to an increased reliance on loans to finance higher education. Additionally, during the Reagan years, merit-based aid continued to surpass need-based aid as a result of neoliberal and conservative policy that favored a small government approach (and Reagan's War on the Poor) and a growing distrust of the public towards higher education as a result of continually rising costs (Elliott and Lewis, 2017). And while the American system of higher education has often been a system rife with racial and social inequalities, it was during this period of the 1980's that the governing view of higher education in America began to shift both politically and publicly towards that of an investment rather than an entitlement for every citizen (Burt and Baber, 2018; Loss, 2012). 


\section{The 1990's: Neoliberal Student Loans Policy is Bipartisan}

During the mid/late 1980's and early 1990's, the federal government offered several different loan programs as borrowing limits continued to increase (Elliott and Lewis, 2017). In 1986, the PLUS/ALAS auxiliary loan program was split into two programs - the PLUS loan program for parents and the Supplemental Loan to Students (SLS) program which further expanded loan access to independent and graduate students (Luminal Foundation, 2017). By 1992, there were four available loan programs for students, subsidized Stafford ${ }^{1}$ Loans, Unsubsidized Stafford loans, Parent Loans for Undergraduate Student (PLUS) loans, and Federal Consolidation Loans. Increases in tuition charges, coupled with the failure of legislators to increase Pell grant maximums to match these increases, the increase in available borrowing limits, and the elimination of income qualifications on PLUS and Stafford Loans led to a shift from grants/scholarships to loans as the primary vehicle for students and their families paying for college (Zumeta et al., 2012).

Through the decade of the 1990's educational policy passed by the Clinton Administration continued to support middle- and high-income learners. During the late 90's the federal government passed tax-credit programs that benefited middle- and upperincome families (Zhou and Mendoza, 2017) while increases to grant and scholarship programs continued to diminish. In addition, the usage of privatized loans not guaranteed or regulated by the federal government began to increase; between 1996 and 2008 private loans increased tenfold (Zumeta et al., 2012). All of these factors worked to create an era

\footnotetext{
${ }^{1}$ In 1988 the Federal Guaranteed Loan was renamed to Stafford Loans.
} 
of increased stratification among colleges and universities as middle- and upper-income families were able to get private loans as well as benefit from tax credits (Best and Best, 2014; Zumeta et al., 2012). Further, the shifts towards merit-based rather than need-based aid started to impact students from low-income backgrounds in particular. For Zumeta et al. (2012), "the nature of the admissions process, with its emphasis on academic quality coupled with the rise of merit aid, would mean that most of the spaces in the elite private and public institutions would go to children of well-educated, higher income families" ( $\mathrm{p}$. 80). Dependence on loans and the questions of what to do about this continued reliance on loans as the primary method of financing higher education progressed through the 1990’s.

\section{The New Millennium: A Student Loan Crisis?}

In 2005, the federal government made the discharge of student loans through bankruptcy almost impossible (Zhou and Mendoza, 2017). The problem here then becomes the inconsistent nature of determining "undue hardship" because it is up to the creditor to determine (Keller, 2017). Hunt (2020) highlights the fact that creditor (which in many cases, might be the federal government) must weigh hardship and costeffectiveness, i.e., is it worth our time and money to go after the indebted individual or is their debt enough of a hardship that we can forgive it in bankruptcy? Only once it is determined that it is financially viable for the creditor to fight the undue hardship request do the courts get involved (Hunt, 2020; Keller, 2017). What this policy change really highlights is one example of a debt that is never ending, one that can (must) be passed down through generations unless the creditor decides it is not worth the cost of court fees to fight OR that the debtor has successfully lobbied in favor of their undue hardship 
request. The passage of this policy is a critical component of the foreclosing of futures via debt, further cementing the fact that creditors have no interest in the futures of the indebted, instead attempting to create an endless cycle of indebtedness which ensures the servitude of those with debts for not only years, but generations to come.

During the second Bush administration, there were loans from two categories available to students: Direct Loans and Federal Family Education Loans (FFEL) (Federal Student Aid, 2004). According to the Office of Federal Student Aid (2004), "funds for Direct Loans come from the federal government; loans made through the FFEL program are provided by private lenders and are insured by guaranty agencies and reinsured by the federal government" (p. i). Additionally, "the federal guaranty on the FFEL loans replaces the security (the collateral) usually required for long-term loans from banks and credit unions" (Federal Student Aid, 2004, p. i). This restructuring of student loan availability is further emblematic of the public-private partnerships, and full on privatization of once public services, so critical to neoliberal policy.

By 2010, the Obama administration ended the FFEL program of loans being guaranteed by the federal government and instead moved towards a model of loans directly from the government (Best and Best, 2014). According to Best and Best, "the Obama administration recognized that direct loans might reduce the amounts borrowers owed, but they would hardly eliminate crushing debt. It offered a range of other programs designed to make debt more manageable" (p. 95) including loan forgiveness programs and other perks (Best and Best, 2014). Of course, these policies were passed during the height of the global financial crisis; a period which exemplified the failures of decades of neoliberal policies that prioritized profits over working people (Welch, 2012). Further, 
the changes highlighted above actually did very little to alleviate the debt burden of millions of students, failed to address the structural problems that created the crisis in the first place, and were a stopgap measure meant to save the system of debt as it existed at the time.

Welch (2012) argues that it was the proponents of neoliberal policy (specifically economic and political elites) that utilized debt systems as ways to pacify working people into believing they could achieve a middle-class lifestyle. I would extend this notion into the context of American higher education by arguing that in addition to taking on debt to buy a larger house or a new car to feel middle class, by incurring thousands upon thousands of dollars of educational loans, individuals were able to live the "middle- and upper-class" experience of attending college. Additionally, at a time when job opportunities were limited due to the financial crisis, as Looney and Yannelis (2015) highlight, may students were faced with the choice of "having" to go into debt or face a fate that might have been worse, ultimately creating an environment where the idea of having "choice" fails to capture the limits placed on individuals in such a position.

By 2013, Sallie Mae was:

split into two publicly traded companies. One, since named Navient, houses Sallie Mae's legacy of federally guaranteed and now-underperforming private sector loans, which are no longer issued; it also services a portion of the U.S. Department of Education's new "direct" student loans. The other, called Sallie Mae, houses its newer, better performing, and multiplying private loans for students, increasingly including international students who banks as well as colleges and universities are now trying to capitalize on (Zhou and Mendoza, 2017, p. 13).

This split has continued the stratification of higher education and further increasing inequality. For Best and Best (2014), 
Essentially, everyone is invited to participate in direct loans, but if you need more money than direct loans are willing to provide, you have to be one of the lucky few with a credit report favorable enough to get private loans from Sallie Mae to cover the difference (p. 154).

During the later years of Obama's second term, the federal government created additional informational support aimed at making the costs of college and their associated loans more transparent (Zhou and Mendoza, 2017) without addressing the failures of federal policy to provide affordable college going opportunities for middle- and working-class families; the federal Pell grant still fails to cover tuition and fees at many public colleges and universities and the student debt ledger continues to increase.. By the 2016 presidential campaign, tuition free college became an important position among candidates in the Democratic party, spearheaded by candidate Bernie Sanders, eventually being adopted by Hilary Clinton as well.

Since the inauguration of Donald Trump in 2017, the current president's administration has begun to eliminate and/or weaken programs meant to protect students in debt from their education. This included eliminating the student loan oversight division of the Consumer Financial Protection Bureau, attempts to eliminate the Public Service Loan Forgiveness program, among other programs meant to protect students against forprofit colleges and ensure that institutions are providing meaningful employment opportunities for students in order to continue utilizing federal aid dollars (Minsky, 2019). Trump-era higher education policies are aligned with neoliberal ideology given the widespread rollback on regulations that protect students and the reliance on the freemarket to correct any issues, for example those related to continued tuition increases. 
Despite other student loan policy changes made by the Trump administration, the four types of direct federal student loans have remained the same - Stafford Loans (Subsidized and Unsubsidized, PLUS loans, and Federal Consolidation Loans) (U.S. Department of Education, Federal Student Aid, 2019) since 2010. Of the available loan programs, only the Subsidized Stafford Loan has any income related restrictions, which remains true to this day (Looney and Yannelis, 2015). Unsubsidized Stafford Loans begin accruing interest while students are enrolled, while subsidized loans do not begin to accrue interest until after a student graduates. PLUS loans provide parents with dependent students the opportunity to take out loans for both undergraduate and graduate students (Looney and Yannelis, 2015). While independent students are not eligible to receive PLUS loans, they are able to increase their Stafford Loan maximum. Federal Consolidation Loans provide students with the opportunity to consolidate their federal loans into one loan package, in theory making it easier for students to manage and repay their debt burden (Looney and Yannelis, 2015).

\section{The Student Loan Crisis by the Numbers}

In sum, American students have had to combat rising college costs for decades and given rising tuition costs and the failures of federal and state government to provide grant aid that offsets the cost of education the problem is getting worse. Feiveson, Mezza, and Sommer (2018), write that the amount of total student loan debt in the US has more than tripled between 2001 and 2016. As of the end of the fourth quarter of 2018, there was a total of $\$ 1.46$ trillion worth of outstanding student debt in the United States (Federal Reserve Bank of New York, 2019). Since the 1988-1989 school year, the published cost of tuition and fees at private non-profit four-year institutions has more 
than doubled ( $\$ 17,010$ to $\$ 35,830)$ and the published costs at public four-year institutions has basically tripled $(\$ 3,360$ to $\$ 10,230)$ (College Board, 2019). There does not seem to be an end in sight to the rise in college costs.

Due to shifts in funding, tuition dollars (generated by students) have become the largest share of institutional budgets, making up over $50 \%$ of financial revenue at public colleges and universities (SHEEO, 2019). For public institutions, net tuition made up $26.4 \%$ of total educational revenue in 1991; by 2013 this number peaked at $48.5 \%$ (State Higher Education Executive Offices, 2016, p. 25). The reliance on student tuition, ballooning tuition costs, and the failure of federal and state aid to keep up with rising costs has led to an increase in the number of students and families taking on financial debt in order to pay for college (Zumeta, Brenneman, Callan, and Finney, 2012).

For families in the lowest $20 \%$ of household income, the percentage of income needed to pay for a public four-year university was 55\%, and $197 \%$ for a private nonprofit college/university in 2012. For those families in the top $20 \%$ of income the percentage of income needed for a four-year public university was $9 \%$, and $20 \%$ for a private nonprofit college/university (Zumeta, Breneman, Callan, \& Finney, 2012, p. 158). According to Hsu and Fisher (2016), roughly 20 percent of American households took out at least one loan to pay for educational expenses. As of 2017, the maximum Pell grant award covers $29 \%$ of tuition, fees, room, and board at public, four-year institutions, compared with 79\% in 1975 (Protopsaltis and Parrot, 2017). Pell grant coverage and tuition costs show the uncomfortable reality facing American students as they start to consider college; given the numbers presented above, it is easy to see why families are "forced" to take on debt. 


\section{What Makes Today's Crisis Different?}

Since the 1970's, there have been concerns in popular media regarding the ever increasing reliance on student loans as a method to finance higher education. A1970 article published in the New York Times with the headline, "Student Loan Crisis May Block Return of Many to College" (United Press International, 1970), is strikingly similar to a 2019 article from the same newspaper titled "What's Scarier than Student Loans?" (Harris, 2019). Further, Best and Best (2014) note an increase in news articles about student loan borrowers entering default; "in 1977, Newsweek ran another story ("Study Now, Pay Never") accompanied by a graph titled "The Rise in Student Deadbeats," while a U.S. News \& World Report story ("Time of Reckoning for Student Deadbeats") featured a similar graph labeled "How Defaults Have Zoomed" (Best and Best, 2014, p. 43). What separates this era of student loan fears from those in the past is the sheer volume of borrowers, those currently in the process of repayment and those who are soon to be exiting their college/university to begin their repayment efforts.

According to Looney and Yannelis (2015), there was a drastic increase in student borrowing during the beginning of the great recession of 2007, leading to a large number of student borrowers who then began to enter repayment as the economy began to pick up. Borrowing during the recession was also exacerbated by "short-term enrollments" such as certificate programs or students who began a program, but did not complete it after 1-2 years; "moreover, many more borrowers are in the earliest years of repayment, a time when the loan burdens (relative to earnings) are highest and when default rates peak" (Looney and Yannelis, 2015, p. 31). Specifically, during the Obama years (20092017) outstanding student loan debt in the US doubled from $\$ 650$ billion to just under 
$\$ 1.2$ billion and by 2012 , the student loan default rate surpassed the default rates of credit card and mortgage debts (Federal Reserve Bank of New York Research and Statistics Group, 2019; Tatham, 2019). Despite concerns about reliance on student debt in the past discussed above, by the middle of Obama's second term, questions about the student debt bubble began to arise, raising questions of a student loan crisis (Fraser, 2016; Nova, 2018).

With the introduction of the National Defense Education Act in 1958, the United States federal government laid the groundwork for the explosion in student loan debt and default in American higher education. Additionally, neoliberal shifts in understandings of the value of higher education further contributed to the shift from grants and scholarships to the presently loan dominated model.

While Pell grants are only one example of grant aid that has failed to match the rising cost of tuition, fees, room and board, it highlights a major reason why so many American students and their families have had to go into debt to fund their college education - over the past 45 years students have support and assistance as they navigate the experience of paying for their higher education, best exemplified by the US government's decisions to expand loan access without ensuring grant aid is sufficient to cover educational costs. Loans and debt "carry out the logic of [a] post-welfare state because they reconfigure college funding not as an entitlement...but as self-payment" (William, 2006, p. 91).

Ultimately, the transition from grants and scholarships to a dependence on loans exemplifies American society's valuation of lender profits over student well-being, creating "ransomed futures" for students as they make decisions about their futures (Zhou 
and Mendoza, 2017, p. 50). Given the percentage of family income it takes to pay for college, students are starting to let debt (or the aversion to debt) dictate the decisions they make about their futures (e.g., Mitchall and Jaeger, 2018; Minicozzi, 2003; Zerquera, McGowan, and Ferguson, 2016). Further, as the need to take on debt increases, the potential for the foreclosing of opportunities becomes a reality for families, educators, and students themselves as they navigate their time in college.

\section{Neoliberalism \& Higher Education}

Ideas associated with neoliberal policy, like human capital theory and other economic policy have broadly reshaped American education policy through the 1970's, 80's, and 90's. In his 1962 article, Becker, over the course of several examples, works to place the value of going to college solely in the hands of the individual based on the income they can generate for themselves as a result of their attendance. Valuing education as a means for individual income generation can then limit the experience of higher education to a cost/benefit analysis for the student (or parent, guardian, and/or financer). Pasternak (2005) argues that because higher education is seen as a good, much like one in a marketplace, it makes sense that the decision to attend college would contain some form of cost/benefit analysis. Her study, a qualitative case study, explored students' retrospective reasons for attending college framed from a cost/benefit perspective.

Ultimately, Pasternak (2005) found that "the choice of an institution of higher education is dictated by factors resembling those that motivate selection of any other consumption good. Packaging, reputation and convenience represent the most meaningful factors considered by students when choosing a knowledge supplier” (p. 196). 
In fact, the governing rationale of neoliberalism, acting to marketize education, has resulted in a system that almost exclusively provides benefits the individual (Brown, 2015; Lightcap, 2014). For Marginson (2011), "higher education institutions held in the public mind to be factories for producing private status goods and private knowledge goods [have] come to focus largely on those functions alone" (p. 414). Students are now tasked with finding ways to pay for their own education partially because of the view that the outcome is a private good, rather than a public good (Coco, 2013), as highlighted by the literature on student loans presented above (Best and Best, 2014, Burt and Baber, 2018).

Saunders and Blanco-Ramirez (2017) suggest that one of the ways neoliberalism has impacted higher education is the commodification the degree and, in reality, the student's entire college experience; “the representations of students' educational experiences, which come into being in our world through the material objects of the degree and resume, become more important than the experiences themselves" (p. 191). When college degrees are seen as commodities, it becomes increasingly easier for institutions of higher education to act in ways that support this commodification and ultimately reduce and subjectify the "products" of this system, i.e., the students, to "the broader neoliberal ideology that is shaping our world" (Saunders and Blanco-Ramirez, 2017, p. 191). As parts of higher education have become commodified (parking, dining, housing, etc.), the logic supporting that process began to spread to other areas (academic ones in particular).

McCowan (2017) terms this idea "unbundling," where the goods and services provided by an entity can be separated out into their component parts. In the case of 
higher education, this takes many forms: "an obvious manifestation of unbundling — and one that has been in evidence for some time-is outsourcing of services within universities such as catering, cleaning, ICT, library services, and accommodation" (McCowan, 2017, p. 737). As this has taken effect in the aforementioned services, it has also seeped into academic areas as third party services have become a key component of course management, assessment, and knowledge validation (McCowan, 2017). One example of this practice is at a large community college in the Southwestern United States that awards traditional Associates degrees and certificates while simultaneously providing more non-traditional learning opportunities in the form of 12-week boot camp type courses that circumvent the need for many of the experiential components of a college education that are marketed in terms of their length (shorter than a regular degree) and immediate job opportunities following the program (CNM Ingenuity Inc., 2018). Further, colleges and universities have partnered with private corporations and donors to develop and hand select hires, departmental direction, and learning outcomes, meant to inculcate and produce graduates with particular ideological perspectives (Green and Saul, 2018). As the college going experience becomes less about the experience than about the commodity produced, it highlights one major way that neoliberalism has shaped our modern understanding of "the value" of a college degree.

In addition to the commodification and unbundling of the college experience, the evolution of student loan policy in the US highlights another way in which the societal value of a college degree has shifted. Specifically, it is easy to see a relationship between the shift in the financial support for grant funding to funds for student loans as a bellwether for how a college degree is valued in America. The 1970 article by Campbell 
and Boyd, published relatively early in the history of student loan research, is one example of a way debt can be seen as a foreclosing agent in an individual's life; when the government chooses to support funding for student loan programs over grant programs, students are left with a precarious decision to make - go into debt or try to succeed in the American economy without a college degree.

Less than 15 years into the federal government's involvement in supporting individuals' higher education finance through loan programs, there were already concerns about the stratification within the American higher education system and how lowincome students might be impacted from a college choice perspective (Campbell and Boyd, 1970). American policy makers continued to cut funding for higher during the Reagan administration and through the passage of tax-credit programs during the Clinton administration meant to support middle-income families (as opposed to those most in need), American leadership was sending a clear message to low-income learners - go into debt or risk entering the American workforce without a college degree.

Ultimately, how a degree is valued places limits on the choices individuals make about their future, because of the illusion that everything must be decided through an economic lens and you must be accountable for every dollar and decision. In the previous passage, Zhou and Mendoza (2017) discuss the notion of a "ransomed future" for borrowers of student loans. Neoliberal rationale and the resulting educational policies have led to changes in the discourse around higher education that places success and failure almost entirely within the grasp of the individual, which allegedly creates greater autonomy and freedom for students as they navigate their educational experiences (Lissovoy, 2015). An increased neoliberal culture of assessment, management, and 
accountability in higher education has inadvertently led to a decrease in the decision making capabilities individuals within the academy. Termed "modes of accountability" by Joseph (2014), neoliberal policies in higher education have pushed institutions to value "measurement outcomes rather than substantive direction" (p. 131). Such measures of accountability actually work to limit an individual's scope of practice by causing them to "accept narrow definitions of their work determined by forces outside themselves" (Madeloni, 2014, p. 83).

\section{The Example of Advanced Analytics}

One example of determining futures by forces outside of the individual is the use of advanced analytics and predictive modelling as it relates to student decision making. Put directly by Phillips (2013) in an article outlining the overview of some advising technology at her institution:

Academic advising requires empathy as well as academic expertise, and the tendency is to assume that the advisors are the ones to tell students that their dreams of becoming a biologist or dancer are not practical because their grades in the critical courses are too low. But many advisors find this hard to do. Because the impersonal eAdvisor has identified the difficulty and both the advisor and the student receive the same message and information, their conversation is about not about failure but about improving the student's chances of success (p. 51-53).

While the spirit of this passage presents the benefits of using advanced analytics and modeling (that advisors do not have to break bad news to students because the data already did it!), this shows rather strongly the guardrails institutions are willing to put around students as they make decisions around something as important and individual as their program of study. Students are essentially gas lit, guided, and sometimes coerced into a choice by their institution because the data says so! Ultimately, these evolutions 
and conditions in higher education have been detrimental to students in terms of their autonomy and freedom to make decisions.

Smithers (2018) argues that "The undergraduate student produced by data-driven control is the in/dividual, a flow of dividuals channeled by cultures of data and data management systems, including predictive analytics, under the justification of enacting student-centered practices" (p. 249). By arguing for the use of data-driven, predictive analytics that fail to actually capture student's needs, desires, and goals, the academy falls in to the trap of neoliberalizing college students' experiences. More specifically, through the use of this data driven techniques, despite the thousands of choices presented to students, they are actually limited by what the data tells student affairs and services practitioners that students might be able to accomplish. In fact, some community colleges are starting to move towards a fully prescribed "pathway" model for graduation requirements, because their data showed that the choices students were making were the “incorrect” ones (Mangan, 2017). These efforts supported by public-private partnerships, such as the Bill and Melinda Gates Foundation, have been met with skepticism by faculty, ironically prompting one of the key supporters of the program to state, "It's a pathway, not a prison” (Mangan, 2016; Mangan, 2017). The absurdity of comparing datadriven advising techniques to a prison sentence cannot be overstated enough, but oddly enough also speaks to the ways in which these advanced analytical approaches to student services can in fact be "imprisoning."

I came across this experience at my own university at a training for academic advisors - through the use of a data analysis tool, the university was allegedly able to determine what students could handle light, medium, or strenuous course loads, without 
ever having a conversation with the student in question; while the student had the illusion of choices in front of them (e.g., courses, credit load, schedule, etc.), they were instead funneled into a reality not of their own making, but one created for them through data. Anecdotally, students often left the advising session disheartened when I told them that we did not recommend pairing a science and math class together, that taking a language class did not fit in with their program of study, or that, "oh by the way, you have to start in X courses so it's going to take you an extra year to graduate if you stay in this major." Data and metrics became such a critical component of the student experience that students were quickly reduced to data points on a spreadsheet (high school GPA, Math Placement Score) and shuffled along without having much choice along the way. Ironically, as Smithers (2018) highlights, these choices are often made in the name of "student-centered approaches" that do not in fact put students at the center of the decision making process.

\section{College "Choice"}

Camp (2016) argues that policies adopted after the Vietnam War period of civil unrest and uprising by marginalized groups during the mid to late 1970's accelerated the turn towards neoliberalism, especially in the United States. Cuts to grant/scholarship programs and the reduction of state spending on higher education, introduced by lawmakers after this period of unrest, have put students in the precarious position of having to ransom their future decision making by taking on debt in order to have the potential of expanding their future decision making capacity through higher education. As a result of the system in place within higher education that presently requires an increased reliance on debt, one that supposedly works to increase autonomy and provide 
choices, that places the burden of cost on the individual, students are left with a potentially life altering (or crippling) decision: do not go to college at all, drop out (and consider all of the debt you may already be in a sunk cost), or continue accumulating debt that you may never be able to pay off.

In fact, many of the changes to federal appropriations for higher education during the 1990's were actually passed under the guise of increasing college choice (Best and Best, 2014). The passage of a system of tax credits during the mid-late 1990's was meant to help middle-income students fund their attendance at more prestigious public and private four-year institutions (Best and Best, 2014); thus placing the value of "choice" in the hands of a small minority of students, while the vast majority of students (i.e. lowincome learners) were left to rely on grant programs that did not keep up with college costs and predatory student loan programs (Nelson, 2011). Soria, Weiner, and Lu (2014) found

that undergraduate students from low-income and working-class backgrounds were significantly more likely to engage in financial actions/decisions that are potentially harmful in the immediate and long-term...Additionally, students' decisions may impact their immediate academic experience, serve as disruptive barriers to success, or prolong graduation, including working more hours, taking a leave of absence, or not retaking classes.

More broadly, Hsu and Fisher (2016) reported that households with educational loans had lower incomes than those without loans, ultimately concluding that:

the current system does not seem to be supporting lower-income households in terms grants and non-loan forms of financial aid, as net worth, home ownership, and stock ownership all have a negative relationship with having education loans. Having to repay education loans places another burden on households with fewer financial resources (Hsu and Fisher, 2016, p. 76). 
Despard et. al (2016) found that student debt is associated with low- to moderate-income families being unable to meet their most "basic needs" (p. 15) as well as with issues managing household finances. The research of Hsu and Fischer (2016) and Despard et al. (2016) highlights the impact that debt has on the autonomy of individuals. Because of their indebtedness, people are not able to begin planning for the next phases of their life, an idea which intersects with Nowotny's (1994) conceptualization of the extended present as described in Chapter I. When individuals are saddled with debt, their extended present begins before they even enter their college/university; in addition to planning for future decisions, individuals are stuck "making up" for past choices. For Hartlep, Hensley, and Eckrich (2017),

since neoliberal ideology is self-insulating, it conceals unfortunate truths on the damage inflicted upon student debtors, its victims. In spite of these indebted "casualties," the neoliberal higher education agenda in the United States is a wellkept secret. Neoliberal arguments that the market will fix everything...further obscure brutal realities (p. 259).

The idea of obscured realities however extends well beyond the homogeneity plaguing traditional discussions of student debt in the United States. In actuality, the "choice" to go into financial debt is just one obscured choice presented to students as they navigate the world of postsecondary education.

According to Marginson (2016), "the opportunities that education is meant to bring are not universal, not in capitalist societies that...are stratified by unequal earnings and hierarchical power, in which...there is an absolute limit to the number of socially advantaged positions on offer" (p. 415). One way to examine the differences in admission to elite colleges/universities is through a lens of exploitative opportunity hoarding. Often used as a model of analyzing class mechanisms in exclusionary employment practices 
where "middle class jobs are differentiated from the broader working class by creating barriers that in one way or another restrict the supply of people for desirable employment," (Olin Wright, 2015, p. 12), this model can be translated into the context of American higher education.

According to Tilly (1998), opportunity hoarding occurs when groups "acquire access to a resource that is valuable, renewable....and enhanced by the network's modus operandi" and when there is an "unequal exclusion...from resources controlled by [an] other" group because of "asymmetrical relations across a socially recognized dividing line” (Tilly, 1998, p. 8-10). Organizations (e.g. elite colleges and universities) adopt, what Tilly terms, categorical distinctions (e.g. upper-class vs. working-class), which become "pervasive and decisive in social life at large" (Tilly, 1998, p. 9). These categorical distinctions and the resulting opportunity hoarding "shape[s] the...processes through which individuals acquire class-relevant attributes" with a focus on the fact that there are "mechanisms of exclusion that sustain the privileges of those in middle class positions" (Olin Wright, 2015, p. 12-13). These mechanisms of exclusion thus contribute to the continued cycle students self-selecting out of a variety of college going opportunities that might present themselves as they're applying or even as young as elementary age.

Marginson (2016) discusses the fact that "education is a positional good subject to an absolute scarcity of high-value opportunities" (p. 430). As such, middle- and highincome families are able to invest the time and money necessary to help their children access the most elite colleges/universities in the U.S., disproportionately shutting out students from economically disadvantaged backgrounds. Specifically, opportunity 
hoarding further cements inequality when one group (upper-class students) takes advantage of the distinctions privileged by a certain network (elite colleges and universities). This is supported by Hoxby and Avery (2013) who found that many highachieving, low-income students do not apply to selective/elite institutions despite being qualified for admission. According to their analyses, they determined that some combination of "cultural, social, or familial issues...make them unwilling to apply" (p. 47). Further, they conclude that such cultural, social and familial factors were the most likely contributor to the lack of high-achieving, low-income student applications to the most selective institutions in the U.S. (Hoxby and Avery, 2013).

Even outside of "elite" institutions there are ways in which college choice is impacted simply as a result of being from a low-income background. For Cox (2016), “At the heart of the established college choice model is a set of assumptions about college aspirants' decision making —including a sequential, linear process, and an array of possible alternatives - that does not hold true for various groups of students" (p. 22). Specifically, and most importantly for this study, the temporal aspects of college choice vary greatly for individual students (Cox, 2016). From the moment a student is born, the factors that shape their chances in life have already started to take shape, bringing to mind Lazzarato’s (2015) discussion of "life debt." In fact, an individual's opportunity to even play the game [of college admissions] is preordained long before an application reaches the admissions office. Access to the game is determined by an elaborate, self-perpetuating arrangement of social and economic privilege that systematically grants advantages to affluent, welleducated families, while systematically shutting the gates of opportunity to those without such advantages (Sacks, 2007, p. 130). 
The preordained nature, for many, of the American higher education system is one way in which time is a critical component of college choice. In one study of Ivy League students, Mullen (2009) found that students from economically privileged families are taught the importance of receiving an elite college education from a young age. Children were "inculcated" to the expectation they would attend an Ivy League university; wealthy students were taught to "feel at home" at these elite universities rather than seeing their attendance as an anomaly (Mullen, 2009).

Among the respondents of the High School Longitudinal Study (HSLS) of 2009, parental expectations of college going as early as 9th grade were associated with students' ultimate educational attainment (LoGerfo, Christopher, and Denton Flanagan, 2011). For students whose parents expected them to earn a high school diploma or GED as their terminal degree, only $9.6 \%$ went on to enroll in a non-profit four-year institution, while $60.4 \%$ did not enroll in college and less than $30 \%$ enrolled in any two-year institution. To the contrary, students whose parents expected them to earn a Ph.D., M.D., J.D., or other professional degree enrolled in non-profit four-year institutions at a rate of 63.5\% (LoGerfo, Christopher, and Denton Flanagan, 2011). While the HSLS does not capture students' reasoning behind their college choice, clearly their parents' views on their college options in 9th grade somewhat accurately reflected the choices they may have felt they were able to make several years later, supporting the idea of a temporal stretch of the college choice process that reaches throughout a student's educational lifespan. College choice processes start at a young age and impact how students self-sort into different college choice groupings. 


\section{Time and College Choice}

In his seminal work on class and access to higher education in America, Peter Sacks (2007) discusses the young age at which some children's apparent choices begin to take shape. Sacks describes this phenomenon through the contrasting stories of two students from divergent class backgrounds and how each passing year impacts their college going aspirations and possible decisions. For the student from a low-income background, years of family, medical, and/or housing insecurity may lead to compounding educational problems such as an attempted expulsion from her high school and mental health conditions that ultimately limited the scope of the student's college choice process to a local community college with the potential hope to transfer to a fouryear university.

On the other hand, Sacks (2007) also describes the case of a wealthy student whose parents encouraged her to attend an elite college from a young age, using their free-time (something the parents of the low-income student did not have access to as a result of the inflexibility of their work schedules) to volunteer in her school to better understand what was going on with their daughter in regards to her education as well as get to know the important players in their daughter's college admissions "game." From a young age this student's activities and classes were calculated to give her the best chance of getting into college; her parents were also able to spend their time reading about colleges with their daughter and as a result she had the full gamut of choices available to her during the college application process - there were no colleges off-limits (Sacks, 2007). The class differences between these students created two dramatically different pathways for students at a young age that ultimately shaped how they were able to think 
about the college admissions and decision-making process. Much like American healthcare system presents "choices" that leave millions without insurance, the American system of higher education leaves individuals constrained to "choices" they may never have had or wanted in the first place.

This is also supported by Chetty, Hendren, and Katz (2016) who found that the fewer years a student spends living in poverty impact their college choice decisions. Here, it is important to note that their sample was not focused on individuals whose income surpassed the poverty level, but instead simply of individuals not living in a highpoverty area. In their analysis of a program that provides low-income families housing vouchers to move to lower-poverty areas, Chetty, Hendren, and Katz (2016) found that "every year spent in a better area during childhood increases college attendance rates...so the gains from moving to a better area are larger for children who are younger at the time of the move" (p. 856). Further, not only did a family's neighborhood impact the likelihood of attending a post-secondary educational institution, it also increased the quality of the institution the student attended (Chetty, Hendren, \& Katz, 2016). This finding is particularly robust as it relates to this manuscript; simply moving out of highpoverty environment works to open a litany of potential choices that children who remain in high-poverty areas are, in many ways, unable to make. What also makes this finding so important is the temporal aspect, the less time an individual spends in a high poverty area, it could be argued, the more time they can spend focusing on their education and dreams for the future.

In addition to the temporal conditions presented above, wealthier families are able to use their time differently than families from low-income and working-class 
backgrounds. Families from middle- and upper-income backgrounds can use their free time to work with their child during the college choice process, while students and families from low- and working-class backgrounds often do not have such time to spare. Laureau and Wenniger (2008) discuss the idea of "parental involvement [as] an overwhelmingly middle-class phenomenon" (p. 141), which raises the question, how can one be involved in their child's college choice process without time to spare? Lower wages mean that low-income individuals must spend more of their available time working, leaving fewer hours for leisure or college planning activities. Williams, Masuda, and Tallis (2016) describe this phenomenon as experiencing time poverty;

Time allocation involves decisions based on monetary constraints, social pressures and norms, personal preferences, and other available resources...Some activities, such as childcare or cleaning, can be done by hired labor. Because of this, wealthier individuals (i.e. those with more monetary resources) are more likely to have time to allocate to activities they prefer, holding working hours constant. Poorer individuals, in comparison, may lack time saving devices (e.g., appliances, Internet access) and services (e.g., childcare, housecleaning). As a result, individuals with limited resources may lack the time necessary to escape income poverty (e.g., they may not be able to work enough hours at their current wage rate), or they may only do so at the expense of their individual and household well-being (e.g., neglecting childcare or sleep) (p. 269-270).

As stated in the passage above, individuals from low-income backgrounds do not have the same temporal opportunities as individuals from middle- and upper-income backgrounds; as it relates to the college choice process, economically disadvantaged students and thus do not get to experience the advantages of their families being "time rich" (e.g. ability to volunteer in school, take off from work to take their children on campus tours, etc.) further limiting the options and choices they are able to consider.

In addition, many students from low-income backgrounds are more likely to have to spend their time during high school, and even college, working to support themselves 
and their families. Among the students sampled in a study by Cox (2016), the research suggests that many students from low-income backgrounds spent a lot of their "freetime" working to help support their parents at home, relegating their college search process to the periphery. Generally, "students from low-SES backgrounds...work more, study less, are less involved, and report lower GPAs than their high SES peers" (Walpole, 2003, p. 63). Academic difficulties and a lack of connection to the campus community can lead to lower self-esteem and self-efficacy among students, ultimately leading to higher rates of attrition (Froggé and Woods, 2018), which also work to limit the choices students have to continue in college post-enrollment and the choices available to them if they graduate as a result of the time they must spend during college working to earn additional money.

\section{Promise Programs}

In order to combat some of the difficulties faced by students from low-income backgrounds, many U.S. states and institutions are beginning to reconsider their financial aid programs in lieu of the federal government providing enough financial assistance for low-income students. As highlighted in chapter 1, promise programs are starting to become popular policies among states and institutions looking to begin increasing individuals' abilities to access higher education, hopefully providing them with choices of where to attend and what to study, for example. Perna and Leigh (2019) report that there are currently 420 promise programs that meet their criteria, which is: "a goal of higher education attainment, place based eligibility criteria, and provide benefits to students" (n.p). Of these 420 programs, there are 18 that: (1) offer support services to students, (2) limit the awarding of funds to students who demonstrate financial need, and 
(3) do not limit students with academic achievement requirements (Perna and Leigh, 2019).

The early returns for the effectiveness of these programs is mixed. Some researchers, in the limited research available on promise programs, have found evidence of effectiveness (Carlson and Laderman, 2018; LeGower and Walsh, 2014; Swanson et al., 2016). Swanson et al. (2016) conducted a meta-analysis of seven promise programs that are either universally awarded or merit-based. The authors found that, "the evidence is highly suggestive that promise programs have positive effects on community development, high school, and postsecondary outcomes" (Swanson et al., 2016). Similarly, in an examination on the impact promise programs have on public school enrollment and housing prices, LeGower and Walsh (2014) found that promise scholarships that could be utilized "at a wide range of institutions were effective at increasing total public school enrollment" and found community benefits in the form of housing values and regional population increases.

In contrast, another review of promise programs in Tennessee and New York found that promise program funds from those states were benefiting middle- and upperincome learners rather than students from low-income backgrounds (Poutre and Voight, 2018). In Tennessee for example, low-income learners were still left with sizeable tuition/fee balances after promise fund awards, while students from high-income backgrounds, who could easily afford the cost of community college, received $\$ 1,500$ towards community colleges costs (Poutre and Voight, 2018). New York’s Excelsior promise program did little to help ease the burden for low-income students, leaving students with between $\$ 3,000$ and $\$ 14,000$ (depending on where they attend college) in 
unmet need and converting grant dollars to loans for any student who leaves New York state after college (Poutre and Voight, 2018). Swanson et al. (2016) also suggest that given the programs in their sample were not need-based, they hypothesized that non-need based programs might benefit learners from middle- and upper-income backgrounds more so than those from low-income backgrounds.

For LeGower and Walsh (2014) their finding that public school enrollments increased with the introduction of promise programs was "mitigated by the imposition of merit requirements," which also had the effect of "providing strong incentives for white enrollment and the expense of non-white enrollment" (p. 34). Ultimately, the authors suggest that the imposition of merit requirements for promise programs could have the impact of further increasing educational inequality as a result of changes in housing prices and the types of students enrolling in promise neighborhoods and school districts (LeGower and Walsh, 2014).

The need for the existence of promise programs is one small piece of the financial aid reality created by lawmakers and politicians consumed by neoliberal policies; a reality of decreased appropriations and increased reliance on loans for a growing percentage of American learners seeking a postsecondary education. Yet despite their growing numbers, promise programs have not proliferated enough to ease the financial burden of attending higher education for college students in the U.S. Lastly, through these research articles on promise programs, there was a lack of direct student voice as it relates to the experiences of students in these relatively new programs. Further, the entrance of promise programs into the student aid landscape has allowed for the creation of a discourse on "debt-free" students in higher education (Lacayo, 2017). 


\section{Conclusion of Literature Review}

Overall, the literature presented in this chapter aims to justify the present study and create space for a conversation that seems to have been foreclosed in research on debt in higher education. In addition to examining the financial costs of attending college, the literature presented above highlights why it is necessary to consider the non-financial costs associated with a student's pursuit of higher education. As neoliberal policy has shifted the way higher education is understood in America (and the world at large), shifts should also be seen in the ways that students are indebted by attending a college/university beyond our common understanding of "The Student Debt Crisis."

Despite these phenomena not being explicitly seen as debts in the literature, based on the work of Lazzarato (2011) and Gildersleeve (2017), it is possible to see how students are indebted to their families, communities, and colleges. The "costs" of a higher education are more than just money - students pay with their time, their social relationships, and their emotional well-being. Additionally, this chapter explores the ways in which students of color and women from low-income backgrounds might feel the impacts of family obligation and social and societal pressure.

Ultimately, the reason that students pay these costs is as a result of neoliberalism's reach into domains of temporality that now suggest "the right way" to spend one's time. Students are put in a precarious position where their decision making today will have lasting impacts on their future (the extended present), but also live in a world where their past and past decisions are always shaping the decisions they make in the present. 
The alleged meritocracy in American higher education creates a world in which there is an illusion of free-will and choice associated with every student's pursuit of postsecondary education that is foisted upon the psyche of elementary and middle school aged students from the beginning of their educational lives. While every student allegedly has the chance of getting into Harvard, in reality there are circumstances and choices made well before a student is born that extend beyond the past into the present and future, impacting the true autonomy they have in their college choice process.

Choosing to take on debt to pay the cost of tuition and fees at a university is now one small part of the decisions that students must make as they pursue college. However, as demonstrated by the overview of federal financial aid policy in the US, the "choices" that students are left with are the result of policy decisions made by the lawmakers since the passage of the NDEA in the 1950's. In addition, students must also determine if it is worth accruing the emotional, social, and temporal debt associated with attending as well.

Ultimately, it is the goal of this study to examine how students understand these non-financial debts and to what degree they impact student decision making autonomy. This literature presented above also works to illuminate the ways in which time and debt work in concert to limit the choices students are able to make. With that in mind, the following chapter presents the methods and methodology of the present study examining debt and choice. 


\section{CHAPTER III: METHODS}

\section{Conceptual Framework}

This study examines indebtedness across multiple temporalities created as a result of neoliberal governance both in higher education and more broadly. Specifically, Lazzarato $(2011 ; 2015)$ discusses the impact that neoliberal ideology has had on indebtedness' role in society as a governing tool as it relates to temporality. Essentially, the indebted individual, by "choosing" to go into debt, must consider "that which is inestimable - future behavior and events" - thus "expos[ing] oneself to the uncertainty of time" (p. 47), meanwhile, foregoing the ability to make decisions in the present.

This study draws upon the work of Lazzarato $(2011 ; 2015)$ and Gildersleeve (2017) specifically as a means of contextualizing the ways debt operates for individuals across temporalities in both financial and non-financial ways. Lazzarato establishes the concept of debt as more than just the balance an individual owes a financial institution. He describes indebtedness as a moral and social condition that is rooted well outside of solely financial terms, while still maintaining the subjectifying role that the conditions of financial debt can create. What is critical about Lazzarato's analysis of debt for this study is (1) the claim that both financial and non-financial components of debt exist and (2) how such debts act upon us are an essential component of individuals' choices. For Lazzarato, debt acts to subtly guide the relationship that individuals have with not only one another, but also with critical societal institutions that impact a person professionally, socially, academically, and/or romantically, to name a few.

Gildersleeve (2017) applies Lazzarato's understanding of debt to college students by establishing the notion of the indebted student. For Gildersleeve, the indebted student 
may owe money to their institution or have student loan debt and also extends to students who have not incurred financial debts associated with their education. Gildersleeve's conceptualization of indebtedness stems from the actions that students undergo as part of their "duty" to their college or university, such as having to complete student surveys or pose for brochure photographs. Of course students are not required to complete these tasks, but rather these example highlight Gildersleeve's oversimplified conceptualization of debt. What is important however is the idea that, for Gildersleeve, if students want to have certain choices available to them, they must do what is asked of them by their college or university. I aim to elaborate on this understanding by extending the idea of indebtedness to include not only the student-institution relationship, but the relationship that students have with their families, peers, and communities, ultimately questioning the existence of a "debt-free" student.

Finally, this conceptual foundation serves as a guide for examining the role of debt within a promise program meant to eliminate the existence of educational financial debt for students. Through the utilization of the word promise, I argue that colleges and universities are, in essence, entering into "contracts" with their students. Thus, instead of “promising" students a "free" education, colleges and universities are asking for a commitment from their students in the form of their emotional state and time, for example. Students are obligated to meet these requirement or risk being dismissed from this aid program, jeopardizing their ability to attend college at all, removing even the façade of choice. Critically, beyond the obligations required for this hollow promise, research suggests that students also experience obligations to their families, peers, and 
communities that work to shape the choices they have available as well (Fuligni, et al., 1999; Tseng, 2004).

Using Lazzarato's understanding of debts as foreclosing, it is possible to consider the idea of obligations as debts because of the ways individuals' obligations work to shape the decisions they are able to make. This conceptualization of obligation stems from the suggestion of the research literature on debt and morality, in which individuals view their debts as a moral obligation that need to be repaid, whether it is through financial or non-financial means (e.g., Card, 1988; Lazzarato, 2011, 2015; Lowenberg, 1995; Peebles, 2010; Polletta and Tufail, 2014).

\section{Research Questions}

My research examines the experiences of 13 students who, at the time of this study, qualified for the Golden Promise program financial aid program at Florida International University. The following research questions guide this study; (1) How do allegedly "debt-free" low-income students express non-financial debts related to their educational experiences? (2) In what ways does non-financial debt act as a foreclosing agent in student decision making for allegedly "debt-free” low-income students?

\section{Research Design}

To successfully answer the research questions presented above, I collected, analyzed, and interpreted data that aimed to accurately capture students' experiences with debt from both a financial and non-financial perspective. Ultimately, I chose a qualitative interview research design to complete this task. For Creswell and Poth (2018), qualitative research should be utilized when "an understanding of the contexts in which participants in a study address a problem is warranted" (p. 46). More specifically, qualitative 
methods were chosen due to the nature of the topic; quantifying the experiences of students who are, allegedly, debt-free would be difficult given the variety of nonquantifiable factors being explored such as family obligation and decision making opportunities, for example.

Given the relative youth of promise programs, research is still being conducted to make sure that aid is reaching the intended hands, examine the impacts promise programs have on property values, and analyze how promise programs impact degree attainment (e.g., Carlson and Laderman, 2018; LeGower and Walsh, 2014; Perna and Leigh, 2019; Poutre and Voight, 2018; Swanson et al., 2016). Across the literature explored in chapters I and II relating to promise programs, the existence of qualitative student experiences in the process was non-existent (see Carlson and Laderman, 2018; LeGower and Walsh, 2014; Perna and Leigh, 2019; Poutre and Voight, 2018; Swanson et al., 2016). I believe sharing individual stories is especially important in areas such as debt and financial aid where researchers have conceptualized student experiences but have not yet empirically investigated them.

According to Maxwell (2013), "a useful theory illuminates what you see. It draws your attention to particular events or phenomena, and sheds light on relationships that might otherwise go unnoticed or misunderstood" (p. 49-50). The theoretical framework presented in chapter 2 and summarized earlier in the present chapter provides the foundation upon which this study is based. By expanding the ways institutions and researchers consider indebtedness through generations, this study adds to the discourse on debt by examining not only the debt relationship between student and institution, but that between students and their families, communities, racial identities, and selves. Further 
this study aims to examine whether these debts act to foreclose decision making capabilities and if so, how?

\section{Contextualizing the Research Site}

All interviews for this study were conducted at Florida International University, a research institution located in South Florida with an undergraduate enrollment of 37,912 (Florida International University, Analysis and Information Management, 2019). The demographic breakdown at FIU presents as follows: 61\% Hispanic, 15\% White (nonHispanic), 13\% Black, 4\% Asian/Pacific Islander, and 7\% other minority groups (Florida International University, Analysis and Information Management, 2019). According to the US Department of Education College Scorecard (2019), 49\% of the students at FIU received a federal Pell grant in 2019. Presently, 61.44\% of students are enrolled full-time (12 or more credits per term, excluding summers), while the remaining population attends part-time (Florida International University, Analysis and Information Management, 2019).

The annual cost of attendance (tuition and fees) for in-state students attending full-time is estimated at $\$ 6,558$ (US News and World Report, 2019). In addition, the cost for a shared bedroom in one of the residence halls, plus the cost of the required meal plan for the Fall/Spring terms is $\$ 4,599$ total and an additional $\$ 1,656$ for the Summer term (Florida International University, 2019). The 2014 First Time in College cohort at FIU had a four-year graduation rate of $36.2 \%$; overall, four-year graduation rate has been rising steadily over the past several years (Florida International University, Analysis and Information Management, 2019). Recently, FIU was ranked for the first time in their history by U.S. News and World Report (USNWR) as one of the Top 100 Public 
Universities in the U.S. and ranks twelfth in "Top Performers on Social Mobility by USNWR (US News and World Report, 2019).

\section{Sampling Universe: The Golden Promise Program}

One critical aspect of selecting a sample for qualitative research is "defining the sample universe" which is the "totality of persons from which cases may legitimately be sampled" (Robinson, 2014, p. 25-26). Because the aim of this study is to understand the experiences of low-income "debt-free" students, for the purposes of this study, all students who qualify for the FIU Golden Promise Program made up the sampling frame. The present study focuses on low-income debt-free students, as promise programs were created in response to issues of access and equity. Because their education-related financial debts are allegedly removed, they are considered debt-free. Yet, as Lazzarato discusses, financial debt is only once source of indebtedness.

The Golden Promise program is a "last-dollar" scholarship that provides financial assistance to cover students' unmet financial need, not including housing, after federal and state aid are awarded. The program is housed within the Office of Financial Aid at Florida International University. A report by Joseph (2017) shows that students who qualify for the Golden promise program come from families making $\$ 33,000$ or less. Students are not recruited for the Golden Promise program, but instead qualify automatically if they meet the necessary criteria. As such, no particular student population or major is favored over another. Students must meet five to requirements qualify and three additional criteria to maintain the scholarship. To qualify students must:

(1) be a first-time in college first-year student, (2) be a U.S. citizen or permanent resident,

(3) be a Florida resident, (4) submit a FAFSA prior to enrollment at FIU, and (5) have an 
EFC of zero (Florida International University, OneStop, 2019a). In order to maintain the scholarship students must: (1) registered for at least 12 credits per term, with a recommendation for 15 credits, (2) complete 30 credits per year, and (3) maintain a cumulative GPA of 2.0 or higher at the end of each semester (Florida International University, OneStop, 2019a). The program was established for students entering FIU in the Fall 2017, and is awarded to students in their first semester as long as they are enrolled in twelve or more credits. Beyond these requirements, there are no other requirements requested of qualifying students, such as meetings or mentorship programs. Students can lose their Golden Promise aid for two reasons: (1) if their cumulative GPA is below 2.0 at the end of the semester (Fall, Spring, or Summer) or (2) if when refiling their FAFSA for a later term, the student's EFC is determined to be above zero. I was unable to attain the total number of Golden Promise students or the annual cost of the program for FIU directly due to unanswered requests from the office. According to a report by the Miami Herald, 1,131 students qualified for the Golden Promise program in 2017 (a more recent figure could not be attained) at an annual cost of $\$ 300,000$ to the university (Gross, 2017). Unfortunately, at the time of this writing, I was unable to obtain these figures directly from FIU, despite multiple requests on June 30, July 1, August 9, and August 26 of 2019.

\section{Participant Recruitment}

With the assistance of the Office of Financial Aid, an initial email was sent to 60 Golden Promise students total, 20 students each from African-American, White, and Latinx backgrounds. The invitation email message (see appendix A) provided potential recruits with background information on the study, noted they would receive a small 
incentive for their participation (a $\$ 10$ Amazon or Publix gift card), and my contact information should they be interested in being interviewed. Students wishing to participate were instructed to reach out to me directly to schedule an interview via email. The emails seeking recruits were sent to each chosen demographic group of students. I was able to schedule and complete interviews with both of the students who responded to the initial outreach. After only two students responded after the first email, revisions were made to the outreach message and email subject and a second email was sent to the entire population of Golden Promise students, per the Office of Financial Aid at FIU.

After the low response rate from the first email, I decided to expand the potential pool of participants given that I did not have enough responses I felt I needed to proceed with the study. The second email outreach yielded responses from eighteen students total, six of with whom I was able to schedule an interview. After the first two rounds of outreach, the sample of scheduled students was made up of primarily female students. During the first two rounds of outreach I failed to consider the gender makeup of FIU, which is $56 \%$ female and $44 \%$ male. This required me to send out two more outreach messages to all Golden Promise students coded in FIU's database as male. Both of these outreach attempts yielded a response of eight students, five of whom I was able to schedule for interviews. After all four outreach messages were sent out, a total of twentyfive students responded. I was able to set up interviews and meet with thirteen students. The remaining students either did not reply after reaching out to me initially, had to cancel our interview, or did not arrive for their interview on their scheduled date. The total response rate of the study is unknown due to the unknown number of total Golden Promise students contacted during each outreach. 
The sample of students is not meant to be representative of American college students, but instead aims to highlight the diversity among students at FIU. According to Trost (1986), in qualitative research it is not necessary to have a representative sample, but instead one that highlights "variations" among the groups in question (p. 57). More specifically, the purposeful sample is not meant to produce results that are generalizable to a broader population, but instead is an intentionally selected subset of participants that can best speak to the present research questions (Creswell and Poth, 2018). Ultimately, I chose individual participants from the broader sample based off of what participant characteristics I felt fit the needs of the study, backed by the research literature (Robinson, 2014). It is up to the researchers to choose "what cases they could learn the most from" with a "focus on studying and understanding selected cases of special interest" (Patton, 2002, p. 222-223).

\section{Sampling Strategy}

In order to choose students from the sample universe of the Golden Promise population, I utilized a purposeful sampling strategy. For Maxwell (2013), "selecting those individuals that can provide you with the information that you need to answer your research questions is the most important consideration in qualitative selection decisions" (p. 97). In qualitative research, purposive sampling is utilized because it allows for the researcher to choose sites and participants that "purposefully inform an understanding of the research problem and central phenomenon in the study" (Creswell and Poth, 2018, p. 158). Critical to this study, and one of the major reasons I selected FIU as a research site was the existence of a promise program for students from low-income backgrounds that hopes to produce "debt-free" graduates, thus allowing for a sample of students whose 
experiences would be able to speak directly to my research questions. An additional benefit of my research site is the fact that it is a majority-minority institution, which allowed me to work with students from a variety of traditionally marginalized and underrepresented backgrounds in higher education whose experiences, as highlighted in chapter II, spoke directly to indebtedness and choice. As such, I sought to recruit students from African-American, White, and Latinx/Hispanic backgrounds due to the prevalence of students from such backgrounds appearing in the research literature on family and social obligation. Additionally, given the relative demonstrated financial need of students from African-American and Latinx backgrounds and differences in college enrollment among such students (US Department of Education, NCES, 2015a), I wanted to include the experiences of students from these backgrounds in order to provide "adequate description, interpretation, and explanation" (Maxwell, 2013, p. 79) of their experiences in relation to the research questions.

Maxwell (2013) argues that one of the major goals of a purposeful sample is to "deliberately select individuals or cases that are critical for testing the theories that you began the study with, or that you have subsequently developed" (p. 98). Given the fact that I came to this study with a theoretical foundation based on Lazzarato (2011/2015) and Gildersleeve (2017), a purposeful sample allowed me to select cases that specifically spoke to the phenomenon of alleged "debt-freeness." For the purposes of this study, I am examining a class-based phenomenon (debt-freeness) that intersects with race and ethnicity. With that in mind, I sought to sample from a population of low-income students who are considered by their university to be debt-free. The struggles of low-income students in college are well documented (e.g., Engle and Tinto, 2008, Mayhew et al., 
2012, Tinto, 2006-2007) but when examining experiences of the low-income "debt-free" student it is also necessary to consider how class-based issues are moderated by race, ethnicity, and/or gender.

For example, Mitchall and Jaeger (2018) reported that students from low-income backgrounds often feel they need to make academic decisions based on perceived obligations to their families. However, the obligations that students feel to their families are often impacted by racial, ethnic, and gender based factors as well (e.g. Fuligni, 2001; Stein et al., 1998). Given these findings, it is clear that it is important to have a sample of men and women from culturally diverse backgrounds to best understand the debt-related experiences of students who might have additional debts and obligations weighing on them. Since this study is an examination of the experiences of students surrounding debt, when selecting a purposeful sample it was necessary to choose students from socioeconomic, gender, and racial/ethnic groups who are able to speak to the phenomena being studied as explained by Creswell and Poth (2018) and Maxwell (2013).

\section{Sample Size}

According to Smith, Flowers, and Larkin (2009), the most important aspect of the sample size is the quality of the interviews, rather than the sheer number of them. In thinking about my own sample for this study, I was able to interview 13 students. This number of participants was manageable, yet still provided an opportunity "for the development of meaningful points of similarity and difference between participants, but not so many that one is in danger of being overwhelmed by the amount of data generated" (Smith, Flowers, and Larkin, 2009, p. 51). For Seidman (2013), there are two critical components of choosing a sample of the right size: enough participants so 
individuals outside of the sample might be able to connect to the experiences the participants of the study, and reaching data saturation. During the month long process of completing interviews, sample size was a constant consideration; as I completed interviews 11, 12, and 13, I began to feel as if there was both, enough variation in experience as well as enough repetition within the sample that I felt it was appropriate to cease student outreach.

In regards to sampling students from a variety of backgrounds, I felt that utilizing an outreach frame that I could contextualize through research was critical, however given the low initial response rate I was pressed to recruit any participants regardless of background. I was able to be more selective regarding the students' gender, which according to the research explored in chapter 2, can play a role in students' indebtedness (e.g., De Feliciantonio, 2016), however one of the limitations of this sample is the fact that the race and ethnicity of the sample for the present study was determined by the response rate and the overall population at FIU. Given the large number of students from Hispanic/Latinx and African-American backgrounds at the university, I was able to maintain a sample of students that is justifiable by the research literature and one that provides the variation in experience as discussed by Maxwell (2013).

One of the claims I attempt to make with the present study is the existence of a lack of nuance and variation in how debt is discussed in higher educational literature (see: Archuleta, Dale, and Span, 2013; Callender and Jackson, 2005; Elliott and Lewis, 2017; Polletta and Tufail, 2014; Sweet, Nandi, Adam, and McDade, 2013). As such it was important to me to utilize a sample of students that would highlight the multitude of experiences that students can have in relation to debt. One of the wonderful things about 
FIU is the diversity of the student body - students from Latinx backgrounds at FIU come from countries around the globe, such as Mexico, Cuba, Honduras, Peru, and Colombia, to name a few. The same was true of students from African-American and AfroCaribbean backgrounds - students made their way to FIU from a variety of countries including Jamaica, Portugal, Haiti, and the United States, for example.

\section{Sample of Participants}

The present study examines the experiences of thirteen $(n=13)$ students at Florida International University, all of whom qualified for the Golden Promise scholarship program. My sample of students was made up of first $(n=6)$ and second $(n=7)$ year students. The students are all from a variety of self-identified racial and ethnic backgrounds and I had students share, in their own words, how they would describe themselves. The sample was made up of: two students of Haitian descent, one White student, one student of Puerto Rican descent, one student of Honduran/Cuban descent, one student of Mexican descent, one student of fully Cuban descent, one student of Peruvian descent, one student of Dominican/Puerto Rican/Nicaraguan descent, one student of Columbian descent, one student of Argentinian descent, one student of African-American descent, and one student of White/Afro-Portuguese/Jamaican descent. Ten of the students in this sample were born in the United States and 3 were born outside of the US.

The students in this sample varied in age from 18-21 years of age (age 18, $n=3$; age $19, \mathrm{n}=5$; age $20, \mathrm{n}=3$; age $21, \mathrm{n}=2$ ). The sample was made up of 8 female students, 4 male students, and one gender non-binary student. The students in this sample came from a diverse set of majors, including: Biology $(n=2)$, Music $(n=1)$, Hospitality Management 
$(\mathrm{n}=1)$, Political Science/International Relations ( $\mathrm{n}=3$ ), Social Work ( $\mathrm{n}=1)$, Psychology $(\mathrm{n}=3)$, Criminal Justice/Psychology double major $(\mathrm{n}=1)$, and Mechanical Engineering $(n=1)$. Among this sample of Golden Promise students, seven have taken out loans or received direct financial assistance from a family member to cover the costs associated with their education and six students have not had to take out loans to cover the cost of their education.

\section{Data Collection Procedures}

\section{The Qualitative Interview}

To capture detailed student experiences, I conducted one semi-structured interview with each student. For this study, interviews were a useful data collection method because they can provide the researcher with a tool to "invite participants to offer...rich, detailed, first person account[s] of their experiences" (Smith, Flowers, and Larkin, 2009, p. 56). For many, the interview accomplishes this goal (Creswell and Poth, 2018; Seidman, 2013; Smith, Flowers, and Larkin, 2009). Another reason for using interviews is the "emphasis on meaning and meaning in context...To observe provides access to their behavior...Interviewing allows us to put behavior in context and provides access to understanding their action" (Seidman, 2013, p. 18-19). The interview allowed students to provide their own detailed accounts of their perceptions and experiences in the contexts in which they were experienced.

Given the limited understanding of non-financial debt in higher education, the analysis of rich student interviews can help shed some light on an area that desperately needs deeper empirical examination. Ultimately, this exploratory study begins the process of engaging with a topic and experiences that have largely been neglected in research on 
financial aid, promise programs, and student life. I chose to conduct a single interview due to the difficulty of scheduling multiple interviews for personal reasons, right before a hectic point in the semester professionally and the fact that I was in the process of moving out of Miami at the time. At this point in the research process, I wanted to establish a foundation for future work and use the results from this study to consider future directions that directly result from student responses and areas of interest that arose during the initial interview. Part of the researcher-participant relationship is understanding that the participant "is the experimental expert on the topic in hand...and the aim of the interview is to enter the participant's lifeworld or allow [them] to recount their life experience" (Smith, Flowers, and Larkin, 2009, p. 58). Students in promise programs are the experts of their experiences within the program and their insights and articulations on various forms of debt will be invaluable in preliminarily exploring the ways in which low-income "debt-free" students understand and make meaning of their own debt and decision making.

Given the semi-structured nature of this study, I developed an interview schedule designed to best capture each student's experience as it relates to debt, choice, and obligation. For Smith, Flowers, and Larkin (2009), "the aim of developing a schedule is to facilitate a comfortable interaction with the participant which will, in turn, enable them to provide a detailed account of their experience under investigation" (p. 59). The interviewer should provide questions to the participant that are "open and expansive" (Smith, Flowers, and Larkin, 2009, p. 59), giving the participant plenty of space to provide in-depth answers. Interview questions should try to avoid making assumptions about a participant's story or be leading (Smith, Flowers, and Larkin, 2009). A sample 
interview protocol is attached in appendix C. Additionally, the semi-structured nature of the interviews for the present study allowed me to reorganize planned questions and ask follow-up questions based on the flow of the conversation, creating a more cohesive experience for student and researcher.

\section{Individual Interviews}

Eleven of the thirteen interviews were conducted in my professional office, located in an academic advising suite on the campus of Florida International University. I chose this location out of convenience for the students in the sample, many of whom were already on campus during the scheduled interview time, thus not requiring students to transport themselves to a second location. Further, this location provided a quiet, private space for personal conversations. The remaining two interviews were conducted via a scheduled phone call. Phone interviews were scheduled with two of the students in the sample because they were distance learning students that did not reside in Miami. Both phone interviews were conducted using my personal cell phone (students were given a Google Voice number to call, rather than my personal number).

The interviews for this study were conducted over a 23-day period in March of 2019 (March 8 through March 30). I wanted to conduct interviews during this time because it was after many students had completed their midterms and a few weeks before students would have to start focusing on final exams. While this seems like a short period of time in which to conduct interviews, during my outreach period I tried to immediately schedule students who responded to my outreach request. Given the difficulty I experienced during my initial outreach and my fear of having to further rely on the Office

of Financial Aid, it was my goal at the time to ensure I maximized the number of students 
I was able to schedule, which happened to take place over this 23-day period. I provided students several interview slots during our initial communication to ensure that students would be able to choose a time that was convenient for them and when they might already be on campus. All interviews were conducted during regular business hours (8:30am - 5pm), with the exception of two in-person interviews, one that took place from 4:45pm to 5:35pm and one that took place on a Saturday morning (10:00am - 11:01am). The range of interview lengths was between 26:54 and 1:08:18 (hours:min:sec). On average interviews lasted 48:09 (min:sec). During the interview process students were asked to select their own pseudonym for confidentiality purposes. Each participant was very forthcoming about their personal history and experiences during our interview. Further, the participants were engaged and interested in the research process, often asking me questions about next steps and when my research might be completed.

Each interview was recorded using an Olympus VN-702PC digital voice recorder. The files were then transferred to a personal computer and uploaded to Temi, a secure transcription service, to be digitally transcribed. After receiving each transcript file, I listened back to each recording and compared it to the transcript to check for any errors. After each transcript was reviewed I uploaded it to Atlas.ti for analysis. All recordings and transcriptions were stored securely on a password protected and encrypted Dropbox account. Following the review of each transcript, member checks were conducted with each participant via email. Participants were emailed a copy of their interview transcript (through FIU's Google based PantherMail) and given two weeks to review and approve the transcript. Only one of the thirteen participants responded to my request for feedback 
and provided no edits or feedback along with their approval. It is unknown at this time if the remainder of the participants reviewed their interview transcripts.

\section{Participant Profiles}

According to Seidman (2013), participant profiles are an important part of providing readers with important information as it relates to contextualizing a participant's individual experience. Given the importance of each students' experience in shaping the findings from this study I thought I was important to allow readers to engage with who these students are, providing insight into their backgrounds that might not fully be capture by the direct quotes used in chapter IV. Seidman writes, "what others can learn from reading a profile of a participant is as diverse as the participants we interview" (p. 122). With that in mind, the following section details each participant's background information including their gender, age, race/ethnicity, year in college, college major, and career goals. Table 1 (on page 92) provides a brief overview of each participant's demographic information, while the remainder of the section provides more detailed profiles. 


\section{Table 1}

Participant Demographic Information

\begin{tabular}{|l|l|l|l|c|c|}
\hline \multicolumn{1}{|c|}{ Name } & \multicolumn{1}{|c|}{ Heritage } & \multicolumn{1}{c|}{ Major } & Age & Gender & Year \\
\hline Julie & Haitian & Biology/Pre-Med & 19 & F & So. \\
\hline JM & White & Music & 21 & M & So. \\
\hline Charlie & Puerto Rican & Hospitality & 19 & F & Fr. \\
\hline Jennifer & Honduran, Cuban & Political Science & 21 & F & So. \\
\hline Olivia & Mexican & Social Work & 19 & F & Fr. \\
\hline Analise & Cuban & $\begin{array}{l}\text { International Relations, Political } \\
\text { Science }\end{array}$ & 20 & F & So. \\
\hline Madelynn & Peruvian & Psychology & 18 & F & Fr. \\
\hline Rachel & $\begin{array}{l}\text { Dominican, Puerto } \\
\text { Rican, Nicaraguan }\end{array}$ & Criminal Justice, Psychology & 20 & F & So. \\
\hline Mateo & Colombian & Biology, Pre Physician's Assistant & 20 & M & So. \\
\hline Scott & Argentinian & Mechanical Engineering & 19 & M & So. \\
\hline Jay & African-American & $\begin{array}{l}\text { International Relations, Political } \\
\text { Science }\end{array}$ & 18 & M & Fr. \\
\hline Jordyn & Haitian & $\begin{array}{l}\text { Psychology, Pre Physician's } \\
\text { Assistant }\end{array}$ & 18 & F & Fr. \\
\hline Mars & $\begin{array}{l}\text { White, Afro-Portuguese, } \\
\text { Jamaican }\end{array}$ & Psychology & 19 & NB & Fr. \\
\hline
\end{tabular}

Julie is 19 -year-old female, college sophomore of Haitian descent. She is a firstgeneration American and was born in New York. As a young child she moved to Haiti and then to Florida when she was around 5 or 6 years old. Growing up her parents moved back and forth between Haiti and the US while trying to work on citizenship and for job requirements. Growing up Julie mentioned spending a lot of time with aunts and cousins who helped her mom raise her and her older sister. Julie discussed being unsure if she would be able to attend college during her high school years due to the financial strain it 
would put on her family and being unsure that her grades and test scores were high enough the get admitted. After taking the SAT a couple of times and learning about the Golden Promise scholarship, Julie applied to FIU and was admitted. She is currently majoring in Biology with a focus on pre-med. Ultimately it is her goal to work as an OBGYN to assist women with family planning and work with new-born babies.

JM is a 21-year-old male, White, college sophomore born in the northern Midwest. JM's is a first-generation college student; his father was a high school graduate and his mother did not complete middle school. When he was three years old his parents divorced and his mother remarried. After his mother and step-father divorced he moved to Florida with his mother and half-brother to live with his grandparents with his stepfather remaining in the Midwest. While in Florida he gained a second step-father and two younger twin sisters. For a time JM, his mother, and siblings were able to move out of his grandparent's house while his mother and second stepfather both worked steadily. Eventually, his mother and second step-father split. Then, after his mother was in an accident leading to a brain injury and an addiction to opioid medication he and his siblings were cared for by his third step-father. JM is currently a student majoring in music at FIU. His ultimate goal is to get tenured with an orchestra and also provide music lessons and mentoring to young members of his community. Currently JM is not working, but he and a few music school peers play gigs every so often to earn a little extra money. He lives in off-campus housing located in the community near campus. JM has taken out loans to assist with educational expenses.

Jennifer is a 21-year-old female, college sophomore of Honduran and Cuban descent. Her mother was born in Honduras and her father was born in the US to parents 
from Cuba. Her mother, despite being married to U.S. citizens, never applied for citizenship in the U.S., which complicated her life growing up. Jennifer was born and raised in Miami and raised by her mother. When Jennifer was around 4 years old her father passed away due to medical negligence. After her father passed, Jennifer and her mother we supported by aunts and uncles, with one uncle in particular acting as a fatherfigure for her growing up. During this time, Jennifer and her mom lived in Miami Dade County, while many of her family members lived in Broward County causing them to have to travel each weekend to see one another. Additionally, Jennifer was admitted to a prestigious IB middle school and had to commute a long distance for middle and highschool. Currently, Jennifer is taking classes through FIU Online and living in North Carolina with her partner and his family. During the Fall 2019 semester she plans to return to Miami and return to living with her mother and commuting to school 30-40 minutes each way. Jennifer is currently a political science major and eventually plans to attend law school. She was inspired to become a lawyer after spending years of her youth in and out of courtrooms during medical malpractice hearings related to the passing of her father. Jennifer reported taking out loans during her first year because she was afraid of not having enough money to cover her costs, but ended up regretting it stating that she would not have taken out loans had she had more information about college expenses.

Charlie is a 19-year-old female, first year college student born in Puerto Rico. She and her family came to the US when she was 5 . She was raised in the Orlando area and continues to live there presently. Both of her parents completed some college, but neither completed their degree. Charlie reports having a close relationship with her immediate family, while her extended family still live in Puerto Rico, which has made it 
difficult to maintain really close relationships. Charlie has two siblings, an older brother and an older sister. Growing up Charlie attended a bilingual magnet elementary school, which she credits with making her transition to the mainland US easier, having moved from Puerto Rico only speaking Spanish. Throughout middle and high school Charlie was very involved in extracurricular activities and was a member of AVID, a pre-college program. She reported receiving support through middle and high school from her AVID counselors and parents, which really encouraged her to attend college. Due to medical issues that arose from her mother's car accident Charlie provides care and assistance to her mother presently. Charlie originally wanted to attend college in St. Augustine, FL, but due to her mother's ailments Charlie restructured her plans. She applied to several colleges within the state of Florida and ultimately chose FIU online because it allowed her to stay back in Orlando and help take care of her mother. At this time she still lives at home with her parents. At FIU, Charlie ultimately landed on hospitality management. She was inspired to pursue this major as a result of the experience she has gained working for a major hotel chain in the Orlando area. Charlie uses the money she earns from her job to pay for educational expenses and to help her family out with expenses around the house. As of the writing of this dissertation Charlie has not had to take out any educational loans, but is concerned that she may need to in future years because money has been tight. She is also concerned about paying for law school in the future.

Olivia is a 19-year-old female, first-year college student of Mexican descent. Both of Olivia's parents were born in southern Mexico. She was born in Naples, FL and has 5 sisters ( 3 older and 2 younger). Olivia reported that her and her family moved around a lot, with her some of her sisters being born in different places (e.g., Arizona, 
Oregon). Olivia and her family lived comfortably in a home together until 2007, when the economic recession hit the US. After 2007, Olivia discussed having to move between apartments eventually ending up in a mobile home with her family. While her father had his green card, Olivia shared that at the time her mother did not, which placed a lot of stress on the family. During the process of trying to obtain her green card, Olivia's mother was deported and forced to live in Mexico for one and a half years, away from her family. During this time Olivia and her younger sisters was cared for by her father and older sisters (who were in middle school at the time). As of the result of the time away from her mother, Olivia's relationship with her mom suffered greatly. As she was getting ready to apply for college, Olivia's mom and her older sisters were not supportive and instead encouraged Olivia to stay home and help around the house. Olivia is the first person in her family to go on to non-technical post-secondary education. During the college choice process, Olivia was deciding between USF, FIU, and FAU, ultimately choosing FIU because it was somewhat close to home and had a specific academic program she wanted. Olivia is currently majoring in Social Work with plans to get her master's in the same field. Ultimately she wants to join the Peace Corps., and eventually work for them as a full-time employee. Olivia lives in on-campus housing during the school year. During each semester at FIU Olivia has had to take out loans to cover education related expenses.

Analise is a 20-year-old female of Cuban descent in her sophomore year at FIU. Both of Analise's parents were born in Cuba; she was raised in Miami. She does not have any siblings. Growing up Analise and her family moved around Dade County fairly often. Her parents were part of a Home Cares program that provided assistance to senior 
citizens to bring in additional income. Analise's family invested her college savings into a piece of property that did not provide returns at the level expected. She also discussed her parents not starting a Florida Prepaid account, an investment savings account that families can pay into to cover the future cost of tuition and fees at a Florida state college or university, which caused her stress and anxiety throughout the college application process. Due to her family's financial situation Analise only applied to one school, FIU. Analise is currently working over 30 hours per week and taking online courses, but had a conversation with her parents about leaving her job to be more involved on campus, get an internship, and take face-to-face courses. She is currently majoring in International Relations and plans of getting a master's in the same field. Analise was originally a business major but switched because she did not want to complete the required math track. Ultimately, she wants to work as a diplomat. Analise currently lives at home with her parents. As of the writing of this dissertation, Analise has not had to take out any loans related to her education.

Madelynn is an 18-year-old female first-year college student of Peruvian descent. She is a first-generation college student; neither her mother nor father completed college. Both of her parents were born in Peru and divorced when she was around 10 years old. She has one sister. The remainder of her family currently lives in Peru. Her mom and step-dad live in south Florida and her dad lives in South Carolina. Currently, Madelynn lives at home with her mom and step-dad but is planning a move to South Caroline in the next couple of months to live with her father. Initially Madelynn was interested in a major in English, but was unsure if it would be able to provide her with job stability in the future. She is currently pursuing a major in psychology and hopes to one-day work as 
a child psychologist. Currently, Madelynn lives off-campus at home with her mom and step-dad but is planning a move to South Carolina in the next couple of months to live with her father. During her first semester Madelynn worked, but has recently quit her position due to her impending move to South Carolina. She has not had to take out any loans to cover expenses related to her education.

Rachel is a 20-year-old college sophomore of Dominican, Puerto Rican, and Nicaraguan descent. She was raised by her mother and reports that her father was not in the picture during her childhood. Later on in her youth, Rachel's mother remarried and her sister was born. According to Rachel, this led to some difficult times as her mother and step-father went through periods of unemployment and economic hardship. During this period, she and her family moved three or four times as a result of evictions and her step-father not paying their family's rent. At one point during her childhood, Rachel discussed living out of a hotel for several weeks. Rachel, her sister, mother, and stepfather also moved in with her Aunt and her family for several months. Following her mother's separation from her step-father, Rachel discussed a period of improvement, eventually culminating in her mother's marriage to a new partner who was able to provide the family some more stability. While all of this was going on, Rachel was able to remain in the same elementary school until 4th grade, until she was pulled out and sent to a new school before fifth grade, unable to finish elementary school all in one place. Rachel attended private school for middle and high school. Rachel chose FIU because they admitted her to start in the fall, rather than the summer, and she would not have to pay for housing. Currently she is majoring in Criminal Justice and Psychology, with an eye on going into law enforcement, specifically, working for the FBI. After her 
bachelor's she plans to pursue a master's at FIU and move on to her career. Rachel is currently working as a student assistant at FIU and lives at home with her Mother, Stepfather, and sister. She has not had to take out any loans to cover expenses related to her education.

Mateo is a 20-year-old male sophomore of Columbian descent. He was born in New Jersey to his parents, who both emigrated to the US in the late 90's. As a young child, Mateo moved to Florida and has lived there ever since. Mateo has a brother who is 9 years older than him who was also born in Columbia and came to the US with his parents as a young child. The rest of Mateo's family still lives in Columbia and he has been traveling there regularly since he was 4 years old to spend time with his extended family. During the college application process, Mateo only applied to one school, FIU. He thought about applying to FAU as well, but never completed the application once he was accepted to FIU. Mateo ultimately chose to attend FIU because he had some connection to the campus as part of the programs he was involved in at his high school and due to the financial factors related with attending. At FIU Mateo is pursuing a degree in Biology with a Pre-Physician's Assistant track. He was inspired to pursue a degree in the medical field because of an Aunt who passed away at a young age due partially to insufficient medical care. Her passing inspired him to switch from a pre-Veterinary track to one involving human health care. At first he planned to pursue medical school, but after considering the years and additional costs, he decided to pursue a career as a Physician's Assistant. Mateo currently lives on his own in an off-campus apartment near FIU's campus. When he is not taking classes he works a part time job in a pizzeria because he does not want to continue relying on his parents for financial support given 
their economic situation. Mateo has taken out two loans to assist with the cost of his educational expenses.

Scott is a 19-year-old male sophomore of Argentine descent. He was born in Argentina and came to the US with his parents when he was a baby. He grew up in Miami-Dade County before moving to Homestead, Florida before middle school. While he was in middle school his brother was born and his parents went through a divorce. Currently, Scott has a relationship with his mother and father, both of whom he is able to spend time with regularly. While he was a child, Scott's mother was taking college classes at night, but never finished her degree. He also discussed his mother attending college in Argentina before coming to the US, but stated that she was not able to finish due to her having children. Scott's dad did not attend college and works in the automotive industry. Scott stated that he does not have much of a relationship with his younger brother because his brother is always out with friends. Growing up Scott's parents both had college going expectations for their oldest son. While he had aspirations to pursue martial arts at the Olympic and professional level, an injury caused him to see college, originally a safety in his mind, as a necessity that was also strongly encouraged by his parents. Scott is presently working towards a major in Mechanical Engineering as a result of his interest in cars and in wiring units. Throughout our interview, Scott discussed many of his entrepreneurial pursuits outside of major, and may consider a career in one of his entrepreneurial avenues post-graduation. In addition to engineering, he also has interests in real estate and investing. Currently, Scott lives at home with his mom, brother, and one of his good friends, who is renting a room in their house. Scott using some of the earnings from his job to help his mom pay for rent, groceries, insurance, and 
other household expenses. At the time of this writing, Scott has not had to take out any loans to cover educational costs.

Jay is an 18-year-old male, first-year college student of African-American descent. Jay was born and raised in Jacksonville, Florida by his mother and father. He has four sisters. Jay's father was laid off from his job when Jay was 11 and then was diagnosed with cancer, which caused great financial difficulty for his family. During this time Jay's mother was integral to the household, taking care of the children and managing the rest of the household duties while his father recovered. During high school, Jay spent the first two years attending high school normally and then his last two years as a full-time dual enrollment student, which meant he was exclusively taking classes at his local community college. Jay accumulated many college credits during high school and graduated HS with an Associate's Degree. After applying to USF, FSU, and FIU, Jay ultimately decided on FIU because his interest in Political Science and International relations, the cost of attendance, and the ability to live in Miami. Currently, Jay is double majoring in Political Science and International Relations and plans to attend graduate school after he finishes his bachelor's degree. Jay's long-term goal is to work as a diplomat. Jay is on track to finish his undergraduate degree in two-years, but has concerns about his ability to get into graduate school after only being in college for twoyears. As a result, he is not currently working and is currently applying to an internship program in Washington DC to boost his resume. Jay currently lives on-campus at FIU. While Jay has not had to take out any loans per se, he did have to rely on his older sister to cover some of the cost of his tuition, room, board, and fees not covered by the Golden Promise. 
Jordyn is an 18-year-old female first-year student of Haitian descent. She was born in Haiti and moved to Port St. Lucie, Florida in the early 2000's with her Mom and Brother. When they first moved to the US, her family moved in with her Aunt. Jordyn discussed relying on her aunt financially during this time because her mother was unable to work. Eventually, they moved out of her aunt's house once her mom was able to start working. She discussed having a very close relationship with her mom, who took care of everything around the house, while working as a single parent. Growing up, she was always expected to go to college and continue her education. While she was deciding on what college to attend, Jordyn was choosing between several schools within the state of Florida due to cost and wanting to remain close to her mom. Ultimately, she was deciding between FIU, FAMU, and FAU. She chose FIU because it was the closest to Port St. Lucie and they offered her the most aid money. During high school, Jordyn took college courses and ended up graduating high school with an associate's degree. Presently, Jordyn is a Psychology major on a Pre-PA track. Jordyn lived with her mom and brother in Port St. Lucie until moving away for college. Currently, she lives on-campus at FIU. Jordyn has had to take out several loans to cover the cost of additional educational expenses not covered by the Golden Promise.

Mars is an 18-year-old gender non-binary first year student of White, AfroPortuguese, and Jamaican descent. They were raised primarily by their mother because their father left when they were around 3 years old. Mars has three siblings that they are close with, one full brother and two half-siblings. During the college application process Mars discussed a difficult decision between FIU and Pace, a college in New York City. Ultimately, due to the price difference between the two, Mars chose to attend FIU after 
learning that the financial aid from Pace would only cover half of the cost. At FIU, Mars is studying psychology with the aim of becoming a sex therapist in the future. In the past Mars considered pursuing a career in the fashion industry, but was unable to find relevant classes at FIU. They were also inspired to go into the field of psychology due to health issues they are presently facing and the desire to assist people in their relationships. Presently, Mars lives on campus and has not had to take out loans related to their education.

\section{Data Analysis}

I performed data analysis using Creswell and Poth (2018), Maxwell (2013), and Saldaña (2009/2016) as guides. The first step of my data analysis process was the review and revision of each interview transcript. During this step of my analysis I carefully listened to each interview recording and compared it to the interview transcript generated by the Temi transcription service in order to make revisions and ensure that the text matched the audio recording verbatim. After this process was completed I reread each interview transcript, taking note of quotes and phrases relevant to my research questions. I selected these quotes and phrases based off of my theoretical framework and the initial interpretations of each interview, which were documented across several analytical memos. Each analytic memo consisted of general demographic and biographical information about the student and some of the tentative ideas I had for future codes.

For example, in the analytic memo I wrote after my interview with JM I wrote, "JM felt that his ability to attend college needed to be "paid back" to the people/communities/even FIU that were so influential in his life." Similarly, in my interview with Julie I wrote, "the participant was very clear with the sense of obligation 
she felt to her family members. She noted that her parents worked very hard to provide a stable life for her sister and her and she wanted to use college as an opportunity to pay them back for their sacrifices." Upon reviewing JM and Julie's transcripts, I was able to use each memo to recall the initial impressions I had of our discussion, providing me a framework with which to begin my data analysis process. It was also in these memos that I was able to note some of the unexpected phenomena my participants Once this initial analysis was completed, I moved on to my first cycle of coding. This process was repeated for each transcript. Ultimately, I wanted to create a coding scheme that allowed me to successfully answer my research questions.

\section{Code Choices and Their Operational Definitions}

According to Saldaña (2016), during the coding process it is critical to "rationalize your specific choices for the data" which serves as an "internal reality check or your thinking processes" (p. 46). During my first cycle of coding, I was careful to operationalize each code, ensuring that I would have consistency about how each code was applied to the students' interview transcripts and quotes. These operational definitions created consistency across the coding cycle, which is a critical component of data integrity (Creswell and Poth, 2018). The number in brackets next to each code represents its frequency. Each description represents when and how I created each code, the operationalization of my codes, and the criteria I used when applying each code. Ultimately, the following section aims to reflect on the coding process and clearly delineate the specific thought process for each code. 


\section{“Allegedly Debt-Free" [10]}

One of the reasons that I chose to sample from a population of students in a promise program was because of the alleged debt-freeness of these students. According to the language of the program, the goal is that students will be able to graduate in fouryears without educational debts. As I was reviewing each transcript, one of the items that became clear to me was the fact that many of these students did in fact incur financial debts as part of their education. Additionally, given Lazzarato and Gildersleeve's conceptualizations of debt, I also used this descriptor when students discussed "owing" or "feeling obligation" towards individuals and communities in their lives. This code was generated theoretically, but also came to be used for more unexpected findings in the study.

Use "ALLEGEDLY DEBT FREE" when an interview discusses a form of debt they are experiencing in their lives. This could mean both financial and non-financial debts.

Typical exemplar: "And then when I, but when it came time for school I was doing online and that was like almost a thousand dollars, just take one class and I'm like, oh my God, I don't have that money right now. So my sister had a, she took out a loan but she took it out under her name so she didn't take it out under my name and she's like, um, just pay me back when you can.”

\section{"Being an Example" [22]}

One of the topics that came in during my literature review was the idea of racial uplift or being an example for your particular community. For this study, one of the ways I have conceptualized the idea of a non-financial debt is "repaying" someone or 
something through non-financial means. This could be personal stress, diminished decision making, feelings of obligations that dictate actions, etc. For some of the students interviewed for this study, there were clear instances of them feeling like they had to "be an example" to their community or "represent their race" while they were at FIU. This was especially true for students from traditionally underrepresented and minoritized communities.

Use "BEING AN EXAMPLE" when an interviewee discusses feeling like they must be a representative of their race or that they feel like they have extra pressure put on them as a result of being from a specific demographic group.

Typical exemplar: "Like, [if] I don't answer some correctly or [if] I'm [not] able to get my thought out quickly in the back of my head. I feel like, Dang, am I a stereotype because I couldn't articulate myself correctly or I feel intimidated to kind of be... stand out and I raise my hand if I have a question because I don't want to be that person. Yeah. Yeah. So it kind of makes me, I'm trying to get out of it now. I just kind of makes me, I realized that I should actually do the opposite and um, be better...So that's something I need to work on. But really just, it makes me kind of get in a shell a little bit and it makes me really quiet."

\section{"Community" [92]}

Anecdotally, one of the phenomenon I observed during my five years as an academic advisor at FIU was the importance of students' communities to their success academically, socially, and professionally. In conversations with students they would frequently discuss the impact that their communities had on their lives, something that was also true of the students within this sample. The impacts of community on students' 
lives were also well documented in the research literature (e.g., Fuligni, Tseng, and Lam, 1999; Malcom, 2015). Given the importance of community both in my own professional experiences and through the research literature, I felt it was important to consider each instance a student spoke about their relationship with their community (familial, social, academic, or professional, etc.) to further analyze each low-income promise program students' experience with indebtedness.

Use "COMMUNITY" when an interviewee talks about the impact community has had on their life. This can be used to describe both foreclosing and opportunity creating examples.

Typical Exemplar: "I'd love to be able to teach others you know and maybe get them inspired. I think that's the big end goal is to be able to inspire others to take up this path, the music's very a very wonderful path.”

\section{"Dependence on Family" [9]}

One thing that was very clear during each interview, and something that I documented in almost every analytical memo, was the clear and defined role that each students' family had on their ability to make decisions about their academic lives as a direct result on the dependence they had on their families, which resulted in a feeling of obligation or a "debt of gratitude."

I ceased use of "DEPENDENCE ON FAMILY" after coding the second interview transcript. I phased out this code because I did not feel it was specific enough to capture the depth of this particular phenomenon. Instances that were originally coded as "dependence on family" were re-coded utilizing more specific codes. See codes: Expectations; Parental Support; Positive Outlook; Recognition of Parent's Actions. 
Typical exemplar (later re-coded to "Recognition of Parents' Actions"): “[My

Grandparents] kept me on the straight and narrow because I'm generally like I said my family's never been really tight together between my mother and my and my, the multitude of stepfather or father figures I've had. So they really helped keep me a little bit sane, you know while it was going on because there weren't there were very many easy days you know in the household."

\section{"Emotional Debt" [232]}

Coming into this study, one of my goals (and eventual research questions) was focused on the examination of how/if students experience non-financial debts associated within their college-going experiences. As I began to operationalize the idea of nonfinancial debt for the present study, one of the most common instances of how students "paid for" their ability to attend college was with their emotional well-being. Sometimes this emotional debt was a result of a student having to go against their family's wishes or leaving a single-parent at home in order to have a "better future" as a result of attending college, for example. While it was initially expected that many of these instances would be foreclosing, after each interview and the subsequent review of the interview transcript, this emotional debt had the potential to be foreclosing as well as opportunity creating.

Use "EMOTIONAL DEBT" when a student discusses the emotional toll that their decisions or experiences have had on their lives. Specifically, this speaks to the emotional stressors students have experienced or are experiencing as a result of life events in their past and/or present.

Typical exemplar: "Like seriously [my mom] doesn't really talk about much so like I'll worry about her a lot. So a lot of decisions I make include her, so like where I 
wanted to go to school. I didn't want to go to school far away. So like, um, FSU like, FAMU in Tallahassee, those are like 6 hour drives. I was like, it's too much.”

\section{"Expectations" [246]}

As I was first reviewing the transcripts, one general student experience stood out to me as important in the conceptualization and operationalization of non-financial debt, the weight of expectations. As highlighted in the research literature, familial expectations can be a critical piece of a student's attainment the collegiate level, something that came up during each of the student interviews. Beyond the weight of parental expectations, students also seemed to feel the weight of the expectations they placed on themselves, which could work in crippling or motivational ways for different students.

Use "EXPECTATIONS" when students discuss their feelings about the expectations placed on them or the expectations they place on themselves.

Typical exemplar: "When it came to bringing me here and all that my parents put a lot of their eggs in one basket... [I have] my own personal pressure that I put on myself to try to be my best and not to like try to disappoint them."

\section{"Fewer Options" [312]}

Prior to the interviews one of the ideas that was clear in my mind was that of debt as foreclosing of possibilities and choices as a result of my engagement with the work of Lazzarato (2011/2015). The idea of foreclosure became a critical component of my study, culminating in the generation of my research questions meant to better understand the existence of debts that may or may not act as foreclosing in student decision making. As I conducted each interview, there were clear instances of the phenomenon of foreclosure, both as a result of past and present experiences. Both prompted and unprompted, students 
discussed the variety of ways in which both financial and non-financial debts acted to foreclose their decision making abilities.

Use "FEWER OPTIONS" when students discuss experiences related to the foreclosure of their decision making as a result of their experiences with financial and non-financial debt.

Typical exemplar: "But I like to let myself to believe that I did have a choice. But in the end I feel like it really didn't have a choice. Like, no."

\section{"Financial Stress" [203]}

This code was inspired by the reality that it difficult to separate the impact of each participants' financial situation from some of the other non-financial factors explored in this study. While this study suggests that there are non-financial debts associated with attending college and that such debts can act as foreclosing forces, the students in this sample also spoke at length about their families' financial situation. They each discussed how money was a factor in many of the decisions they made and the ways in which their families' finances created emotional, for example. This code was generated after interviewing each student and reviewing their transcripts. Even outside of the specific questions geared towards evaluating each student's financial situation growing up, during questions and follow-up questions about the non-financial debts explored in this study, instances of financial hardship, and the resulting emotional hardships, were an integral part of each student's experience.

Use "FINANCIAL STRESS" when students discuss their family's or their own financial stressors. These stressors may be related to loans, past financial hardship, and/or, the feelings of stress associated with the cost of college, for example. 
Typical exemplar: "I actually was originally not planning on coming to FIU. Um, I was planning on going to New York if I have, I got accepted into Pace. It's a private school in Manhattan and obviously I don't have to $\$ 32,000$. I got a half scholarship. But still there was no possible way...So, I basically, I came to a Florida school because Florida schools are a lot cheaper when you're a Florida resident. So I wanted, it was my dream to go to New York, but I knew that I didn't have the financials to cover it. And so, yeah."

\section{"First-Generation" [31]}

Surprisingly, one of the factors that I failed to consider coming into this study was the fact that many of my students might be first-generation students, i.e., students whose parents did not attend college. The academic and social struggles of first-generation students are well documented in the research literature, so when it started coming up during interviews, I added this to my coding scheme to categorize examples of students discussing their experiences being a first-generation student.

Use "FIRST-GENERATION" when students discuss their experiences as a firstgeneration college student.

Typical exemplar: "For the most part I feel like I'm on my own for that just because no one else in my family has gone to school."

\section{“Golden Promise" [59]}

One of the key components of this study was each students' participation in the Golden Promise financial aid program, the parameters of which are highlighted earlier in this chapter. When developing my semi-structured interview protocol, examining students' experiences with this program was important to me because of the claims of 
debt-freeness for the students involved. Overall, I was interested in understanding students' perceptions of the notification process and, perhaps more importantly, how they understand the idea of promise in relation to their position at FIU. The code was used to identify quotes that were related to the Golden Promise and how each student internalized the meaning of the word promise when considering the goal of the Golden Promise program. Interestingly, some students expressed the feeling that they made a promise to FIU as part of the program, while others expressed that FIU had solely made a promise to them.

Use "GOLDEN PROMISE" when students discuss their experiences with the Golden Promise and their interpretation and understanding of what it means to be a part of a "promise" contract.

Typical exemplar: "The way I see it, it's a promise that because I'm low income, if I do well, they're promising to help me. And that's what that means to me. That's why I try to do the best I can because I feel very lucky to have this.

Michael: And do you feel that you have promised FIU anything?

Jennifer: Yeah, I promised FIU that I'm going to maintain the criteria to keep receiving the Golden Promise as well as not waste that degree, like be successful with that degree."

\section{“Guilt" [134]}

This code was generated after my initial read through of each interview transcript. The relationship of debt and morality was examined in chapter 2 and informed its development. I felt that I needed a code more specific to capture the emotional and moral aspects of non-financial debt. Throughout each interview, each participant expressed a variety of ways in which they felt some guilt about their decision to attending college, 
whether it was leaving home, having to take out loans, or the fact that they could not graduate sooner and start working as soon as possible. Each student expressed the individual reasons they felt guilt about their decisions and how they felt it impacted their past, present, and future decision making. This code also felt necessary as a standalone code (outside of Emotional Debt) because of the specific nature of how students discussed guilt and the theoretical framework from which it was derived.

Use "GUILT" when students discuss feelings of guilt associated with their college pursuits and/or the impact that guilt has had on their decision making.

Typical exemplar: (1) "the truth is that I think about them all the time. Um, all the time. Like every day. It just, that I guess a lot of people, you don't call them, they assume, you know, you don't think about them, but it's really, obviously I could think about somebody all day, but don't call it because of some things I'm dealing with or something that's going on around me." (2): "So I felt like kind of like what did I do wrong? Because like I have the grades, you know, like what did I do wrong to like not be able to pay for everything? Like my test scores weren't that high, but I still felt like, you know, embarrassed. I guess it's the word that um that I couldn't pay for everything, you know. So I didn't, I didn't want to tell my mom but I had to tell her."

\section{"Loans" [49]}

The idea for this code was generated after my first interview where the participant, Julie, discussed the fact that she had to take out loans to pay for costs associated with her attending FIU. Coming into the interviews, I was not expecting to hear that any of the students in my sample would be in any educational financial debt. As 
such, I utilized this code to notate and student quotes that talking about having to take out student loans.

Use "LOANS" when students discuss their experiences with student loans.

Typical exemplar: "I have a weird thing about not really like, not really wanting to tell people I took out loans just because of like, like, oh my God. It's like, how are you going pay it back? Just like, so that question, just like, it's just makes me stressed. So like, yeah, I don't, um, yeah, I didn't mention to her that I got, I took out a loan.

\section{"Parental Support" [10]}

After my first several interviews I started to notice the complicated relationship that many of the students in this sample had with their families. In addition to their feelings of guilt, emotional stress, and the weight of expectations, the students also discussed, in a variety of heartfelt ways, the positive support they received from their families as they navigated the often difficult college going process. Students spoke elaborately about how the support from their family motivated them to attend college or how the encouragement from their families led them to push through some of their more difficult moments and apply. This was a code that I generated throughout the interview process while reflecting on each interview through analytic memos. It was important to me throughout the present study to highlight students' protective factors as well.

Use "PARENTAL SUPPORT" to highlight examples of student's discussion of their parental/familial support systems. I utilized to code any student quotes that included examples of the ways they were supported by the families and some of the positive impacts their families had on their lives. 
Typical exemplar: "And you know, there was like when I would step out of the room to like get some food or anything or walk the dogs, they would be like is everything ok? Do you need anything? Like anything I can do for you. So I feel like um setting boundaries and stuff for, it was very easy, like my mom, um, when I went off for like college and like she helped me get my laptop. She bought me a laptop stand, it would be easier to do my work with it, like everything. So I feel like they were very understanding of when its family time, personal time and when it's school time and then have to be serious, just focus on it. Like they were really understanding of that.”

\section{"Positive Outlook" [32]}

This was another code that I developed midway through the interview process. Coming into this study and after working on initial drafts of my literature review, I had a negative outlook of what each student would discuss, expecting each student to talk about all the ways in which they were indebted, especially non-financially. Instead of each interview being solely the negative aspects of each students' life, many students shared examples of their resilience and positive attitude that helped them get to where they are today. And while some of the students did express disappointment, many of them were able to view their opportunities and experiences more positively than expected.

Use "POSITIVE OUTLOOK" when students discuss their experiences in a positive light. This code will be utilized when students look back on their experiences and take pride in their accomplishments or express satisfaction with their journey thus far.

Typical exemplar: "My mom, she was more set on just me staying home. And like when I think about it, like yeah, it was easier financially obviously. Like I don't have to 
worry about anything else. Like I have the luxury of going home and having a meal at home and, and not worrying about, I don't know, anything else like or gas and stuff like that. Like I don't have to really worry about that yet."

\section{“Recognition of Parents' Actions" [53]}

As I was coding each interview transcript and utilizing the "Parental Support" code, I realized that there were more specific ways in which the students in this sample acknowledged their family members' support in their lives. As such, I developed the code "Recognition of Parents' Actions" to notate quotations that exemplified the ways in which students clearly affirmed that they recognized the sacrifices their parents made for them. This topic came up a lot during my conversations with students and I felt that it was representative of one way students might feel indebted to their family members, clearly recognizing their sacrifices.

Use "RECOGNITION OF PARENTS' ACTIONS" when students discuss a time when they clearly noted the sacrifices their parents made for them.

Typical exemplar: "[My mom] already had her, uh, her teachers diploma and she was already a teacher, but she was going to be a lawyer and she had two years left. But then I was born and she was like, oh no, Argentina's economy's really bad. So they moved over here and like her teacher's diploma wasn't accepted here. So she went to Miami Dade, like when I was young. I was mainly with my dad at night and my mom would be going to Miami Dade."

\section{"Temporal Factors" [128]}

As I began thinking about how to conceptualize the idea of non-financial debt, I relied on each students' transcript. During each interview, I noticed how many of the 
students in this sample "paid" for their college going experiences with their time. As students discussed having to work during high school or, in one case, having to take off two years to support his family between high school and college, the students in my sample all had to sacrifice some of their time in order to attend college.

After I reviewed each transcript and continued to work on my literature review, I also utilized this code to highlight student quotes that exemplified experiences in their lives that might have had an impact on the choices that they had in front of them. In deciding to utilize this code for this purpose I used Sacks (2007) as a guide, specifically his descriptions of how events in a young student's life can drastically effect where they ultimately attend college. This use of this code was also supported in by other works in the research literature.

Use "TEMPORAL FACTORS” when students discuss the time "costs" associated with their pursuit of a college education. This code is also to be used when students discuss experiences in their lives that might impact their college going decision making capability.

Typical exemplar: (1) "But so yeah. So my schedule was really packed. I didn't, I didn't have fun in high school. If you think about it like that, like if I went out, it was extracurricular activities because there was a banquet for thank you for participating in this club. So I was very, I was more mature in high school than I was my first year of college."

\section{Coding Process}

Ultimately, I created (1) theoretically based codes directly related to my research questions and (2) codes that were related unexpected based on the data upon the multiple 
reviews of each transcript. Per Maxwell (2013), one of the methods for developing codes is theoretical categorization, which "represent the researcher's concepts... [and are] derived either from a prior theory or from and inductively developed theory" (p. 108). Coming into my initial coding, after having reviewed each transcript, I had a clear sense of the concepts I wanted to analyze as a result of my engagement with Lazzarato (2011/2015), Gildersleeve (2017), and the presented research literature on neoliberalism, promise programs, financial aid, low-income students, and students' obligations (e.g., Gillespie, 2018; Lowenberg, 1995; Mitchall and Jaeger, 2017; Perna and Leigh, 2019; Tinto, 2006/2007; Tseng, 2004). Additionally, I came across student quotations that spoke to important phenomena related to, yet theoretically outside of what I had considered using my theoretical framework.

To analyze the data collected during the interview process, I chose to utilize two distinct coding methods: concept and simultaneous coding. According to Saldaña (2009), the researcher should "be prepared and willing to mix and match coding methods...overdependence on [one method] ...can limit your ability to transcend to more conceptual and theoretical levels of analysis and insight" (p. 76-77). In concept coding, the researcher chooses a word or phrase to ascribe an idea to a passage of transcribed data (Saldaña, 2009). Saldaña uses the example of a clock and time; the object being described by the participant is a clock, but the represented idea, or "conceptual attribution" is time (p. 119). Additionally, concept codes can refer to processes, which was critical for the purposes of this study. I used codes to represent the processes and concepts of debt within the stories and experiences of each student that participated in this study. Further, given the strong theoretical framework of this study, concept coding is particularly applicable 
because it allows the researcher to "transcend the local and particular of the study to more abstract...concepts (Saldaña, 2016, p. 120). During the coding process, the concept codes I created allowed me to operationalize and further conceptualize ideas of non-financial debt within the everyday experiences of students.

Next, during my review of each transcript, one thing became clear - the complicated and intertwined nature of many of these concepts. As such, many of the quotes that I coded using concept codes were simultaneously coded. According to Saldaña (2016), simultaneous coding may be used "when the richness or complexity of an event or participant's story makes it difficult for a researcher assign only one major code to the datum (p. 96). In the present study, many of the coded passages highlight the interactive relationship between concepts. For example, when students started to discuss the emotional hardships or foreclosures associated with their college decision making process, they would often speak at length about the relationships they had with family members or describe the sacrifices their parents made for them. A specific example of this was the following quote by Jordyn who said, "it's like there's pressure, but it's also, um, [my mom] deserves [being provided for in the future]. So like I want to be able to do that. So, um, I wouldn't say it's a negative feeling. I think she deserves every bit and maybe more, more so like, um, I wouldn't say it's, uh, it's like, it feels like a weight on my shoulder just because my mom is very like understanding. So like she's like she's very patient." The preceding passage received both the EXPECTATIONS and the RECOGNITION OF PARENTS' ACTIONS codes as the student's words represented both thankfulness for her mom's sacrifices, as well as the resulting obligation and pressure it caused. 


\section{Themes}

Following the completion of coding, I identified themes that spoke to the research questions of the present study and guided by its theoretical and conceptual framework. Saldana (2016) writes that "a theme is an outcome of coding, categorization, and analytic reflection, not something that is in itself coded" (p. 198). The development of themes is a critical part of the research process and is a "strategic choice as part of the research design that includes primary questions, goals, conceptual framework, and literature review" (Saldana, 2016, p. 198). For the present study, I actively created each theme through my own understanding of the research literature and subjective interpretation of each student's interview transcript.

I developed my themes through the use of abstraction (Smith, Flowers, and Larkin, 2009). According to Smith, Flowers, and Larkin (2009), "abstraction is a basic form of identifying patterns between emergent themes and...involves putting like with like and developing a new name for the cluster" (p. 96). Based on my use of simultaneous coding and the interwoven nature of many of these concepts, there was some overlap in terms of specific coded phrases applying to separate themes, i.e., two passages coded "EXPECTATIONS" might work towards the foreclosure theme and non-financial debt theme. Codes (and the coded phrases) were turned into themes based on the conceptual threads that connected them. For example, passages that were coded temporal factors and first-generation were conceptually related to the theme of Non-Financial Debt and its sub-theme "Paying with Time."

Working from Lazzarato and Gildersleeve's conceptualizations of debt, I used the choices I made during the coding process to help develop a theme centered on how 
students' experiences were shaped by the financial, emotional, and temporal debts they discussed during their interviews. In Chapter IV this theme will be analyzed as "The Conceptualizations of Financial and Non-Financial Debt." This section in Chapter IV discusses my suggestion, through the use of student quotes, of the existence of nonfinancial debts and explore the complicated family, social, and moral factors that define such debts for low-income students in a promise program.

Further, given that the Golden Promise was such a critical component of this study, one of my other themes centers on "The Meaning of a Promise." This theme explores how the students in this sample understand and conceptualize the idea of a promise and whether or not the university has made a promise to them and/or they have made a promise to the university, i.e., did these students feel indebted to their university? Further, I examine the "philosophy" of the promise program and grapple with the ethical implications of colleges and universities covering the cost of tuition and fees vs. full cost of attendance.

\section{Computer Assisted Qualitative Data Analysis Software}

Another crucial part of the data analysis process was my selection of a Computer Assisted Qualitative Data Analysis Software (CAQDAS). I ultimately chose Atlas.ti after reviewing both that software and NVivo, another CAQDAS. I choose Atlas.ti because I found that the description in Saldaña (2009) fit my needs better as a researcher.

Specifically, I found the categorization, sorting and organization tools highly effective. Additionally, I found the user experience design cleaner and more navigable than the NVivo software. For Saldaña (2009), coding software "efficiently stores, organizes, manages, and configures...data to enable human analytic reflection" (p. 22). Using 
CAQDAS allows for researchers to review previously created codes with ease, for example they can "list each code by name and [provide] descending frequency counts of the codes in progress" (Saldaña, 2009, p. 26).

During the first cycle of coding I used Atlas.ti to catalog my concept codes and ascribe simultaneous codes when applicable. Atlas.ti easily allowed me to recall the concept codes I had already created, thus making organization flow more seamlessly. During the development of my themes, I was able to use Atlas.ti to create thematic groups based on my conceptual and simultaneous codes, which, as discussed earlier were developed based on the theoretical and methodological considerations presented in Chapter II and earlier in Chapter III.

\section{Data Integrity}

According to Maxwell (2013), "the validity of your results is not guaranteed by following some standard, accepted procedure" (p. 121). Across the methodological literature consulted for this study (e.g., Creswell and Poth, 2018; Maxwell, 2013; Saldaña, 2009/2016; Smith, Flowers, and Larkin, 2009), validity concerns were a critical component of qualitative research, given the disputes within not only the qualitative research community, but the research community at large regarding how to best ensure validity in qualitative studies. Ultimately, "many perspectives exist regarding the importance of validation in qualitative research, the definition of it, the terms to describe it, and procedures for establishing it" (Creswell and Poth, 2018, p. 254). Specifically, Creswell and Poth (2018, p. 260) outline strategies for validation in qualitative research:

1. Corroborating evidence through triangulation

2. Discovering a negative case analysis or disconfirming evidence 
3. Clarifying researcher bias or engaging in reflexivity

4. Member checking or seeking participant feedback

5. Having a prolonged engagement and persistent observation in the field

6. Collaborating with participants

7. Enabling external audits

8. Generating rich, thick descriptions

9. Having a peer review or debriefing of the data and research process

Of these nine strategies, I engaged with numbers three (clarifying researcher bias), four (member checking and seeking participant feedback), and eight (generating rich, thick descriptions) for the present study. For Maxwell (2013), one of the most prominent threats to validity for qualitative researchers is researcher bias. Reactivity is "the influence of the researchers on the setting or individuals studied" (Maxwell, 2013, p. 124). For studies using interviews as a data collection method, reactivity is a major validity threat. While it is not possible to eliminate my own preconceived notions, it is possible to document them and acknowledge them. Similarly, in terms of reactivity, it is important not to ignore the role that I play in the research process. In coming to this study with such a strong theoretical foundation, it would be impossible to claim that I approached this study without biases. In the interest of reducing bias, I utilized analytic memos to clearly document my feelings on interviewing, carefully noting my perceptions of how I influenced the responses of my participants and conducted data analysis.

In thinking about how my own history might impact this study, it is clear that my own experiences were different than those of the students I interviewed While I've been working since the summer after 8th grade, it was never because I had to. I empathized 
with students, but never fully understood their experience of having to work 20-30 hours a week while taking 12 credits and taking care of various family members or felt the weight of the feeling that I would be responsible for financially caring for my parents and siblings in the future. Anecdotally, in my time as an academic advisor at a large, public research university I have seen first-hand the struggles that low- and moderate-income students face. I have heard stories of students not be able to attend class because they did not have a way to get to campus, couldn't miss a shift at work because they needed the money to help their family, or had to pick their little brother up from school.

Hopefully, through my research I have continued the work of other researchers working to help low-income students share their stories in their own words. It is my hope that this study enhances inclusivity by learning about the experiences of individuals from traditionally underrepresented and marginalized backgrounds. While I cannot claim to be providing a voice, I do hope that presenting students' stories in a truthful, thoughtful, and compassionate manner helps increase the amount of diverse representation present in the research literature. Through the use of memos, I was able to write through and process my experiences interviewing students from economic (and racial/ethnic) backgrounds different from my own, especially in relation to times of discomfort. After the completion of the interview process, I was confident that I was able to build rapport with the student participants in this study and was upfront and willing to answer any questions they had about me.

In addition, part of considering these biases is being particularly attuned to the ethics when conducting qualitative research (Creswell and Poth, 2018). This was especially important for my study considering the sensitive nature of the subject material: 
financial aid, debt, obligation, etc. Creswell and Poth (2018) highlight three areas of concern when thinking about the ethical dimensions of a study: "1) respect for persons (i.e. privacy and consent); 2) concern for welfare (i.e., minimize harm and augment reciprocity), and 3) justice (i.e., equitable treatment and enhance inclusivity)" (p. 151). Throughout the duration of this study I maintained strong ethics as I conducted this research.

All participants were consented into the study and I maintained their privacy through strict data storage methods (e.g. passwords). During this study I attempted to limit any harm participants faced by being open with participants from the beginning about what I was exploring which allowed each participant to make an informed decision about their participation during the consent process. During the interview process each student was engaged and eager to participate, with the exception of one student who became increasingly uncomfortable as the interview progressed. Throughout the interview however, I made sure to remind the student that the process was entirely voluntary and that she was free to end the interview at any time. While the student was able to stay and answer all of the predetermined questions I had, I made sure not to prod to deeply, making sure to value the feelings of the student over the perceived "quality" of the interview recording.

During the interview process, I sought to collect rich data and conduct member checks with my participants. Collecting rich data in the form of interview transcriptions, allowed me to have a concrete artifact to consult with, thus reducing the likelihood of misremembering or misinterpreting information (Maxwell, 2013). During each interview participants were asked to clarify or expand upon any points deemed unclear by the 
researcher to make sure each participant was fully able to articulate their thoughts. This was done through a counseling technique known as reflecting, where the therapist paraphrases the participants answer to make sure they understood the gist of what was being said. Given my background in counseling, this technique proved to be an effective method for validating student responses. For Maxwell (2013), respondent validation gives researchers the opportunity to gather feedback from the very individuals being studied. This validation is critical in terms of "identifying your biases and misunderstandings of what you observed" in order to create a fuller picture of the analyzed data (Maxwell, 2013, p. 127). Beyond validation during the interview process I also offered the participants the opportunity to review the transcript of our interview to see if they wanted to amend or change any of their responses. Each participant was sent a copy of their interview transcript for review. I received no responses from the student participants following this outreach.

\section{Ethical Considerations}

While there were no anticipated risks associated with participation in this study, steps were taken to make sure that participant identities were protected. All of the names used in this manuscript are aliases that were chosen by each of the students individually. If a student referred themselves, a specific location, or the name of their high school, that information was redacted from their transcript. Names and locations of participants friends and family members were also redacted from each transcript to further anonymize each participant's identity. Further no specific identifying information, specifically PantherID number, was ever collected from participants. Aliases were stored in a password protected DropBox account for additional protection. 


\section{CHAPTER IV: RESULTS}

Introduction

One of the critical philosophical dilemmas of qualitative research, and one of the most difficult parts of writing this chapter, is taking each student's words and honoring that voice without reducing or stuffing their experiences into my own preconceived notions of what I thought their experiences might be. During drafting and rewriting, this was actually a problem for me as I was thinking about the results section of this manuscript. I was so deeply invested in producing a document that I started to squeeze students' experiences into thematic categories that failed to accurately capture the phenomena in question. As I continued to work, I realized that it was more important to discuss each student's experience thoughtfully and deliberately, rather than shoehorning them into preconceived categories. In reality, qualitative research is messy and complicated. Students' experiences are not going to tie perfectly or completely into the stories that we build for them in our heads. Preconceived notions, even those based in theory, may fail to fully capture the diversity of students' experiences.

Upon reflection, I was able to think more clearly about my themes in relation to the research questions and present not only quotes and passages that affirmed my biases, but some of the more unexpected and perhaps more important representations of students' experiences as they relate to my research questions. Ultimately, it is the direct quotes of the thirteen participants of the present study that make up the results section of this manuscript. Each participant brought fresh and illuminating insights into conceptualizations of indebtedness and foreclosure for low-income students in a promise program. These thirteen students are the experts in their experiences and spoke 
eloquently on (1) the ways non-financial debt manifests in their lives and (2) if/how debts, both financial and non-financial, act as foreclosing in their ability to freely make decisions. Of course, subsumed within these experiences are the sociocultural and political factors that weigh so heavily on American students such as neoliberalism, the student loan crisis, and the politics of race and gender.

This chapter attempts to dissect and advance the conversation on a number of nuanced and intersecting concepts including time, debt, morality, and the meaning of a promise. All of these deep concepts will be discussed through the lens of both neoliberalism and higher education, specifically, promise programs within higher education. As discussed in Chapter II \& III, for the data analysis process I utilized Lazzarato $(2011 ; 2015)$ and Gildersleeve (2017) to conceptualize my understanding of non-financial debt. In addition, to further inform this understanding of indebtedness, especially for low-income students I synthesized a variety of research articles on obligation and race/gender, college access and choice, and student loan debt, to name a few (e.g., Feiveson et al., 2019; Fuligni et al., 1999; Mitchall and Jaeger, 2018; Sacks, 2007; Tseng, 2004). Once again, the following research questions guided the present study: (1) How do allegedly "debt-free "low-income students express non-financial debts related to their educational experiences? And (2) In what ways does debt act as a foreclosing agent in student decision making for allegedly "debt-free" low-income students?

Ultimately, it is through student interviews that I try to make sense of the concepts of non-financial debt and foreclosure and establish the real-world implications of debt and foreclosure. Despite early stumbles, a critical component of the present study 
was the utilization of students' words and experiences as a guiding light, letting their expertise push forward the formulation of the themes and findings that make up this chapter. Their words, whether they fit neatly into my theoretical conceptualizations or sit awkwardly outside of my preconceived understanding, were critical in making meaning of the often-convoluted concepts of debt and foreclosure.

The remainder of the present chapter discusses both students' experiences within the Golden Promise program and two major super-ordinate themes, broken down into several sub-themes. The first super-ordinate theme encapsulates students' experiences with non-financial debt and the ways in which it manifests. The sub-themes within this section include: paying in conduct, paying in commitment, paying in time, and paying in emotional health. The explanations and student quotes around these themes present some of the ways that I suggest the students in this sample are/were indebted non-financially as a result of their decision to attend college. The second super-ordinate theme involves debt and foreclosure and includes sub-themes dealing with the ways debt (both financial and non-financial) is both foreclosing and opportunity creating. The sub-themes in this section are: financial debt and foreclosure, financial debt and opportunity, non-financial debt and foreclosure, and non-financial debt and opportunity. The explanations and student quotes around this theme/sub-themes represent the ways in which debt acts as foreclosing (per Lazzarato, 2011) as well as the ways in which students' debts acted to create opportunities for them within their educational experience. Table 2 highlights each theme and their relevant sub-themes. 
Table 2

Super-Ordinate and Sub-Themes

Super-Ordinate Themes Sub-Themes

1) Non-Financial Debts

2) Debt, Foreclosure, and Opportunity
a) Paying in conduct: "I don't want to be that person
b) Paying in subjective commitment: "What did I do wrong?"
c) Paying with time: "I wish I could, but I'm working"
d) Paying with emotional health: "It was pretty crushing"
a) Financial debt and foreclosure
b) Financial debt and opportunity
c) Non-financial debt and foreclosure
d) Non-financial debt and opportunity

Lastly, the present chapter is made up of my interpretations of students' words and is solely meant to advance conversations on non-financial debt forward and offer suggestions about how I understood/interpreted their experiences, not provide definitive answers about any of these concepts. The direct quotes you will see in the following sections have been edited for clarity - "likes," "ums," and false starts have been removed to ensure that each participant's contribution is considered clearly and accurately.

\section{The Meaning of a Promise}

As I began the process for interviews for the present study, I was eager to examine the ways that non-financial debts existed and acted within a population of students who, discursively, should have had no financial debts associated with their decision to attend college. The students who volunteered to participate in interviews for this study were all a part of a program, The Golden Promise, that claimed to cover the 
full cost of tuition and fees for qualifying students. What particularly intrigued me about this program was the fact that some upper level administrators at the school were claiming that FIU was providing students with the opportunity to graduate "debt-free." In fact, on the FIU FAQ about the Golden Promise Program, the university states, "Golden promise only guarantees a minimum of 30 credits of tuition and mandatory fees in grants and scholarships. If a student needs additional funding, they can still opt for student loans" (n.p). As explored in more depth in Chapters II and III, through my own understanding of Lazzarato's $(2011 ; 2015)$ and Gildersleeve's (2017) conceptualization of debt as not only a financial obligation, but a non-financial one as well, the concept of a "debt-free" student was perplexing. Through my interviews with each participant, it was my hope that this study would be able to examine the ways students articulate nonfinancial debts. As I began my interviews however, the alleged existence of "the debtfree" student was thrown deeper into flux.

\section{It Can Be a Little Rough; Sometimes I Have to Take Out Loans}

Merriam-Webster (2020) defines a promise as "a declaration that one will do or refrain from doing something specified" (n.p). By introducing the Golden Promise to the FIU community, FIU was making a promise to its students - if you are a low-income student, take 30 credits per year, and maintain a 2.0 GPA, we will cover the cost of your tuition and fees. In the initial press-release announcing the creation of the Golden Promise program, FIU stated, "We are going to find the scholarship money so that these hard-working students can graduate as soon as possible, $\boldsymbol{b e}$ debt-free, and go to work (emphasis added)" (Lacayo, 2017, n.p.). 
Unfortunately for many of the students in this sample, this "promise" rang empty. Seven of the students in this sample were required to take out loans in order to fund additional costs associated with their education, specifically living expenses. Despite knowing that the Golden Promise never claimed to cover the cost of housing, as a result of my professional experience and biases working with students who mostly commuted to campus, I was still surprised to hear that seven of the students in this sample had to take out loans in order to attend FIU. In the interest of discussing my own biases in relation to these students, coming into the interview process, I was not expecting students to share stories of having to take out student loans. In my naiveté, I took the university at their word that these students would in fact be debt free. Further complicating matters were the issues of alleged debt-freeness that I was hoping to explore through this research study. The alleged "debt-free" reality of the Golden Promise failed to capture the real world experiences of many of the students in this sample, who could not ever be considered debt-free due to the fact that they were financially indebted as a result of their decision to attend FIU.

In fact, the possibility of the "debt-free" promise program student was further complicated during my conversation with Julie, the first participant I interviewed for this study. During our interview, Julie shared that she had expenses that were not covered by her scholarship money, specifically the cost of housing. When I asked how she was paying for the cost of housing, Julie shared, “

Yes, I took out loans. I didn't this semester just because I didn't want to pile on loans already. So, I started taking them out in fall or spring of 2018. I started taking off loans and I didn't want to, but yeah, we had to. So, I just started taking out loans." 
JM, a 21-year-old, second year college student, shared:

I live here based strictly off the financial aid I'm given. It can be a little rough sometimes. Sometimes I have to take out loans. I'm able to make sure that I don't have to really pay for much. But sometimes housing can be expensive [and the] meal plans, you have to take out loans.

For both Julie and JM, FIU had failed to meet the "promise" of the Golden Promise, as both students were required to take out loans to ensure they were able to live on campus and, in JM's case, afford a meal plan.

Given the difference between the cost of tuition and fees and the full cost of attendance, it is not surprising that many of the Golden Promise students in this sample were required to take on financial debt. For the 2019-2020 school year FIU estimates that the total cost of attendance per semester will cost students $\$ 11,933$ (Florida International University, 2019). Included in this cost of attendance is the cost of tuition and fees, which FIU states costs $\$ 3,283$ (Florida International University, 2019). Returning to the Golden Promise program, which covers the cost of tuition and fees for qualifying students, anyone who wants to live on campus is left with an $\mathbf{\$ 8 , 6 5 0}$ difference per semester (after accounting for transportation, room, board, personal expenses, and books and supplies) (Florida International University, 2019).

In thinking about issues of access and choice, one of the reasons FIU claims they introduced the Golden Promise (Valines, 2017), the fact that students are left with such a deficit is a major problem of this promise program. While they may be meeting their stated goal of covering $100 \%$ of students' tuition and fees, it is clear, as demonstrated through the experiences of the students in this sample, that paying this cost is not enough 
to ensure that students are able to "be debt-free and go to work," as stated in the initial press release.

\section{I've Heard of It, But I Did Not Know They Had Me Under That}

Part of allowing students to "be debt-free" is also ensuring that they are aware of the financial aid opportunities they are entitled to as part of their aid eligibility. One of the more surprising refrains from the students in this sample was the fact that they were unaware of their "participation" in the Golden Promise program. One of the most disheartening moments of the interview process occurred at the beginning of my meeting with Mars when they asked, "So, you're interviewing people that are involved in the Golden Promise program. So that means that I already have the benefits that come from that?” When I asked Charlie, a 19-year-old female first year college student, about her experience in the program she said,

I read the email about the Golden Promise [the recruitment email for this study] and everything, but I did not know that I was part of it. I've heard of it, but I did not know they had me under that, honestly. I'm so sorry. I feel like you probably thought I was aware, but I wasn't.

When asked if she was notified about the Golden Promise program, Olivia, a 19-year-old student of Mexican descent, replied:

No, I wasn't, I was not told. Up until I got your email that was sent out to all these students that were recognized. I didn't know I was, because I remember my roommate was telling me that she was, and I'm like, "man, I wonder how she's a Golden Promise [student] but I'm not [one]."

At the present time I cannot confirm why students did not understand they were part of the program. Was it a failure on FIU's part to clearly notify eligible students or did students not open and/or understand the messages they received about the Golden 
Promise? When I attempted to ask how students were notified by FIU, my email requests went unanswered.

Regardless, several of the students in the sample reported not knowing about the Golden Promise until they received my recruitment message. In fact, during the interview process this scared me, because I was unsure if the FIU Office of Financial Aid had correctly contacted the requested student population, causing me to double check to make sure they sent my message to the correct population of students. Upon being asked this question, one of the financial aid officers at FIU conceded that, "maybe the university has to do a better job of notifying students about the Golden Promise." Charlie shared her experience of feeling like she was on her own at FIU regarding her knowledge of her financial aid status:

I have been fortunate enough that with the cost of online and the cost of the textbooks, it hasn't been to the point [where I've had to take out loans], but I'm afraid that maybe come to next semester or the semester after that I might have to because I feel like I don't have enough support doing online or something. But like I'm just kind of figuring things out through FIU on my own.

Returning to the dictionary definition of a promise, which states that a promise is a declaration of an intended actions, it seems, at least from the perspective of the students, that FIU has failed to make the initial declaration of promise, raising several other important questions.

Given the fact that there are criteria to maintain eligibility, how are students who are unaware that they are even part of a program supposed to meet said criteria? Further, for students in such a precarious financial position, the thought of losing such a critical piece of financial aid could be disastrous. Unsurprisingly, research suggests that as more aid dollars are provided to students, their likelihood of enrolling and staying enrolled in 
college increases (Castleman and Long, 2016). While research has been mixed on the effectiveness of promise program aid dollars (Poutre and Voight, 2018; Swanson et al., 2016), students should still be aware of the aid they are receiving, what it covers, and how to continue to qualify.

Instead of being another data-driven program that fails to consider students' experiences (Valines, 2017), the experiences of the students in this sample highlights the importance of student stories in program development. From my own personal experience, I had a bias towards assuming most of the students in this program would be commuter students. While a sample of thirteen students is far from representative of the total Golden Promise population, let alone the broader FIU population, almost 50\% of the students in the present sample lived away from home, whereas $6 \%$ of students enrolled at FIU live on-campus. It is possible that FIU failed to consider that the Golden Promise attracted students from outside the Miami-Dade metro area, causing there to be an influx of students who would need housing assistance, something to be explored in future studies and discussions with the FIU administration.

\section{An Unclear Promise}

The earlier sections of this chapter explore and question some of the claims of the Golden Promise program at FIU. While it was my hope that this study would be able to examine solely the non-financial debts experienced by allegedly debt-free low-income promise program students, the complicated nature of everyday life took over, causing me to quickly realize that these interviews were not being conducted in a lab. I was meeting with real students, who had a variety of differing real experiences, not some platonic ideal of a student free from all financial debts. Instead, I interviewed thirteen students 
who each had their own experiences with the U.S. financial aid system. Some were required to take out loans in order to move out of their homes and attend FIU, others did not have to take out loans but were worried about having to do so in the future, and still others did not express concerns about every having to take out student loans to pay for costs associated with attending FIU.

The sections presented above discuss the idea of a promise as a noun, something tangible that is bestowed upon students. We are giving you our promise that you will graduate debt-free. This section on the other hand aims to examine the idea of promise as an action. Essentially, in the case of the Golden Promise, how do students understand the question, "who is promising to whom?" During my interviews it was important to me to consider the idea of promising because of its relationship to debt. To Lazzarato (2011; 2015), debt is a promise. A promise to your creditor about your future ability to pay them back, in whatever from "payment" takes. Sometimes this payment takes the form of money, sometimes it is time, emotion, feeling, thought, etc. (Lazzarato, 2011). Returning to the action of promising, when thinking about "a promise" in the context of a promise program, there is an important power dynamic at play - the dynamic between student and institution. What further complicates this dynamic, is the type of student in question, specifically students from low-income backgrounds. Research on low-income students in higher education has been conclusive about the struggles faced by such students, including under-matching, managing student loan debt and family financials, difficulty transitioning to college life, and lower degree attainment (Bastedo and Jaquette, 2011; Hoxby and Avery, 2013; Mayhew et al., 2012; Shea, 2015; Soria, Weiner, and Lu, 2014). 
As I began to discuss earlier in this chapter, there is a clear promise that FIU is making to the students who qualify for this program despite its shortcomings, their covering the full cost of tuition and fees. Meanwhile, as demonstrated by some of the students in this sample, there is also a feeling of responsibility that they feel towards the university as well. When I asked if there was anything additional she felt FIU could do to support her academically, financially, or otherwise, Jordyn replied, "It's a weird question. Just because I'm more of the mindset of what can $I$ do rather than what can someone else do for me. So that's why it's kind of a weird question." Being unable to think about what more FIU could for them was a common feeling among the students in this sample. Mateo, when asked the same question, replied "honestly I don't really think so. The thing that I love about FIU is just how many things there are out there that they provide to us students here on campus. But the thing is, it's there, but you yourself have to make that step forward to try it to take the most advantage out of it." In this quote, Mateo describes being excited about everything that FIU had to offer but placed the onus on students to make the most of what the school has available. Underneath the surface layer of positive thinking and go-getting attitudes, there is, in my view, something more problematic at work.

According to Bourdieu (1974), institutions of education are tools that can be used to reproduce "elite-ness" and the dominant social order. The act of the low-income students in this sample failing to question, or even consider, the ways additional ways in which they could be supported by their college speaks to an unbalanced power dynamic within the relationship between student and college. Additionally, beyond even questioning whether there was more FIU could do to support them, several of the 
students in this sample also discussed the feelings that they had made a promise to FIU. When asked about how he understood the concept of a promise in relation to the Golden Promise, JM, a 21-year-old second year college student, shared, "FIU made the promise to me that I'd be able to go to school. That was a really big moment in my life and I made [a] promise back that I wouldn't let them down." Mateo expressed a similar feeling when he shared his thoughts on the same question, stating:

Yeah. But even going past the university, I feel like it just interconnects both alongside the university, alongside my parents, because I feel like it's kind of a three-way agreement and promise. My parents, they have the obligation to try to help me as much as possible and support me while conversely, I try to do my best academically to succeed in my career and where I want to go. And it's the university's obligation to help support me and my endeavors as much as possible, to help me flourish, succeed, and shine in whatever my future entails.

Despite adding on to the obligation the university made to him, Mateo still discussed the idea of making a promise to FIU to do his best academically and succeed within his career.

This idea is reminiscent of Gildersleeve's (2017) conceptualization of the indebted student. While Gildersleeve's understanding of the relationship between student and institution is oversimplified, it is useful to consider the notion of low-income students feeling indebted to their college simply for the chance to attend, creating a student populace that does not want to make waves or question the institution "that has done so much for them," allowing their college to continue rolling out the same policies and support systems that have failed to support the university's most vulnerable students. As put by Julie, when asked if there was more FIU could do to support her, "I don't know. I feel like that's enough. I feel like that's more than what I could ask for. I feel like I'd be asking for too much if I wanted more.” 
Not every student in this study expressed the same sentiment towards their institution however. Mars explained their understanding the Golden Promise this way:

it covers the whole educational experience that you're getting, but it doesn't really cover the fact that not everybody can pay to live on campus and not everybody has a car. I do not have a car, so there's not many options when it as a promise, there's not many options into promising that I can stay here when I'm struggling with how I can live and how that's going to affect my living circumstances, it's obviously going to affect my education. So even if my classes are paid for and my fees are paid for, if I'm at home, I'm at home. So I just don't see the whole promise, I guess.

Mars' quote highlights the other side of this problematic promise. Despite not feeling like they've "been promised to," some of the students in this sample felt the emptiness of the alleged promise that FIU had made to them. Taking Mars' perspective, it is possible to see why they do not feel like basking in the glow of The Golden Promise. This idea was summarized by Analise who shared,

I'm the one that's going through the system. I'm the one that's taking the classes and I feel like if I check all your boxes, I should be able to get what you said you were going to give rather than saying, oh no, but you did this, you're okay. But I'm not okay. I still need the help to get through college.

Some of the students in this sample are still struggling financially, feeling like they're missing out on the full experience of being in college. What good is a promise if it is not doing anything for me today?

Ultimately, this beginning discussion of promise, debt, and the experiences of students in the Golden Promise sampled for the present study aims to situate the theoretical conversation about the alleged "debt-free" low-income student in reality, not abstraction. Higher education, especially for students from low-income backgrounds, is a messy place. A program meant to eliminate debt for such students, in some cases, led to feelings of indebtedness to the very university meant to "eliminate" their debt. In the 
sections that follow, I expand upon notions of indebtedness that were touched upon thus far by examining students' experiences with non-financial debt and the foreclosing aspects of both forms of debt.

\section{Non-Financial Debt and Its Repayment}

The first research question of this study asks: how do allegedly debt-free lowincome students express non-financial debts within their educational experiences? As

discussed earlier, I attempted to address this question using Lazzarato $(2011 ; 2015)$ and Gildersleeve (2017) as lenses through which I could view conceptualizations of indebtedness from a non-financial perspective. Lazzarato (2011) writes,

unlike what happens on financial markets, the beneficiary as "debtor" is not expected to reimburse in actual money but rather in conduct, attitudes, ways of behaving, subjective commitments, the time devoted to finding a job, the time used for conforming oneself to the criteria dictated by the market and business, etc." (p. 104).

To varying degrees, each of the students in this sample experienced having to reimburse, or "repay," their families, communities, and/or institutions in the aforementioned ways and beyond. In addition to the topics discussed by Lazzarato, students also "paid" for their education with their emotional well-being and time. Additionally, some of these "repayments" were moderated by racial factors that worked to shape indebtedness" impacts on each student differently.

\section{Paying in Conduct}

One of the ways that the students in this sample experienced non-financial debts was through the obligations they felt to their families and communities and the resulting ways they conducted themselves. The Oxford English Dictionary defines indebtedness as "the condition of being under obligation for services, etc., rendered." With this definition 
in mind it became clear how an individual's family and community obligations and resulting behaviors can be viewed as debts. Lowe (2000) writes "having accepted the benefits of the cooperative efforts and sacrifices of others, we are obligated to give something in return for those benefits (p. 79). One of the common threads between each participant's experiences was the shared experience of recognizing the "cooperative efforts and sacrifices of others," especially parents, siblings, and racial communities.

JM discussed the experience of having to postpone school to work full-time in order to help his grandparents, on top of their salaries, care for his siblings, his way of "paying them back" for the sacrifices they made for him such as taking him and his siblings in and supporting his dream of pursuing a career in music:

I felt pretty lost a lot of the time. A lot of my days I'd sleep as much as possible, wake up, go to work, eat when eat when needed. So I generally I was trying to work through it and I realized I wasn't going anywhere... The disappointment can best be described as sad, crushing, very, pretty miserable a lot of the time, you know, realizing you're in a dead end job and you know you're only doing what you can because you need to [help] support your family. You don't have a lot of time to look for a new job before, you know, you realize oh there's no food on the table. So pretty rough.

Analise discussed a similar experience in terms of having to adjust how she acted, by working over getting involved on campus, "I occasionally butt heads with my parents, in that, when they're like, yeah, we'll support you. But I'm [thinking], yes, I know that you'll support me, but I don't want us to go like broke."

As Lazzarato (2011) describes, one of the ways that individuals are tasked with repaying debts is through the ways in which they conduct themselves - their behaviors or actions. Here, JM felt an obligation to "repay" his grandparents for their support and sacrifices by postponing his pursuit of college by two years. Berger (1975) writes, "we 
owe gratitude to our parents for the sacrifices involved in their caring for us and giving us a decent upbringing, though it is their duty to provide this to the best of their ability" ( $p$. $300)$.

Beyond the feelings of obligation students felt towards their family members, Jay noted the obligation he feels as a member of the African-American community of having to "do better" and act as an example of his race. After a difficult first semester Jay found himself in a course designed for students having academic difficulties. When asked what his experience in the class was like, he shared:

It made me feel bad in a way. I was like, wow, this is the most people I've seen that looked like me in a classroom at FIU and they're all in a bad position. They're here because they didn't do well in their courses, so that got me.

He continued to describe the obligation he felt to represent his community and how it impacts his behavior. When I asked Jay bluntly if he feels like he has to represent the African-American community in his classes, he replied:

Yeah, a hundred percent, yeah. If I don't answer something correctly or I'm [not] able to get my thoughts out, quickly, in the back of my head I feel like, "dang, am I a stereotype because I couldn't articulate myself correctly? Or I feel intimidated to kind of... stand out and I raise my hand if I have a question?” Because I don't want to be that person. So it kind of makes me... I'm trying to get out of it now. I realized that I should actually do the opposite and um, be better. So that's something I need to work on, but really just, it makes me kind of get in a shell a little bit and it makes me really quiet.

In my interpretation, the phenomenon that Jay is experiencing is akin to Perkins' (1983) writings on racial uplift, specifically the idea that persons of color can become fatigued by the obligation of always having to represent their race and act as examples. Jay's feelings are consistent with both Perkins (1983) and Malcom (2015) who both write about the pressures that the obligation of racial uplift can have on an individual. Jay, who 
presented as an outgoing, confident, and thoughtful person during our interview, noticed himself acting differently in his classes when faced with the pressures of feeling like he had to represent his race.

\section{Paying in Subjective Beliefs}

In Chapter II, I discuss the concept of ideology of choice. According to Lowenberg (1995), the ideology of choice is the widespread view that it is individuals who are responsible for the failings of society more broadly. Lowenberg writes, "The rhetoric around the ideology of choice emphasizes individual solutions to social problems, a view particularly rampant within the context of America's exaggerated valuing of individualism and privatization" (p. 320). By subscribing to these views, students are making themselves subjects of this ideology. Jordyn, an 18-year-old student studying psychology, discussed how she internalized her feelings of guilt and shame over needing to go into debt to fund her education. She shared that:

they kind of made me feel like I wasn't smart enough to find the money to pay for everything because I know some kids are. I was good and my grades were really good in high school. So I felt like, what did I do wrong? Because I have the grades, like what did I do wrong to not be able to pay for everything?

The tone of exasperation on Jordyn's voice was palpable as she discussed feeling "less than" despite recognizing her accomplishments throughout high school. Jordyn's expression of shame is emblematic of the ideology of choice in action - she blames herself for the failings of politicians and policy makers to ensure that college access is equitable and that college costs are affordable. I interpret this passage as representing Jordyn's internalization of the systemic failures of policy makers in American higher education at the federal, state, and institutional level. 
Mars also discussed feelings about their perceived shortcomings by stating, "I worked like 45 hours a week, 50 hours a week while going to high school. It made my GPA pretty low, 3.0, 3.2 not that good. So, it could have been better. I could have gotten better scholarships." Mars focused blame inward as they discussed the reasoning they were unable to get more scholarship money rather than the outside factors that required them to work 45-50 hours per week, causing them not to gain scholarships to cover the cost of housing. Neoliberalism plays a huge role in such feelings, as neoliberal policy makers and think-tanks have utilized logic of individual freedom and moral failings to introduce policies that have the opposite effect (Harvey, 2007). This idea was internalized by Mars, who shared:

I need a job. I'm not happy when I don't have a job. I need to have a job, I need to be working and doing things. I'm a person that revolves around responsibilities. So when I don't have that, it affects me because I'm not happy when I don't have a job or don't have money and right now I don't have either.

For Rachel this feeling came up during her time attending a prestigious private high school;

there were times I was like, you know what, I was so stressed out at that school that I was like, I'm just going to go to a regular public school and I'll probably shine a little brighter. And who knows? Maybe I'll get a different scholarship, maybe a college will notice me there instead of being here with all these people that know all this stuff. There were points that I had doubts like, why am I even here? Like might as well just go to a different school. Like this is too much stress.

Rachel blamed herself for the fact that she did not feel like she was one of the top students in her class despite her great success at a prestigious private high school. During our interview I also asked Rachel about how she began to make her decision about where to attend college, which led to the following response: 
the majority of the people at the school I went to went out of state. I thought, "I want to go out of state too, I want to do something different." And then when it came down to it, I can't afford the difference of $\$ 20,000$, a difference of 25 , $\$ 30,000$. Then I realized okay, schools really don't give you that much sometimes. And then I thought back, man, I should have had better grades. So then I was reflecting on myself, if I just did a little better, if I had a higher GPA, if I did better on the ACT, SAT. If I did better, maybe I would go to a better scholarship.

Here, Rachel seemed to be internalizing the idea that if she had only worked a little harder, she would have been able to attend any college she wanted. She saw her "failure" to self-finance (through scholarships) the cost of attending college outside of Florida as solely a personal "failure" despite having been successful throughout high school. She wanted to attend other schools, and when she was unable to, placed the blame solely on herself.

As put by Lazzarato (2011), as far as the welfare state is concerned, the strategic process of the neoliberal program consists in a progressive transformation of "social rights" into "social debts" (p. 104). This transformation is exemplified by the commonly held misconception in the US that talent, creativity, ambition, and drive are more critical to an individual's future success than their family history or social class. A 2011 survey by the Pew Research Center reported that children "having 'drive and ambition' or being 'talented and creative' are seen as more likely to succeed than kids from "two-parent households" and "wealthy neighborhoods" by an average margin of $75 \%$ to $17 \%$ (Pew Charitable Trusts, 2011, p. 5). College access and attainment numbers do not support this view, as students from low-income backgrounds are almost $50 \%$ less likely than their high-income peers to begin bachelor's degree programs immediately following high school (U.S. Department of Education, National Center for Education Statistics, 2016). Further, "At 4-year institutions, 8-year completion rates for the 2009 entering cohort were 
lower for Pell grant recipients than for non-recipients within every institutional selectivity category except open admissions" (McFarland et al., 2019, p. 14). The experiences of the students in this sample exemplify the idea of repaying their non-financial debts with subjective commitments as a result of their internalization of the ideology of choice, personal responsibility, and individualism.

As demonstrated by Jordyn, and the other students in this sample, hard work can only get you so far without the generational assistance of insider knowledge of the college admissions process and, really, the luck of being born in the right zip code (Lareau, 2011; Sacks, 2007). This mentality was ingrained in the minds of many of the students in this sample to detrimental emotional effects. Rachel, one of a handful of lowincome students at an elite private high school, had to deal with the "stigma" of potentially having to attend a two-year college because she was unsure about how she was going to be able to pay for college, while the rest of her peers planned to attend prestigious out of state colleges. This stigma also extended to having taken out loans to begin with. When asked whether or not she and her roommates discuss their financial situations, Jordyn shared, "I have a weird thing about not really like, not really wanting to tell people I took out loans just because it’s like, "how are you going pay it back?"

Finally, many of the students in this sample have clearly internalized the idea that they must "spend" their time appropriately, reminiscent of Nowotny's (1994) writings on proper/improper time where individuals who do not "spend" their time "properly" or risk being passed on by "proper" society. Students discussed feelings of restlessness when they were not working and measured their self-worth through their ability to work and 
"be productive." This idea was internalized by Mars, who felt an unease about not working while they were at FIU.

\section{Paying with Time}

Beyond the ways in which students "repaid" non-financial debts through their conduct and subjective commitments, another non-financial debt experienced by the students in this sample was a "time-debt." Essentially, students were required to "pay" for their ability to attend college with their time. Lazzarato (2011) discusses the idea of paying one's debts with time, but more in terms of the time "spent" on tasks such as employment seeking in order to be a "valuable" member of society. Among the students in this sample, the temporal costs were less concrete. Jordyn discussed being afraid of having to graduate college so quickly but felt that it was a necessity due to the financial strain attending college has put on her and her family. Originally, she wanted to attend medical school, but had fears about going into debt and taking additional time to start earning money and providing for her mom. Jordyn shared:

I'm just afraid of her passing away early before I'm able to give her everything she deserves. So in that sense with medical school, it's hard because medical school is so long. I just imagine wanting to be able to give back to my mom when she's still able to do things. So that's why I'm shifting away from medical school and thinking about like either Pre-PA or Pre-Nursing and becoming like a nurse practitioner.

The fact that Jordyn is worried about the quality time that she has left with her mom brings to mind Nowotny (1994) and her extended present, which discusses the notion that individuals live in an extended present because of our penchant to constantly plan for events that have not yet occurred. Here, Jordyn is having to "pay" for her education through shifts in how she allocates her present time in hopes of it impacting future time 
use. Despite initially wanting to attending medical school, Jordyn determined that this time "cost" was too much and decided to select a shorter major/career path. Currently, Julie is unsure if she is pursuing medical school because it is her passion or if she knows it is a lucrative career that can provide her and her family the life she did not have growing up, i.e., one of financial security. Unlike Jordyn, who was actively planning on how to be in school for less time, Julie is currently weighing whether or not the time "cost" of being in school is worth sacrificing for. Julie asked, "is this my passion? Do I want to do bio because I want to do it? Or because that's where the money is and because I want to keep providing?"

Charlie also described the time sacrifices she has consistently made to help support her parents financially, be involved in school, and get good grades. She shared:

Um, I participated, I did a lot of like after school activities I did volunteering. I was in AVID, I did like AP classes, honors, you know, like everything that a normal student would do that then wants to make it to college. Um, I did work through high school too, I was given that opportunity to do that. So I felt like I was really responsible cause I'll be able to manage. So keep up decent grades and then still be able to work.

This was common among many of the students in the sample. Rather than being able to dedicate themselves to being a student as their full-time "job," they had to dedicate some of their time per week to a professional job. Julie discussed the pressure this can put on a student; "so sometimes it's a little challenging and it can be like, I want to study for my classes cause that's the only free time I have. If not that I'm in class or something. so it can be kind of hard." Research suggests that students who work while they are enrolled in school have lower degree attainment, and less time to dedicate to academic and personal endeavors (Mayhew et al., 2012). In thinking about this in the context of the Golden 
Promise, the fact that many of the students in this sample were employed while attending college, shows that they are experiencing a non-financial time debt as a result of their attending FIU, highlighting another way the idea of "debt-freeness" is called into question.

This time-debt also constrained students socially. In order to cover the costs of her participation in band, which she was using to boost her credentials to get into college, Olivia was expected to pay all of the related expenses. This often meant working while many of her peers were out enjoying themselves; "I'd be [working], while they were, their weekends they were like on their parent's yacht. I'd be working or I remember I worked at Publix at that time, so they'd be like coming by and be like, "Oh, you should join us one day,” and I'd be like, “yeah, I wish I could, but I'm working.” JM described the time cost he pays for his education in the following way:

So there are a lot of times where I've been told of, for instance get togethers or parties that are going on and often times I do decline. It's not as a matter of a free decision like I don't want to go or I'm not in the mood. It's more a matter of I know if I don't if I don't get the grades I need to while I'm down here you know there's no guarantee I can stay. So I you know I try to make sure that while I'm here I'm able to strive for the highest and do what's necessary so I come back in the best position I can.

JM felt that he had to "budget" his time at FIU in order to make sure he kept his grades up not only for himself, but his family, and his siblings. As such, he "paid" for the opportunity to continue attending school with his free-time.

Another example of a time debt was JM's experience after he graduated high school. He explained:

I ended up not going to college for two years. And during this time my mother was getting addicted to opioids at the time. We had a lot of problems in our house generally that could have caused part of it. And due to her accident has you know 
she has seizures and stuff and so she ended up after being prescribed certain painkillers and then addicted to them and you know it ended up hurting us financially a lot. So then for two years I didn't go to college. I had to stay home and I was working to try and support my family.

Here, JM discusses having to "pay" for his ability to attend college today at a "cost" of two years of his time, two years. Further, as a result of the years he spent working nights between high school and college, JM's sleep schedule was greatly affected. He shared that this has had lingering effects on his social life as well. In essence, JM has had to pay for the hours he worked in the past; the cost being the reduced satisfaction he sometimes gets out of his social interactions in class and with friends. He explained it like this:

it's affecting me sometimes in my social life. Sometimes I'll be in a conversation with a friend of mine or we'll be in a group setting and I might sometimes phase in and out of conversation through like generally fatigue or whatnot. That's pretty rough sometimes.

Charlie also discussed a time where she had to miss out on an important social

opportunity because she had to take care of her family. Charlie said:

there was a time where I was actually planning on going on vacation to St. Augustine and I really wanted to go on this vacation trip and everything. That was before my mom told me that she was going to get surgery around that same time. And obviously in my heart I was like, I want to go on this vacation. I want to go. I've been saving up, I've been planning, I have my Airbnb all rented out and everything. But in the end, I ended up canceling it because who else is going to be there for her. Who's going to take care of her? Who's going to make her the coffee in the morning? Who's going to take care of the dogs? Who's going to clean the house? And it was kind of like, yeah, I really want to go on vacation and I felt like I earned it. I had saved up for it. But in the end, I feel like there was just some things that take priority to that. And I think you can YOLO everything in life as I always say, but you can't YOLO health. And that was just one of those things where I was like, I have to accept the fact that no I wasn't going to [be able to go on vacation].

The responsibility of attending college and/or taking care of their families, in the past, present, and future resulted in a "debt of time" for students. Lazzarato (2011) and Padget 
Walsh (2018) establish the concept of "repaying" one's debts with time and the temporal aspects of indebtedness. Once again, understandings of "debt-freeness" are brought into question. In JM's case, his needing to work nights prior to attending college has "cost" him social opportunities and perceived academic success. Jordyn and Julie, at the time of this writing, are still navigating what they're willing to "spend" in terms of their temporal availabilities - stay in school longer or choose a major in the interest of potential future financial satisfaction or pursue your passion, maybe graduate earlier, and have more time with loved ones?

\section{Paying with Emotional Health}

Much like a financial debt is paid off with money, for the students in this sample their cost of attendance not only included the price of the institution, but their emotional health as well. These emotional debts can be especially pronounced for students from low-income backgrounds, such as the students in this sample. According to Jury et al., (2017), low-income students in higher education can experience psychological barriers in terms of “(1) emotional experiences (e.g., emotional distress, well-being); (2) identity management (e.g., sense of belonging); (3) self-perception (e.g., self-efficacy, perceived threat); and (4) motivation (e.g., achievement goals, fear of failure)" (p. 26). By considering how Jury et al. classify the emotional experiences of low-income college students, is possible to see the relevant emotional "costs" required of the students in this sample within the scope of their educational lives.

The Oxford English Dictionary defines emotion as "A strong feeling deriving from one's circumstances, mood, or relationships with others." In thinking about nonfinancial debt and the idea of an "emotional debt," the interpersonal nature of emotion 
comes into play. As Lazzarato (2011) discusses, all debts are social in nature, meaning there is a relationship that exists between creditor and debtor. In the case of the students in this sample this "creditor" took the shape of family members, community, or racial identity, for example. Instead of money however, these creditors required "repayment" in the form of emotional health and well-being. Finally, this conceptualization of emotional debt is not meant to suggest that all of the students in this sample were emotional zombies void of positive outlook and coping mechanisms. Instead, the following section introduces the concept of the emotional, non-financial debts that the students in this sample experienced at varying times to varying degrees, consistent with the research literature (Mayhew et al., 2012; Jury et al., 2017; Stebleton et al., 2014).

During our interview Jay expressed the emotional pressure he placed on himself after he received a low grade in one of his classes. He shared that as a result of some low grades he received during his first semester at FIU, he really started thinking twice about his social life and the impact it was having on his grades. He shared:

I remember it was one time I was so embarrassed myself. I was just hanging with my girlfriend all day and I was like, "ah, this assignment is only worth this amount of points. I'd be okay, I do good on everything else, I'll be fine." And that was the assignment that could have changed, was the difference between a passing and a failing grade. And I looked at it and I just felt terrible because it was as if I put my family security or their faith in me in jeopardy because of what I wanted.

Earlier in this chapter, I highlighted a quote from Jay that discussed how feelings of "racial uplift" (Perkins, 1983) impacted the ways in which he conducted himself in his classes and at FIU. Here, Jay's experience highlights the emotional debt he carries with him as he thinks about his family members. For Analise, cultural differences with her 
family members contributed to the emotional debt she had to "pay" as she navigated the college application process. She shared:

[My parents] grew up in Cuba and they don't understand the difference in the school system. So they were like, why are you taking all these APs? Look at you. you need to drop everything. Quit all your clubs. Why are you going to soccer? They weren't understanding why I was doing this. And I tried to explain it to them, this is how I get college paid for. Just stop fighting with me because this isn't, this isn't helpful. You're just adding stress to me.

Both Jay and Analise's experiences are common among low-income first-generation students who expressed feeling the emotional stressors of their family member's expectations and the tension created as a result of differing expectations (Garza et al., 2014; Olson, 2014).

In fact, Jay, Analise, and Jordyn shared this experience, with one key difference. While Jay and Analise's emotional debts were experienced as a result of their past interactions with their family "creditors," Jordyn's emotional debt is "paid" through her present and future feelings and well-being. Jordyn explained that every decision she makes is impacted by how it will impact her mom and when asked what she considers when making an important decision, Jordyn shared,

My mom [laughs]. Seriously no everything, even where I go to school. I wouldn't want to be far away from my mom. She was a single parent so, I worry about her a lot because, I know it's hard to be at home alone even though I know she knows I'm out here doing good things. She doesn't talk about her feelings. So it always leaves me... [trails off]. I don't have like her telling me "no I'm okay." Seriously she doesn't really talk about much, so I'll worry about her a lot.

Similarly, when asked about potentially leaving her mom, Jennifer shared, "She didn't want me to go to school out of state because it's always been us together and that's it. I don't know. She kind of made me feel guilty for it at first. "You left me alone."” 
In addition to the emotional "repayment" expected by family "creditors," students also experienced emotional debts when navigating complicated experiences as members of a minoritized community. Olivia felt emotional pressure to attend college because of her friends in the DACA program; "My two, three best friends, like they were really encouraging because two of them are DACA, so they weren't allowed to go to college. And they're like, please go. Like, you know, since we can't.” As a Mexican-American student, Olivia felt the added pressure to succeed in the name of her peers, a pressure that was also intensified by some of her more confrontational and less-supportive peers in high school. Olivia shared the emotional costs she faced as a Mexican-American student trying navigate her high school class schedule, including the pushback she received while taking AP and other accelerated high school courses. In her words,

We were, to our friends who are Hispanic and were in the lower division, they would be like, "oh, you're trying to be white. You're always just trying to prove you're better." No, we just want better for ourselves. We're not trying to say we're better than you, but we just want to do better. And then we were too smart for them, but we were too dumb for the white kids. So it was just, it was so annoying because you would think your community would have your support or at least the Hispanic community, but no, it was like you're always trying to be better or you're trying to be more prestigious than you are. Being a Mexican American, I just, I feel like I can never win. I'm too dumb for one and then too smart for the other.

Olivia's experience is consistent with Malcolm (2015) and Pettus' (2007) conceptualization of being a "sellout" to one's race. For many members of minoritized ethnic and racial communities, too much success can be met with suspicions of "selling out" to try and join dominant racial and social communities, sometimes leading to "banishment." As highlighted by Malcom (2015), there is often an emotional toll associated with navigating the difficult waters between having to achieve "racial uplift" and the difficult experience of being labeled a sell-out. 


\section{Summary of Non-Financial Debt}

The preceding sections have aimed to establish some of the non-financial debts that students experience as they attempt to navigate their post-secondary experiences. As examined in Chapter III, these debts were conceptualized through my theoretical foundation, the research literature and my own reflections following my interviews with each student. Further,

as I have demonstrated, the students in this sample experienced multiple types of nonfinancial debt, specifically in the form of conduct, subjective commitments, time, and emotional health. Through these examples I am not suggesting that is a conclusive list of non-financial debt, instead suggesting, that for the purposes of this study, students' descriptions of their experiences seemed to warrant an understanding of non-financial debts presented in such ways. The aforementioned sections also highlight the variety in the types of non-financial debts that students can experience as a result of their decision to attend college and variety within the ways in which each debt manifests for each student. Finally, the examples highlighted above each demonstrate that even if the students in this sample had been financially "debt-free," there are still non-financial "costs" of attendance that are directly related to the students' status as low-income students within a promise program.

\section{Debt: Foreclosure \& Opportunity}

The second research question guiding this study is: In what ways does debt act as a foreclosing agent in student decision making for students in a need-based promise program? This question was developed using Lazzarato (2011) who discusses the notion of debt as foreclosing future choices and decisions. Lazzarato's conceptualization of debt 
as it relates to foreclosure has a critical temporal component. The indebted are always planning for a future that may never come, as a result of their debts. The individual's present behaviors are guided by their debts, because, for Lazzarato, one's debt becomes a moral judgement that follows the indebted person in perpetuity. The foreclosing aspect of this conceptualization involves an individual losing out on opportunities to make choices stemming from the fact that they are indebted, with the repayment of their debt becoming their sole, moral prerogative. According to Lazzarato (2011), "debt directly entails life discipline...a permanent negotiation with one's self, a specific form of subjectivity...Debt [demands] a production of subjectivity" (p. 104). In many cases, the students in this sample became the subjects of their debts, having to foreclose one option to gain the opportunity to make another.

The component of "repayment," as it relates to the present study, is the notion that one's debts can be "repaid" with more than currency. Throughout this chapter I have demonstrated the ways in which the students in this sample were "in debt" as a result of their decision to attend college. The conceptualization on non-financial debt presented in Chapter II and earlier in this chapter serves as the foundation for examining how/if the debts of low-income students in a promise program worked to foreclose their educational opportunities. Finally, as I have highlighted several times throughout this manuscript, while the theoretical foundation of this study might present low-income promise program students without autonomy, the reality for many of these students was one of opportunity and excitement. Despite their hardships, each student showed great resilience as they navigated the college process, using their "debts" as motivation. The remaining sections of this chapter examine: (1) financial debt, foreclosure and opportunity, (2) non-financial 
debt, foreclosure and opportunity, and (3) the difficulty in separating the financial and non-financial.

\section{Financial Debt and Foreclosure}

The experiences of several of the students in this sample supported the idea of financial debt as foreclosing. Additionally, for the students in this sample, the aversion of debt acted in similar ways. When I asked about her experience taking on financial debt, Jennifer, a 21-year-old

political science major, shared that taking out loans was:

stressful because I know that the financial debt and I'm going to take on when I'm done with FIU is going to be a big one. I didn't want to start then. I took it out because I just wanted to have the security blanket, so this is my first year of college. I didn't know the cost of the textbook, all of that. I didn't know the cost of materials. If I could go back, I wouldn't take it out. I think it was being paranoid because I'd rather not have any loans and have a clean slate.

Jennifer's words here highlight the fact that her financial debts already had her scared about her future, reminiscent of Lazzarato's $(2011 ; 2015)$ view of debt as foreclosing future possibilities. Jennifer discussed taking out loans because she was unsure about what the costs associated with her education would entail and accepted a loan to make sure she had "a security blanket" to cover unforeseen costs. She shared that given the chance to do it over again, she would not have gone into financial debt to finance her education because she did not feel she fully understood all the ramifications of a decision she made when she was 18 . She also worried about how paying back that amount would impact her ability to save up for law school applications. She was also worried about the amount of debt she would incur by attending law school and wanted to go into it with "a clean slate." The idea of a "clean slate" here is interesting because it demonstrates the 
overwhelming opinion of debt as something that can reduce what choices students have available in the future as introduced by Lazzarato (2011).

Mars, a 19-year-old student of White/Afro-Portuguese/Jamaican heritage, when asked about their reluctance to take out loans despite struggling financially exemplified this idea of the manufactured choice between going to college or staying home. During our interview they discussed their fear of taking on financial debt, going as far as to potentially sacrifice their opportunity to continue studying at FIU to avoid having to take out loans;

I still am very practical, and I think very practically about like money situations. And that's why I, I'm very cautious about coming back next year. If I don't have enough money, I'm not the type of person that would take out debts, like out of debt because that reminds me of how my parents are because they don't have money. So, if I start off my career out right when I got out of school negatively with a negative balance, it just won't, I don't know. I won't feel well.

This aversion to going into debt essentially shaped Mars' entire decision-making process when deciding on what college to attend; "there weren't many choices for me when it and making the decision to go to schools because I couldn't go out of state. I don't like Florida that much. That's why I wanted to get out of here. But I can't afford to get out of here." Despite being excited about the prospect of attending college in New York City to pursue a career in the fashion industry, Mars' total aversion to take on financial debt drastically limited what choices and opportunities were available to them in the first place. Further, Mars spoke frequently regarding their uncertainty about being able to remain at FIU due to financial concerns, "I love this school...so I don't just want to pick up and leave. I made my friends, but I can't afford it, so [I may have to leave].” While Mars certainly had agency in their decision making process, the aversion to debt limited 
Mars' capacity to attend the college of his choosing in New York and the ability, in their terms, take advantage of living in Miami and attending FIU. Mars shared:

So I didn't have any spending money when I came here and that was my big thing because I'm going to live in the city and that was the whole point of coming to [Miami], living here. I didn't have any side money at all, [all of my money] went to living on campus. And I honestly don't even know if that was the good choice because as accessible and efficient as it is, for me to live on campus, I still don't feel that I'm getting everything out of the dorm life that I should.

Overall, these experiences highlight the foreclosing and limiting powers that financial debts can have on students, and further illuminate the precarious positions students from low-income backgrounds experience as a result of (and despite) federal, state, and institutional aid policies. Again, while the students have agency in their decision making, their debts and/or reluctance to take on debts, seemed to limit and foreclose what choices they felt they had in the first place.

In fact, often, the concern about making the "safest" financial decision led to students having to forego some of their decision-making autonomy to focus on the financial well-being of their families, or chose colleges exclusively based on perceived cost. Scott had Ivy League aspirations in high school, but due to the perceived costs, he readjusted his plans. As the time to apply to colleges approached, he was deciding between FIU, UCF, and the Honors Program at Miami Dade College. Due to a clerical error by his school counselor impacting his chances of getting into the Honors Program at MDC and the increased cost of attending UCF, Scott ultimately decided to attend FIU. Jennifer shared that she chose FIU over other more prestigious schools due to the perceived cost of attendance. She elaborated:

It was a money situation because I applied to 20 schools, as like the Ivy League. I applied to schools out of state. I have a cousin who works for the Department of 
Agriculture in DC and he facilitated a college tour for me. He drove me to Maryland, during spring break, and other parts of Virginia. He drove me to North Carolina so I could see Davidson, one I wanted to go to. I would be going to three colleges in one day. Yeah. So, I applied to the schools and all of that. And it was a situation of money. I got into a lot of good schools, but the money situation wasn't adding up.

While Jennifer was clearly not foreclosed in terms of where she applied, once she started to receive acceptance letters, it became clear that those opportunities were foreclosed by the perceived reality of cost of attendance and an unwillingness to take on financial debt. This is important because many prestigious colleges and universities offer low-income students robust financial aid packages that, at times, can make attending Princeton, for example, cheaper than attending a local state university (Hillman, 2013). Despite this, Rachel discussed the surprise her family members felt when she ultimately decided to attend FIU:

the part that disheartened me about coming to FIU was the fact that the people around me, were like, 'oh, but it's just FIU, why don't you go somewhere else?' Even my grandmother had mentioned it once, 'oh, you're just coming to FIU?' And I said, 'I mean, yeah, unless you're going to pay the difference for me to go somewhere else.'

Here, Rachel is once again discussing the financial reality preventing her from attending college outside of Florida, a goal she had as a high school student until she realized the difference between the aid she was awarded and the cost of attendance at such schools.

Beyond the reluctance to go into debt themselves, the students in this sample also faced pushback from their parents about going into financial debt. Olivia disclosed to me that she had not told her parents that she had accepted loans. She shared:

I haven't told my parents I had taken out loans or like, that I got the loans that the government gave me. They think I'm strictly here on scholarships, but I don't want to tell them that because I know if I tell them that they're going to want me to go 
back home and just go to the community college there and that's something I don't want.

This was a relatively common theme; given the financial struggles these students' families, the thought of going into debt was an almost ridiculous proposition, as highlighted by Olivia's quote above. While studies regarding students' aversions to debt are well documented in the research literature (e.g., Callender and Jackson, 2008; Perna, 2008; Zerquera et al., 2014), this finding suggests that family members' aversion to debt may also play a role in the foreclosing aspects of financial debt. In Charlie's case, the experience of seeing her family members in debt led to her debt aversion. She shared, "My brother and sister they're in debt and they live kind of paycheck to paycheck type thing, so [going into debt is not something I want to avoid.]"

Overall, the notion of debt as foreclosing is mixed within the research literature. In fact, even within the same studies there were examples of findings that both support and refute the notion of debt and debt aversion as foreclosing. The idea of debt providing opportunity is examined in the following section. Zerquera, McGowan, and Ferguson (2014) found that for some students, "not only was debt to be completely avoided, but avoidance of debt also appeared to have an influence on students' decisions about the future" (p. 611). Similarly, Perna (2008) reports that among students in a low-income high school, there was a common belief that student loans were "risky" and that an "unwillingness to borrow causes students to either not enroll [in college] or to attend the local community college" (p. 597).

These impacts are particularly pronounced for low-income students who were more likely to let costs, and the aversion to debt, determine where they attended college. 
As discussed by Callendar and Jackson (2008), "for students with fewer financial resources, fear of debt drove key decisions, suggesting that this group had a greater sensitivity to the costs of university than the middle- and upper-classes. Increasing the cost of higher education and levels of debt, therefore, risks constraining university choice particularly among poorer students" (p. 426).

\section{Financial Debt and Opportunity}

In addition to examples highlighting the foreclosing aspects of financial debt, several of the students in this sample were exposed to decision making opportunities as a result of their decision to take on financial debt in order to FIU. Olivia's experience with financial debt, while emotionally stressful, did allow her to escape a concurrently stressful family life. Olivia shared:

I looked at what's happening and I don't know if I'm right or not, but I'm going to have to take out a $\$ 4,000$ loan. And [my sister was] like, "[Olivia] you're taking out way too much to be going to school. If anything, just stay here and go to FGCU and save some money." I was very hesitant. I was very resistant. No, I don't want to stay home because my family has problems at home and even in high school that would alter me from doing my work and I didn't want that.

Despite the stressful financial situation Olivia faced, going into financial debt allowed her to escape her family struggles and attend college at FIU. Jordyn discussed initially being reluctant to attend college at all out of fear of going into financial debt. Jordyn shared,

I really did want to go to college, but there was a period where I was like, I don't know if I should do this because I don't know how I'm going to pay for it. I really don't. I was scared to take out loans just because we hear all about it; people here are paying loans for like the rest of their lives and I was just like I don't know if I want to do that.

However, following a conversation with her mom, who offered to take out a loan on her behalf, Jordyn eventually decided to take out a loan in order to afford to live at FIU. 
My mom was like, do you want me to take out the loan for you? Those were her exact words and I'm like, mom, I would never make you do that... I. Would. Never. Make. You. Do. That. But she just kept pushing me like go, go, go. She got everyone in the family calling me like, you need to go. So um, yeah. So she, she was the one that kind of like pushed me to still go, even though like I'm kind of figuring out the financial situation.

For Jordyn, in addition to the emotional support she received from her family, her access to student loans allowed her the opportunity to leave home and live at FIU. To put it in perspective, stretched out across four years, the value of the average loan of the students in this sample ( $\$ 1,000-\$ 2,000 /$ year) would be less than $64.3 \%$ of American learners with student debt (Federal Reserve Bank of New York Consumer Credit Panel, 2019). This is not meant to minimize any participant's experience though, as Jordyn and Olivia both described the stress they experienced as they navigating paying back their loans.

Jordyn's situation was similar to the remaining students in this sample who had to take out loans to afford to live on, or near, campus. As a result of their eligibility for the Golden Promise and the relatively low cost of FIU, the fear of debt was actually more "crushing" than the reality of taking out loans. Mateo described his experience with student debt in the following way:

We've taken out two loans as of right now. We recently paid one off a month or two ago and we just took in another one because my mother was like, it's good to have that little extra financial buffer that we can slowly start paying off here and there because it's not astronomical, but it's a good amount of money that gives us nice little safety net in terms of if something happens we have that little extra buffer to help out, to pay rent or something. Plus, my mother paying off that loan will help with her credit and her credit has been low over the last few years. So she appreciates having that loans to help build up her credit a little bit more.

For Mateo and his family, student loans acted not only as a means for him to live at college and have some extra money as a safety net, but also opened up future opportunities for his family in the form of his mother's increased credit score, which, 
despite its problematic nature, has an important role in American society (Montgomerie, 2008).

Overall, despite not wanting to take out loans to cover the cost of housing, many of the students did so because of the lack of options they faced in lieu of going into debt to attend FIU. Consistent with Perna (2008), who found that "acknowledging loans as an acceptable mechanism for paying college prices" as an upper- and middle-class

phenomenon, the students in this sample were reluctant to take on debt. However, for the students in this sample, the necessity of taking on loans, outweighed the perceived negatives. For Olivia, it would have meant living at home, attending college near her family, and potentially suffering academically and socially. Jordyn expressed a similar sentiment - without taking out loans for housing, she would not have been able to attend a four-year college, and attending a two-year school back home would not make sense because she had already earned her AA as a dually enrolled high school student. For JM, not going into debt would have meant sacrificing his dream of going to school to study music, which he had already put on hold for two years while helping to support his family financially. For these students debt was a critical part of their abilities to make decisions. The experiences of the students in this sample support Baum's (2017) claim that the "extension of credit to undergraduate students makes it possible for many individuals, particularly those with limited financial means to go to college, to go to an appropriate college, and to succeed in college" (p. 69).

\section{Non-Financial Debt and Foreclosure}

Beyond the foreclosing and opportunity creating aspects of financial debt, the participants in this study also experienced the foreclosing and opportunity creating 
aspects of non-financial debt. Several of the students in this sample had to confront, often on a daily basis, the emotional toll of expectations or the memories of past difficulties as they continued through college. This is supported by researchers who found that, family obligations, especially among participants of color, were a major factor in the decisions that individuals made, not only during the college choice process, but with other life decisions as well (e.g., Fuligni, 2001; Fuligni, Tseng, and Lam, 1999; Tseng, 2004). Each of the students discussed some of the decision making capability they had to forfeit in order to attend college in the first place, with some feeling like they did not really have any say about some of the decisions they made during the application process. Charlie shared, "I like to let myself to believe that I did have a choice [in where I went to college]. But in the end I feel like it really didn't have a choice, no."

Several students among the sample faced emotional stress around leaving their parents behind at home, especially for the students raised by single parents or those with siblings. Jordyn, a student raised by a single-mother, spoke deeply about her fear of leaving her mom at home. She explained,

Like seriously she doesn't really talk about much, so like I'll worry about her a lot. So a lot of decisions I make include her, so like where I wanted to go to school. I didn't want to go to school far away. So like, um, FSU, like, FAMU in Tallahassee, those are like 6 hour drives. I was like "it's too much."

Jennifer, a 21-year-old student of Cuban and Honduran descent, raised by a single parent, described a similar feeling when deciding whether or not to attend college outside of Miami-Dade County; "so it was basically just me and my mom [growing up] ...So I feel a lot of guilt, and I would've felt a lot of guilt if I would've left for a four-year college somewhere else. [Even though it's] what I wanted to do." While Jennifer also discussed 
wanting to leave home and attend college outside of Florida, beyond the financial costs, there were emotional "costs" that also played into her "choice" to stay at home and attend FIU. Jennifer's aspirations to leave Florida were foreclosed and limited by the obligation she felt to stay home and continue to be with her mom.

Other students, on the contrary, discussed the emotional strain leaving home to attend college put on the relationships they had with their parents who were not as supportive of their endeavors. Olivia spoke about the strain it put on her when she left home to attend FIU;

My mom and my sisters were like not supportive at all because my older sister, she didn't end up going to college because my mom made her stay to help her, to make my, she, made my older sister help, um, take care of us. And then my other older sister, she went to cosmetology school. So like she, she got a degree in something but me, I was like the first one to move away and go to college and like they weren't helpful. They were like, you should have saved up and all that. Um, but yeah, they were, they, my mom was more like hesitant about it. She's like, if you leave, you're not allowed to come back kind of thing. So it was really hard.

While this experience did not foreclose Olivia's decision to leave for school, it did foreclose the possibility of having a positive relationship with her mom in the immediate aftermath of their difficult conversation. Julie also discussed the emotional strain she faced when trying to convince her parents that she could succeed in college on her own. Additionally, students' non-financial indebtedness to their families led some students to foreclose what major they chose to pursue at FIU. Charlie, a 19-year-old student of Puerto Rican heritage, when asked about her college major, discussed that she originally planned on pursuing a career in journalism, as it was a dream for her since she was a child, but decided to choose a career path with more financial stability as a result of her family's past struggles. As a result of the debt she felt to her family, Charlie chose to 
give up on her dream of Journalism in order to "pay" for a better chance at future financial stability. She discussed: I was just worried that if I went out and followed that career path, what would happen to me in the future? If I wanted to start a family or anything like that, would I be able to support them? Or what if my mom ever needed my help?" Jordyn and Julie both shared similar experiences in their discussion of how their sense of family obligation dictated limitations on what majors they were considering.

This is consistent with Fuligni (2007) who suggests that students', especially those from East Asian and Latinx backgrounds, familial obligations shape "residential status, and the provision of financial support to parents and siblings, [as well as] occupational identity, financial independence, and self-reliance" (p. 99). Overall, many of the litany of non-financial debts that the students in this sample experienced as a result of their decision to attend college had foreclosing aspects. Students' desires and goals were mediated and, sometimes, dictated by the desires of their family members or the guilt that they felt about leaving their family members behind. Students, such as Charlie and Jordyn, were clear about the lack of choices they had in their college decision making process as a result of familial pressures.

\section{Non-Financial Debt and Opportunity}

While many students experienced negative aspects of their close-knit family relationships, many were also grateful for the opportunities that their parents and family members provided. Despite the hardships they faced while growing up, many of the students in the sample shared that they felt a debt of gratitude towards their family that shaped their resilience and will be successful in college regardless of the non-financial costs of attending. O'Shea (2015) discusses the role that family support has as a 
protective factor for first-generation students entering college, regardless of family members' knowledge of the process.

For Mars, the relationship they had with their grandparents was the catalyst for getting them to think about attending college in the first place;

So, my grandparents, they are a big help just in the way of, they're kind of, they're the ones that shaped my mindset into coming to school and they're the ones that got me into school, because I never had that mindset.

JM shared this experience with Mars. When I asked what it was like for him leaving home, JM shared, "my grandparents were always a big point in my life. You know just as much as my parents because you know sometimes my mom and my step father, whoever at the time, wouldn't be around. So it might be up to them to try to take care of me. So I was it was pretty emotional goodbye." Throughout our interview JM discussed the impact his grandparents had on his life, ensureing that he "stayed on the straight and narrow." Mateo was also clear about the role that his parents played in his decision to attend a four-year university:

honestly, the reason I'm here today is all because of my parents. They came here to the US to give me a better future and give me the best possible education that they could provide with their income. I see how hard they worked to get me here as such a symbol of strength. It really does help me try to like persevere and push through.

While the research suggests that the obligations students have to their families might work to limit or delay some of the choices students have (Fuligni, 2007), in the short term, this debt of gratitude pushed these students into attending a four-year university.

Throughout this process, it was easy to slip into a negative frame of thinking about the broken promises of the Golden Promise, the strained and difficult experiences of the students in this sample, and the precarious financial situations experienced by 
many of them, but one of the most important takeaways from this study, especially as it relates to non-financial debt, is the fact that despite all of the hardships each student was thankful in their own way for what their parents had done for them, with each student attributing most of their decision making opportunities to the role that their parents had in their lives. This is critical, because students who feel that they are supported in middle and high school are more likely to have more positive outcome expectations when they get to college (Gibbons \& Borders, 2010), something the students in this sample expressed through their interviews.

\section{The Difficulty in Separating the Financial and Non-Financial}

Lazzarato (2011) discusses the making of the indebted man within the context of capitalist and neoliberal thinking, further complicating this separation as many of Lazzarato's examples and justifications for "his" existence is steeped deeply within financial market systems. My examination of the interconnectedness of financial and non-financial debts is not an admission that non-financial debts are solely non-financial manifestations of financial debts - their categorical differences have been established throughout both the research literature and exemplified through the experiences of the students within this student. Instead, the messy realities of the experiences of the student in this study demonstrate the complicated nature of fully separating two interconnected realities.

First, as established in Chapters I and II, as a result of the influence of neoliberal policy and politicians and policy makers aligned with neoliberal ideology, the idea of education as a public good, for example, has been replaced by the investment logic of human capital theory. Throughout their interviews it was clear that several students had 
internalized this logic of radical neoliberalism. When asked what he considers when making a decision, Mateo shared, "first things foremost I think of the costs, in terms of financial or time investment or other things. Does the cost justify the means or if the consequences are too great of a risk for me to take." Mateo has demonstrated a clear interalization of neoliberal ideology, providing a clear exemplification of the ways in which human capital investment logic has entered normal consciousness, which according to Harvey (2011) is one of the most indsidious components of neoliberal ideology.

Among the students in this sample, school was merely a means to an end, demonstrating one of the ways that neoliberal ideology has seeped into the psyche of the American learner. Harvey (2005) writes, "the process of neoliberalization has entailed much creative destruction, not only of prior institutional frameworks...but also of...social relations, welfare provisions...ways of life and thought...and habits of the heart" (p. 470). A reality where students "choose" to side step their dreams in the interest of increasing their human capital. Charlie chose a major based on the perceived reliable income she would be able to attain from choosing hospitality management over journalism, her passion from a young age. Jordyn discussed foregoing her dream of becoming a doctor because it did not fit in with her timeline and she needed to start earning money as soon as possible. Of course, for the students in this population of students this makes sense; they have experienced the hardships of growing up in low-income families and want to create a better future for their families.

Additionally, both Olivia and Mars discussed emotionally draining episodes of financial uncertainty that led Mars to consider dropping out of college and left Olivia 
having to commute back and forth to a job in her hometown several hours away on weekends. Both students had moments of financial distress that led to them being indebted non-financially in ways that cost them some of their autonomy and decision making. This is supported by Peebles (2010), who discusses the difficulty of separating the economic and moral components associated with indebtedness, stating that there are "benefits of not separating the economic effects of credit/debt from the moral debates over it” (p. 234).

Students discussed the stress and degradation they faced as in high school students and wondering if they would be able to attend college at all because of their financial concerns, often limiting where they applied, and in some cases, ended up even considering at all. Rachel explained it this way:

even though I knew what he was saying was true [about choosing FIU over USF because of the financial certainty of what FIU was offering], I was just so sad internally. I started crying in the office. I started crying because I wanted something different. I have a few friends that [took out loans], like close friends that are here at FIU too. I knew that my mom could not afford, even if it was five thousand dollars, I was like, I wasn't going to do that to her because it sounds like... [trails off]. Okay, fine FIU.

So while Rachel might not be in any financial debt as a result of her decision to attend FIU, she certainly felt the emotional toll of having to pay for her education by sacrificing some of her decision making autonomy. Analise also sacrificed some of her decision making autonomy solely out of the obligation she feels to her family; "I only applied to FIU. I did not apply to Dade, FSU, like nothing. This was my only option. I stayed here and I only applied to FIU because of the benefits of staying locally [and] helping my family economically." 
Finally, attending college on a scholarship also came with some additional side

effects for the students in this sample. JM shared his experiences as a student who relied on aid money to attend school. He stated:

I have a lot of stories from people in and out of the school of music who didn't commit as hard as they could and didn't strive for the highest and because of it they didn't they ended up losing their scholarships. I hear about stories where "I lost my music scholarship because I didn't do well in piano classes or I lost my financial aid here because I got a D. I said "you know I can't let that happen because if that happens I don't get another chance; you know I'm done. I don't go back to school."

For JM, his reliance on financial aid both foreclosed some of his opportunities and allowed him to attend college in the first place. This highlights the inextricably linked nature of students' financial and non-financial debts, e.g. the emotional toll of having to delay college due to financial reasons. The foreclosing aspects are clear - due to the obligation he had to his siblings, JM was, essentially, obliged to say home and support his family, ostensibly without a real choice to be made, as seen in the quote above. More broadly, JM's concerns do not solely lie in the realm of education, but speak to wider concerns in the US regarding supporting our most vulnerable members of society.

\section{Summary}

In sum, this chapter presents the results of the present study, which involved oneon-one interviews with thirteen low-income students receiving financial aid through a university promise program. The purpose of the preceding study was an examination of the following two research questions:

(1) How do allegedly "debt-free” low-income students express non-financial debts related to their educational experiences? 
(2) In what ways does non-financial debt act as a foreclosing agent in student decision making for allegedly "debt-free” low-income students?

Overall, the participants, experts in their own experiences, provided illuminating and invaluable insights into the inner workings of a university promise program, debt, and foreclosure. Through the analysis of interview transcriptions, I was able to identify salient themes by utilizing the theoretical framework of the indebted man and the indebted student (Lazzarato, 2011; 2015; Gildersleeve, 2017).

Regarding students' expressions of the non-financial debts associated with their educational experiences, I found that, per Lazzarato (2011), Lowenberg (1995), Nowotny (1994) and many of the other researchers cited above, students' experiences fit into the following categories of non-financial debt: conduct, subjective commitments, time, and emotional health. By choosing to attend college, the students in this sample experienced these debts via family interactions and expectations, community expectations and biases, and the mere passing of time. Further this notion of non-financial debt suggests that the process of allowing students to graduate "debt-free" may be more involved than eliminating the cost of tuition and fees, as claimed by upper level administrators during the roll-out of the Golden Promise. In fact, one of the most important findings of this study was that many of the students in this sample were actually required to take on financial debt in order to attend FIU, despite claims of creating "debt-freeness."

In regard to debt being a foreclosing force in student decision making, the experiences of the students in this sample provide mixed results. Many of students shared experiences of their financial and non-financial debts acting in both foreclosing and opportunity driving ways. This is consistent with the research literature, which has been 
inconclusive on the opportunities that debt can create and foreclose (e.g., Baum, 2017;

Callendar and Jackson, 2008; Fuligni, 2007; Perna, 2008).

Ultimately, these results demonstrate that the experiences of allegedly "debt-free"

low-income students participating in a promise program are complicated. Their

experiences are complicated by their debts and the opportunities they wish they had.

Students could be excited about attending FIU yet still yearn for what could have been.

Students had complicated relationships to their families, their communities, and even, their university. Alleged "debt-freeness" is a complicated subject that needs to be investigated in much more depth to truly capture its nuance. In that vein, Chapter V examines the implications of the present study and future directions for research. 


\section{CHAPTER V: DISCUSSION AND FUTURE DIRECTIONS}

Introduction

The foundations for this study were laid one summer semester during my doctoral coursework. Reading the work of Nowotny (1994) and Lazzarato (2011) inspired me to think more critically about how individuals might experience debt beyond solely owing money. Beyond my engagement with academic texts, I was also able to professionally experience, firsthand, stories from students trying to navigate their way through college. During my time as an academic advisor, I would always hear stories from students about their inability to take classes at certain times, pick certain majors, or even attend the colleges of their choice because they had responsibilities at home; they had to pick up their abuela from the doctor's office or they had to pick up their little brother from soccer practice. These household chores weren't negotiable either.

Whenever I would (insensitively) ask, “can’t you just tell your parents that you're a college student now?" The response, more often than not, would be something about their family's culture that obligated them to take care of their parents, grandparents, or siblings. When I would ask students about changing their major to something they were more passionate about it, they could only think about the familial consequences of such an action; "I'd be letting my whole family down if I don't pursue medical school" or "my parents won't pay for my classes if I'm an English major, they're paying for me to get a degree in engineering." Through the work of Nowotny (1994), Lazzarato (2011; 2015), and Gildersleeve (2017), I now had language I could put to these phenomena - debt. The idea here is that, in one way or another, all of these students were "paying" for their education with more than just money. They were indebted to their families, whether it 
was to help them pay for college or out of cultural norms. Either way, it seemed that the additional burdens these obligations put on such students were impacting students' abilities to immerse themselves in the college experience and succeed academically. The "cost" of their education was their time, their free-will, their social relationships, etc.

With my professional experience and doctoral coursework leading the way, I set out to explore a way to enter these non-financial debts into the conversation around student debt. Due to the unfathomably large dollar value of financial debt currently facing America's college students, it is a crowded conversation to enter, but these non-financial "costs" seemed too substantial to ignore. The results discussed in Chapter 4 suggest both the non-financial and financial costs that allegedly "debt-free" students with an EFC of zero face as they navigated the college application and admissions process and the foreclosing and opportunity creating aspects of debt.

\section{Discussion}

The present study examined students' lifelong experiences with debt and foreclosure using a single-interview data collection format. Through interviews with students I attempted to answer two research questions. The first research question was: do "debt-free" low-income students in a promise program express non-financial debts within their educational experiences? In regard to this question, the results suggest, consistent with Lazzarato's (2011) and Gildersleeve's (2017) discussion of the indebted man and indebted student, respectively, that individuals (students, specifically) experience debts that manifest non-financial "balances" that need to be "repaid." Among the students in this sample this was represented by debts of conduct, subjective commitment, time, and emotional health. 
The second research question I sought to answer was whether debt, both financial and non-financial, acts/acted as a foreclosing agent in student decision making for students in a need-based promise program. As Lazzarato $(2011 ; 2015)$ argues, debt works to foreclose opportunities through the creation of subjectivities to creditor. Individuals are left to consider what they "owe" their creditors and the choices they have left to them as they navigate any present and future decision making. Critical to Lazzarato's conceptualization of debt is the idea that this "owing" is not simply a financial obligation but a moral, social, familial, and temporal one. Uniform with Lazzarato's analysis, this study suggests that debts can work to foreclose the opportunities that students have in their professional, personal, and academic decision-making capabilities. However, the students' debts were not solely foreclosing. Many students discussed the opportunities that their financial and non-financial debts provided as they navigated the college admissions process.

So critical to this study is the notion of "debt-freeness," an unrealized state of being placed upon students by institutional decision makers. In the initial press-release announcing the creation of the Golden Promise program, FIU stated, "We are going to find the scholarship money so that these hard-working students can graduate as soon as possible, be debt-free, and go to work" (Lacayo, 2017, n.p., emphasis added). Of course, the idea of debt-freeness is a complicated and multi-faceted state of being and one that, according to Lazzarato $(2011 ; 2015)$, may not be fully possible. Despite claims of "debtfreeness" by their university, each of the students in this sample experienced both financial and non-financial debts associated with their decision to attend FIU. This university in particular has the idea of creating a "debt-free" student, one able to graduate 
in four-years and enter the work-force free of financial debts (Lacayo, 2017), a state incongruent with reality for many of the students in this sample. This claim is problematic in terms of the students in this sample for several reasons.

Many of the students in this sample were required to take on financial debt in order to afford to live on campus at FIU, something I (naively) did not expect to find coming into this study. While FIU's focus was on allowing students to graduate without debt, it became clear that the financial burden of paying for housing was causing certain students to forego social, academic, and professional opportunities, consistent with Lazzarato's (2011) conceptualization of debt as a foreclosing force in several students' lives. Interestingly, this foreclosure worked to impact students in different ways across different temporalities.

In Chapter II I explored the idea of choice under neoliberal ideology, specifically the ways in which the language of choice can be used as a method for reducing the options individuals have in terms of education and health care, for example (Burt and Baber, 2018; Lowenberg, 1995; Shure, 2019). As Sacks (2007) describes regarding college choice, there are a multitude of generational factors that accumulate over time which work to impact the ways students from different socioeconomic backgrounds are able to progress through the college choice process. Sacks' ideas about these choices are reminiscent of Bourdieu (1986) who discusses the concept of cultural capital, a resource which accumulates over time, and works to impact students' knowledge of the "games" of social and cultural institutions so critical to their advancement within the rhythms of modern society. Students are required to know the "rules of the game" in order to have 
any chance of being successful navigating the often-convoluted world of the college choice process.

Promise programs cannot eradicate the class-based inequalities that shaped students' pre-collegiate careers and continue to shape their lives in college. This is once again suggestive of Sacks (2007), who argues that for many students, especially those from low-income backgrounds, the opportunities they have are more or less decided/diminished as a result of the hundreds and thousands of small happenstances in a person's life. This includes a parent being unable to take off of work due to a rigid schedule, missing school days to care for siblings, and/or missing school due to less than desirable living conditions as a result of their family's economic status, for example (Sacks, 2007).

A study by Paschall, Gershoff, and Kuhfeld (2018) discusses education attainment gaps in math and reading for students of color in poverty that begin as early as pre- $\mathrm{K}$ and continue to exist for students through middle school. Sadly, these gaps and other negative outcomes associated with being raised in poverty pile up and diminish the opportunities students have at the postsecondary level (Sacks, 2007; Ziol-Guest and McKenna, 2014). One of the areas that can affect students in poverty is housing instability. For Julie, this manifested in moving around, being unable to stay in one state, let alone household. Both JM and Rachel had similar experiences as well, moving several times and living with different family members all before stepping foot on campus. And while several of the students felt that these experiences certainly had an impact on their lives, none described it as a specific limiting factor in if or where they felt they could attend college. The research literature on the other hand suggests that, in many ways, factors such as housing 
insecurity, and growing up in poverty in general, have large impacts on students' educational outcomes (Chetty et al., 2019). In fact, students from high-income families are $44 \%$ more likely to complete a bachelor's degree than their peers from low-income backgrounds (US Department of Education, 2015a).

Another key factor that contributes to students' educational outcomes is parents' degree attainment. The struggles of first-generation students are well documented in the research literature, especially as it relates to college decision making, preparation, and academic readiness (Garza, Bain, and Kupczynski, 2014; Olson, 2014; O’Shea, 2015; Ramos-Sanchez and Nichols, 2007). Bourdieu (1974) argues that children from disadvantaged backgrounds face "cumulative" handicaps where disadvantage is compounding; "children from the lower and middle classes who overall achieve a lower success rate must be more successful for their family and their teachers to consider encouraging further study" (p. 35) Ultimately, the end result for low-income students is a diminished opportunity to continue their education. In a sense, students in lower classes must overcome the low expectations inherently placed upon them by their families and teachers in order to achieve admission to college (Bourdieu, 1974).

This is not to say that students from low-income backgrounds do not receive important and valuable support from their families and teachers. Instead I aim to highlight the ease at which students from wealthy and high-income families are able to convert the knowledge and support they receive into the cultural capital necessary to opportunity hoard and gain admission into elite colleges and universities. The experiences of a student's youth cannot be discounted when thinking about the foreclosing aspects of non-financial debt, whether it be emotional, temporal, or social 
debt. For many students the constraints of the decision-making process are begun long before students step foot on campus, and in certain cases, long before they are even born. While students' financial burden is lessened by promise programs, issues of access and success cannot be solved simply through such last-dollar promise programs.

Further, the alleged state of "debt-freeness," especially one placed on students by an institution, raises questions about the philosophical and practical construction of promise programs, given some of the failures of such programs (Perna and Leigh, 2019; Poutre and Voight, 2018). In fact, this study brings into question the entire nature of a "promise" between student and institution. The problems of promise programs have been documented in the research literature (Perna and Leigh, 2018; Poutre and Voight, 2018; Swanson et al., 2016) however the problems within the FIU Golden Promise extend beyond property tax increases and allocation "snafus," but instead call into question the philosophy of the promise between student and university.

While FIU made claims about promising students a "debt-free" future, by failing to cover costs outside of tuition and fees, this promise fell far short of allowing students to achieve this future. Further, whether it was a failure of the institution to send out notification or the students to receive them, the problematic nature of the notification process also calls into question whether or not a university can make a "promise" to its students if they are unaware of the terms. Finally, among the students in this sample, many expressed feeling like they made a promise to FIU. The idea that a student is making a promise to their institution is emblematic of problematic power dynamics within this relationship, especially for some of the institution's most vulnerable students. It also calls into question what type of student the institution is expecting, especially an 
institution with roots in the local community, one that understands the background of the vast majority of its $50 \%$ Pell eligible population. There seems to be some disconnect between the university's definition of "debt-free" and the students' lived experiences. The fact that many of the students in this sample demonstrated debts that fell outside society's traditional understanding of debt as solely a financial obligation, highlights this disconnect.

There is a lengthy historical narrative in the U.S. that schools and universities will somehow educate our society out of complex, intersected, historicized social problems: racism, economic insecurity, discrimination, etc. Brown (2015) writes "providing tools for understanding [the powers and problems they are engaging] has been a key premise of public secondary and higher education in the West over the past two centuries and has especially undergirded cultivation of a liberal arts curriculum in American universities" (p. 175-176). However, as inequality continues to increase, at the macro-level at least, education as an equalizer has failed students from underserved communities. Quite problematically, institutions of higher education, despite allegedly good intentions, perpetuate this failure by couching their need-based aid programs, those being awarded to the neediest students, in bootstrap mentality and language aimed at "hard-working" students. Even without strict requirements needed to maintain eligibility for need-based programs, colleges and universities are placing value judgements that may further disenfranchise students from low-income and minoritized backgrounds. The creation of aid programs that provides students extra dollars over their Pell maximum may not be enough to wipe away centuries of unequal treatment, especially when there are other financial and non-financial costs associated with decisions to attend college. 
Students' decision-making autonomy was impacted by the weight of generations of societal laws and decisions that have led to today's present educational situation. Chapters two and four both explore the histories of student loan debt, promise programs, and other societal factors (e.g., housing insecurity, educational attainment gaps by race/ethnicity and class). Decades of student loan policy (and the broader dismantling of social programming by neoliberal politicians) has created an environment where students are more limited in the choices they are able to make - strong students (much like the ones in this program) often find themselves overmatched for the colleges they attend because of the social, cultural, and familial factors facing them (Bastedo and Jaquette, 2012; Hoxby and Avery, 2013).

In fact, the students in this sample had every right to feel frustrated and down about some of their life circumstances, but instead were able to create a narrative that focused on growth and achievement for themselves, one steeped in speaking their personal truth and self-authorship of their own experience and community. Years of housing insecurity, financial stress, and the anxiety of leaving home and disappointing their parents created a reality of limitations for these students. Luckily, their resilience allowed them to speak their truths about the positives of their individual scenarios, allowing them to thrive in their current educational landscapes.

Critically, despite having several reasons to be upset about their situations, the students in this sample were able to make the best of it. This is important because instead of demeaning these students and what they have accomplished, this study seeks to question the decision making of state, federal, and institutional policy makers and the societal conditions they have created as a result. Tuck (2009) writes, "the danger in 
damage-centered research is that it is a pathologizing approach in which the oppression singularly defines a community" (p. 413). Instead of focusing on a "damage-centered" approach, despite discussing some of their personal struggles, many of the students in this sample instead focused on their achievements and successes. Tuck discusses the idea that even though we may have some sort of historical trauma narrative in our minds as researchers, "but...for many people this context has been made invisible and natural" (p. 415).

This came through in each interview as the students in this sample authored the stories of their personal and community narratives. While I will not claim that this study "gave voice" to these students, especially in an era of social media where individuals have platforms to tell their stories, each interview allowed the participant to author their own narrative about how they wanted to discuss their race, community, gender, and/or life. Foucault (2008b) writes, "in his act of telling the truth, the individual constitutes himself and is constituted by others as a subject as a discourse of truth, the form in which he presents himself to himself and to others as someone who tells the truth, the form of the subject telling the truth" (p. 3). Essentially, instead of extracting and mining from, debt, for the students in this sample, provided an opportunity to speak truth and act, as put by Foucault (2008b), parrhesiatically, or, in other words, were able to speak freely.

\section{Future Directions}

This study shows that further research needs to be done to more substantially tease apart the differences between financial and non-financial debt as this study is one of the few that attempts to pinpoint and define non-financial debt concretely. Because this sample only consisted of 13 students it is hard to make any generalizations based off this 
study, so more qualitative research on non-financial debt is critical to further understand the experiences of low-income college students as they relate to non-financial debt in general.

Among the students in this sample, there were non-financial debts associated with students' racial and ethnic backgrounds. Boyd (2005) provides a concise history of the notion of racial uplift, the idea being that individuals are responsible for acting in ways that uplift the entire group. Given the small sample size, I cannot claim to generalize these results to a large population, however, the stories shared by Jay and Olivia in particular highlighted some of the extra burdens facing students from African-American and Hispanic/Latinx backgrounds in this sample. For example, Jay discussed the feeling of having to "be better" because, according to his professor, he was at college representing his race, whether he liked it or not. Olivia discussed the vitriol she received from some of her classmates, both Hispanic/Latinx and white as she navigated her advanced high school coursework. Further, she felt that she had an obligation to attend college for her friends that were not able to as a result of their DACA status. Further research on influence of racial and ethnic factors on debt could be critical to questions of equity within the college admissions process.

None of the students in this sample discussed anything in relation to their gender identity, except for Mars, who noted the prejudice they sometimes face as a non-binary individual. Given that gender and sex seem to be relevant to both the financial and nonfinancial debts individuals encounter (Di Feliciantonio, 2016), more exploration into this area could yield fruitful results. Given the surprising lack of discussion around gender roles in this sample, future work that specifically examines the role gender identity plays 
in debt formation would be a relevant next step. Per Federici (2018), women hold vastly more of the world's financial debt than men, yet only make up about $50 \%$ of the population. Further, as highlighted in chapter 2, her study examined the ways that financial debts also started to impact women non-financially.

Beyond examining the role debt plays in the lives of participants who identify as male and female, a qualitative study of gender non-conforming individuals related to debt in higher education could also shed light on the role debt plays in the lives of students that fall along different points of the gender identity spectrum. Given the impact that racial/ethnic identity had on the debts faced by some of the students in this sample, it would be interesting to examine how/if students from other marginalized groups are indebted in ways that extend beyond their finances.

Further, more research on the "debt" of being on financial aid would provide deeper insight into the impact that attending school on scholarship can have on the psyche of low-income students. Several the students in this sample discussed the fears they had about losing their scholarships, some as young as middle school. Rachel discussed the pressure she felt to keep her grades up in order not to jeopardize her middle and high school scholarships and place the economic burden on her family. JM discussed the fear of having to maintain good grades, given that without his aid money he would probably have to move back home and start working again. Relatedly, when asked about what the word "promise" meant to them (in relation to the Golden Promise), many of the students, instead of discussing the promise that FIU made to them, spoke about the promise that they had to keep with FIU to maintain receiving their award money. This 
idea in itself creates a creditor/debtor relationship within the university that is worth exploring in greater qualitative detail.

Next, while research in higher education often discusses students' debt aversions, it would be interesting to see how the debt aversions of family members of low-income students impact student decision making. The results from this study suggest that family members' debt aversion may impact a student's willingness to take on financial debt. More research in this area could provide fruitful information about the role of family members in debt aversion and foreclosure.

Perhaps most importantly, given that this was one of the first empirical studies that set out to examine the role of non-financial debt in the lives of low-income students, I would call for similar studies with promise program students from different colleges and universities. It would also be useful to expand on the number of participants to perhaps begin to generalize some of these findings in the hope of providing colleges and universities with a "blueprint" of the circumstances and scenarios that led their lowincome students to college. Perna and Leigh (2018) similarly call for an increase in the research on promise programs.

Beyond students who are (allegedly) completely covered by financial aid, another "debt-free" population of students exists on college campuses: students whose parents are able to $100 \%$ cover their college associated costs. Students from such backgrounds would provide another angle from which to address the issue of a "debt-free" education and give great insight into the ways debt can work non-financially, regardless of social class. And while my ultimate goal is to shine more light on the ways that low-income students are indebted, by examining the experiences of another, allegedly, "debt-free" population, 
researchers can learn more about the ways debt exists non-financially and structure future research aimed at serving low-income student populations.

Lastly, a longitudinal study on non-financial debt would be useful in examining the ways debt acts across the lifespan. An interview study that tracks students through their college decision making process, their college years, and their experiences in seeking employment or graduate school following their bachelor's degree would illuminate the debts students face as the navigate several critical junctures in their lives. In conducting a longitudinal study, student experiences are captured in the moment, rather than having to rely on their recollections. In addition, tracking students through time would allow researchers to understand how students make meaning of debt at different developmental life stages and begin to better understand the evolution of how students understand debt and the variety of ways in which they are indebted.

\section{Limitations}

The goal of this study was to examine the experiences of low-income students in a promise program surrounding debt. One of the limitations of this study is that data collection took place at one at only institution, meaning that this study only examined the experiences of students in one specific promise program.

Further, the participants in this study were all EFC zero students who were part of FIU's Golden Promise scholarship program, one small subset of students who might be considered debt-free. Recipients of merit scholarships that cover the full-cost of tuition and fees as well as students whose parents cover their college expenses could both be considered debt free as well. This study sample did not consist of any students from either of these populations of potentially debt free candidates. 
While it was not my aim to generalize the results of this study to the broader population, the fact that the sample size of this study was 13 , leaves open the possibility that a larger and more diverse sample could have provided deeper and more varied insights into the research question.

Additionally, there were several methodological limitations involved in the present study. Given that I did not have access to the database of students and the fact that I was relying on a third-party (FIU's Office of Financial Aid), I did not have complete control over (1) who was contacted, (2) when they were contacted, (3) if the requested demographic groups were contacted or (4) the final number of students contacted for this study. Further, due to my lack of control over the sampling process, I was unable to sample students evenly from each chosen background and had to rely solely on students who replied to participate. This created additional limitations, as students who self-selected for participation might have had different experiences to share than students who were recruited through word-of-mouth or other outreach strategies. Lastly in regard to sampling, during the sampling process I failed to consider the gender demographics of FIU, which resulted in a sample that skewed female.

This study was also limited by the single-interview format. Given personal and professional time constraints, I was unable to conduct multiple interviews with each student. A multiple interview format would have allowed me the opportunity to followup with students following the review of each transcript, further allowing me to explore each students' experience in more depth.

Finally, considering this was my first qualitative study I feel that the methodology of this study was limited by my lack of experience in coding, analyzing, and using my 
CAQDAS. More specifically, I feel as if I allowed the theoretical framework to limit how I saw the data and analyzed each student's experience. Based on my personal experiences and theoretical framework I had preconceived ideas about what students might be experiencing and I allowed these preconceptions to influence how I saw/read into the data. With more experience, I am hopeful that I can more effectively moderate these issues and allow students' experiences to more fully shine through. I do not feel that this limits the impacts of what I have reported here, however there may have been more depth to my findings had I allowed the students words to truly guide the direction of my coding and analysis.

\section{Conclusions}

While some of the student quotes from our interviews might seem bleak, it is important to me to share that each and every one of the students in this sample was able to find a lot of positives in their circumstances, whether it was the relationship they had with their parents, the satisfaction of being able to attend college at all, or the hopes and dreams they had for their future. This dissertation is not meant to view these students from any sort of deficit model. Instead it is meant to highlight the deficits within the American system of higher education. For Bourdieu, schools are institutions that justify "social inequalities, and give[s] recognition to the cultural heritage...[where] a social gift [is] treated as a natural one" (p. 33). These resourceful students were able to navigate their often-difficult circumstances and find themselves at one of the top 100 public institutions for higher learning in the country. This is no small feat. Further, most of the students in the sample found themselves, despite their original concerns, generally happy with the education and experience they are receiving thus far at FIU. 
I also do not want this dissertation to be solely a criticism of FIU's Golden Promise program. While I certainly believe that it was created with mainly commuter students in mind (which is not surprising given the overwhelming number of commuter students on campus), it is quite admirable for a school where almost $50 \%$ of the student population are Pell eligible to guarantee coverage for the full cost of tuition and fees for all EFC zero students. What makes it so admirable is the fact that FIU is not working with the endowment money or donor funded scholarship money of Harvard, Princeton, UNC-Chapel Hill, or U. Mich - Ann Arbor. While Florida's outsized reliance on performance metrics to gain critical additional funding might be causing FIU's FTIC population to be trending away from admitting as many Pell eligible students (the number of Pell eligible students at FIU has declined over the past few years), the high number of transfer students from Miami Dade College (a local community college in the area) still represents a school that is generally steeped (and reliant upon) students from the surrounding community.

That being said, states, colleges and universities that offer promise programs need to more fully consider the experiences of students to whom they are making a "promise." In the case of FIU, it is worth examining the population of Golden Promise students more deeply to get a sense of the debts (both financial and non-financial) that they face. Given that it was difficult for many of the students in this sample to pay for housing, it would not be surprising to find other students in a similar situation. Since it is the goal of the university to help these students graduate in four-years without taking on financial debt, exploring ways to support students with housing would be helpful in achieving this goal. Given that many students were unaware of this program, it would be helpful for FIU to 
examine the student population that they are supporting and work to make the Golden Promise a more holistic support system for qualifying students.

Providing more emotional and social support for students in the Golden Promise program (and low-income students in general on campus) might also alleviate some of the emotional and social burdens that they are facing. While it is beyond the scope of this research to make programmatic suggestions, for many of the students in this sample, being supported socially and emotionally would provide them with an opportunity to meet students from similar backgrounds who can share and understand their stories. For Mateo, his involvement with an office on campus that works with students from different backgrounds provided not only a figure he could go to on campus for support, but allowed him to really steep himself in the culture of the campus, which has benefits for students (Mayhew et al., 2012). This solution is complicated because for Kezar, Walpole, and Perna (2015), taking advantage of campus engagement opportunities "requires time, and while people in the United States don't like to discuss class issues in our supposedly meritocratic society, time is something that is acquired through wealth" (p. 238). For Tadair (2013), the alleged freedoms of neoliberal regimes can only really be enjoyed by those with "temporal surplus value" that simply does not exist for working class individuals who have to continue to work to prove that their time is valuable.

Ultimately, this study is a call to educators, campus administrators, especially those on admissions committees and in financial aid offices, to more deeply consider the circumstances of the students you admit as part of programs meant to eliminate student debt. As highlighted in chapter I by Lissovoy (2015), "the first task for a pedagogy against neoliberalism — and against neoliberal freedom — is to challenge the prevailing 
definition of freedom itself" (p. 51). By questioning the assumed meritocracy of higher education, it may be possible to start changing some of the structures from within, and meaningfully impact the lives of low-income students. For Tadair (2013), "to attend to the uneven times of the global project of neoliberalism is to interrupt the coherence and homogeneity of the epoch that is assumed to be our shared global present...and an interruption of the time of the "always already" for the redundant populations who are the long-standing victims of colonialism and imperialism" (p. 42).

Clearly, Jordyn, Analise, and the remainder of the students in this sample, despite their current satisfaction with their university, did not really have the same opportunities as their peers from middle- and upper-income backgrounds might. Their opportunities were not completely a result of their financial situation either. Paying the familial, social, temporal, and emotional costs of attending their dream school was too much to ask for these students on top the perceived financial costs. These debts are real and should be considered in the construction of any need-based aid or promise program.

By raising questions about the role neoliberal policy plays in the lives of students, especially around themes of freedom and choice, it may be possible for these students to have control over their time (present and future), and instead spend their high school and college years growing, learning, and experiencing without concern for how they "spend" their time. Further, if colleges and universities do want to make "promises" to lowincome students it is critical that they consider the totality of students' experiences and ensure that their promises do not ring empty. 


\section{REFERENCES}

Ahn, I. (2010). Economy of "invisible debt" and ethics of "radical hospitality:" Toward a paradigm change of hospitality from "gift" to "forgiveness." Journal of Religious Ethics, 38(2), 243-267.

Akers, B. \& Chingos, M. M. (2016). Game of loans. Princeton, NJ: Princeton University Press.

Alexander, M. (2010). The new Jim Crow: Mass incarceration in the age of colorblindness. New York, NY: The New Press.

Archuleta, K. L., Dale, A., \& Spann, S. M. (2013). College students and financial distress: Exploring debt, financial satisfaction, and financial anxiety. Journal of Financial Counseling and Planning, 24(2), 50-62.

Astin, A. W. \& Oseguera, L. (2004). The declining equity of American higher education. The Review of Higher Education, 27(3), 321-341.

Auer Jones, D. (2009, Dec 13). Reforming federal student aid, part 3. The Chronicle of Higher Education. Retrieved from: https://www.chronicle.com/blogs/brainstorm/reforming-federal-student-aid-part3/9188.

Aviram, H. (2016). Are private prisons to blame for mass incarceration and its evils? Prison conditions, neoliberalism, and public choice. Fordham Urban Law Journal, 42(2), 411-449.

Bastedo, M. N. \& Jaquette. O. (2011). Running in place: Low-income students and the dynamics of higher education stratification. Educational Evaluation and Policy Analysis, 33(3), 318-339.

Baum, S. (2017). Student debt: Good, bad, and misunderstood. Change: The Magazine of Higher Learning, 49(3), 60-70.

Becker, G. S. (1962). Investment in human capital: A theoretical analysis. Journal of Political Economy, 70(5), 9-49.

Berger, F. R. (1975). Gratitude. Ethics, 85(4), 298-309.

Bernie 2020 (2020). College for all and cancel all student debt. Retrieved from: https://berniesanders.com/issues/free-college-cancel-debt/. 
Bernstein, D. and Blitt, C. (1986). Central American refugees for profit. In Ganz, E. (Ed., 2017). The age of inequality: Corporate America's war on working people. New York: Verso.

Best, J. \& Best, E. (2014). The student loan mess: How good intentions created a trillion dollar problem. Berkeley, CA: University of California Press.

Bettinger, E.P., Terry Long, B., Oreopoulos, P., and Sanbonmatsu, L. (2012). The role of application assistance and information in college decisions: Results from the H\&R block FAFSA experiment. The Quarterly Journal of Economics 127(3).

Biden for President. (2020). The Biden plan for education beyond high school. Retrieved from: https://joebiden.com/beyondhs/.

Biewin, J. (2012, Nov 23). Little war on the prairie. This American Life [Audio Podcast]. Retrieved from: https://www.thisamericanlife.org/479/little-war-on-the-prairie.

Biss, E. (2015). White debt. In C. Lemert (Ed). Social Theory: Sixth Edition (pp. 531533). Philadelphia, PA: Westview Press.

Bourdieu, P. (1974). The school as a conservative force: Scholastic and cultural inequalities. In Eggleston, J. (Ed.). Contemporary Research in the Sociology of Education. Oxford: Routledge.

Bowen, W. G., Chingos, M. M., \& McPherson, M. S. (2009). Crossing the finish line: Completing college at America's public universities. Princeton, NJ: Princeton University Press.

Boyd, M. (2005). The downside of racial uplift: The meaning of gentrification in an African-American neighborhood. City \& Society, 17(2), 265-288.

Brown, W. (2015). Undoing the demos: Neoliberalism's stealth revolution. Cambridge, MA:MIT Press.

Bureau of Labor Statistics (2019). College enrollment and work activity of recent high school and college graduates - 2018. News Release U.S. Department of Labor. Retrieved from: https://www.bls.gov/news.release/pdf/hsgec.pdf.

Burt, B. A., \& Baber, L. D. (2018). The power of language: Exploring foundations of neoliberalism in federal financial aid policy. The Journal of Negro Education, $87(2), 140-153$.

Callender, C. \& Jackson, J. (2005). Does the fear of debt deter students from higher education? Journal of Social Policy. 34(4), 509-540. 
Callender, C. \& Jackson, J. (2008). Does the fear of debt constrain choice of university and subject of study? Studies in Higher Education, 33(4), 405-429.

Camp, J. T. (2016). Incarcerating the crisis: Freedom struggles and the rise of the neoliberal state. Oakland, CA: University of California Press.

Campbell, R. F., \& Boyd, W. L. (1970). Federal support of higher education: Elitism versus egalitarianism. Theory Into Practice, 9(4), 232-238.

Card, C. (1988). Gratitude and obligation. American Philosophical Quarterly, 25(2), 115127.

Carlson, A. and Laderman, S. (2018). The power of a promise: Implications and importance of adult promise programs. SHEEO Adult Promise Project White Paper.

Carlsson, R.J. (1970). A federal program of student loans. The American Journal of Economics and Sociology, 29(3), 263-276.

Carruthers, C. K. \& Welch, J. G. (2019). Not whether, but where? Pell grants and college Choices. Journal of Public Economics, 172, 1-19.

Cartledge, B. H., Baldwin, M. S., Persall, J. M., \& Woolley, T. W. (2015). College choice determinants of african-american enrollment at a private college. Journal of Academic Administration in Higher Education, 11(1), 1-8.

Castleman, B.L. and Long, B.T. (2016). Looking beyond enrollment: The causal effect of need-based grants on college, access, persistence, and graduation. Journal of Labor Economics 34(4), 1023-1073.

Chen, E. (2013). Neoliberalism and popular women's culture: Rethinking choice, freedom, and agency. European Journal of Cultural Studies, 16(4), 440-452.

Chetty, R., Hendren, N., \& Katz, L. F. (2016). The effects of exposure to better neighborhoods on children: New evidence from the Moving to Opportunity experiment. American Economic Review, 106(4), 855-902.

CNM Ingenuity, Inc. (2018). Our programs and initiatives. CNM Ingenuity. https://cnmingenuity.org/program/.

Coco, L. M. (2013). Mortgaging human potential: Student indebtedness and the practices of the neoliberal state. Southwestern Law Review, 42(3), p. 565-603. 
Collier, D. A., \& Herman, R. (2016). Modifying the federal loan provision in the Higher Education Act of 1965: An overview of federal loan policies that have transitioned higher education from the social good. Higher Education in Review, Special Issue, (1), 9-23.

Collins, S. R., Gunja, M. Z., Doty, M. M., \& Bhupal, H. K. (2018). First look at health insurance coverage in 2018 finds ACA gains beginning to reverse. New York, NY: Commonwealth Fund.

Cox, J. (2019). CEOs see pay grow 1000\% in the last 40 years, now make 278 times the average worker. Retrieved from: https://www.cnbc.com/2019/08/16/ceos-see-paygrow-1000percent-and-now-make-278-times-the-average-worker.html.

Cox, R. D. (2016). Complicating conditions: Obstacles and interruptions to low-income students' college "choices." Journal of Higher Education, 87(1), 1-26.

Creswell, J.W. and Poth, C.N. (2018). Qualitative Inquiry and Research Design: Choosing Among Five Approaches. Los Angeles, CA: Sage Publications, INC.

Cunradi, C. B., Caetano, R., Clark, C., \& Schafer, J. (2000). Neighborhood poverty as a predictor of intimate partner violence among white, black, and hispanic couples in the United States: A multilevel analysis. Annals of Epidemiology, 10(5), 297-308.

Despard, M. R., Perantie, D., Taylor, S., Grinstein-Weiss, M., Friedline, T., \& Raghavan, R. (2016). Student debt and hardship: Evidence from a large sample of lowandmoderate-income households. Children and Youth Services Review, 70, 8-18.

Davies, B. and Bansel, P. (2007). Neoliberalism and education. International Journal of Qualitative Studies in Education, 20(3), p. 247-259.

Di Feliciantonio, C. (2016). Subjectification in times of indebtedness and neoliberal/austerity urbanism. Antipode, 48(5), 1206-1227.

Duvernay, A. (2016). The 13th [Film]. Kandoo Films.

Eagan, K., Stolzenberg, E. B., Bates, A. K., Aragon, M. C., Suchard, M. R., \& RiosAguilar, C. (2015). The American freshman: National norms fall 2015. Los Angeles: Higher Education Research Institute, UCLA.

El Issa, E. (2019). 2019 American Household Credit Card Debt Study. Nerdwallet. https://www.nerdwallet.com/blog/average-credit-card-debt-household/.

Elliott, B. (2018). Work, culture, and play in the neoliberal condition. Information, Communication \& Society, 21(9), 1279-1292. 
Elliott, W. \& Lewis, M. (2017). Student debt effects on financial well-being: Research and policy implications. Journal of Economic Surveys, 29(4), 614-636.

Elliott, J. R. \& Sims, M. (2001). Ghettos and barrios: The impact of neighborhood poverty and race on job matching among blacks and latinos. Social Problems, 48(3), 341-361.

Engle, J. \& Tinto, V. (2008). Moving Beyond Access: College Success for Low-Income. First-Generation Students, Washington, DC: Pell Institute for the Study of Opportunity in Higher Education.

Farrington, R. (2019). How student loans impact your credit score. Forbes. https://www.forbes.com/sites/robertfarrington/2019/12/18/how-student-loansimpact-your-credit-score/\#219c57ce5752.

Federal Reserve Bank of New York Research and Statistics Group. (2019, August). Quarterly report on household debt and credit. Retrieved from: https://www.newyorkfed.org/medialibrary/interactives/householdcredit/dat a/pdf/hhdc_2019q2.pdf.

Federici, S. (2018). Women, money and debt: Notes for a feminist reappropriation movement. Australian Feminist Studies, 33(96), 178-186.

Feiveson, L., Mezza, A. \&, Sommer, K. (2018). Student loan debt and aggregate consumption growth. FEDS Notes. Washington: Board of Governors of the Federal Reserve System, https://doi.org/10.17016/2380-7172.2127.

Field, R. I. (2011). Mother of invention: How the government created "free-market" health care. Oxford, UK: Oxford University Press.

Fifield, A. (1997). Corporate caseworkers. In Ganz, E. (Ed., 2017). The age of inequality: Corporate America's war on working people. New York: Verso.

Florida International University. (2019). Fall and spring costs, Florida resident. Undergraduate Tuition and Fees. https://onestop.fiu.edu/finances/estimate-yourcosts/undergraduate-tuition-fees/.

Florida International University, Analysis and Information Management. (2019). FIU Factbook. https://aim.fiu.edu/factbook2016/dash.html.

Florida International University, OneStop. (2019a). FIU's golden promise. OneStop. https://onestop.fiu.edu/finances/types-of-aid/golden-promise/.

Foucault, M. (2007). Security, territory, and population: Lectures at the College de France 1977-1978. New York, NY: Picador Press. 
Foucault, M. (2008a). The birth of bio-politics: Lectures at the College de France 19781979. New York, NY: Picador Press.

Foucault, M. (2008b). The courage of truth: Lectures at the College de France 19831984. New York, NY: Picador Press.

Fraser, M. (2016). Student debt and the next bailout. New Labor Forum, 25(1), 104-107.

Froggé, G.M. \& Woods, K.H. (2018). Characteristics and tendencies of first and second-generation university students. College Quarterly, 21(8).

Fuligni, A. J. (2001). Family obligation and the academic motivation of adolescents from Asian, Latin American, and European backgrounds. New Directions for Child and Adolescent Development, 2001(94), 61-76.

Fuligni, A. J., Tseng, V., \& Lam, M. (1999). Attitudes toward family obligations among American adolescents with Asian, Latin American, and European backgrounds. Child Development, 70(4), 1030-1044.

Fuller, M. B. (2014). A history of financial aid to students. Journal of Student Financial Aid, 44(1), 42-68.

Garza, K.K., Bain, S.F. \& Kupczynski, L. (2014). Resiliency, self-efficacy, and persistence of college seniors in higher education. Research in Higher Education Journal, 26, 1-19.

Gibbons, M. M. \& Borders, L. D. (2010). Prospective first-generation college students: a social cognitive perspective. The Career Development Quarterly, 58, 194-208.

Giani, M. S. (2016). Are all colleges equally equalizing? How institutional selectivity impacts socioeconomic disparities in graduates' labor outcomes. The Review of Higher Education, 39(3), 431-461.

Gildersleeve, R. E. (2017). The making of the indebted student. Thresholds, 41(1), 54-67.

Gillespie, M. A. (2018). On debt and redemption: Friedrich Nietzsche's doctrine of eternal recurrence. Journal of Religious Ethics, 46(2), p. 267-287.

Graeber, D. (2014). Debt: The first 5,000 years. Brooklyn, NY: Melville House.

Green, E. L. \& Saul, S. (2018, May 5). What Charles Koch and other donors to George Mason University got for their money. New York Times. https://www.nytimes.com/2018/05/05/us/koch-donors-george-mason.html. 
Gross, S. J. (2017, August 7). How many FIU freshmen qualify for new free tuition offer? The number may surprise you. Miami Herald. https://www.miamiherald.com/news/local/education/article165880812.html.

Harris, M. (2019, May 11). What's scarier than student loans? Welcome to the world of subprime children. New York Times. https://www.nytimes.com/2019/05/11/opinion/sunday/student-loans.html.

Hartlep, N. D., Eckrich, L. L., \& Hensley, B. O. (Eds.). (2017). The neoliberal agenda and the student debt crisis in US higher education. New York, NY: Routledge.

Harvey, D. (2005). Neoliberalism on trial. In C. Lemert (Ed.) Social Theory, Sixth Edition (pp, 470-471). Philadelphia, PA: Westview Press.

Harvey, D. (2007). A brief history of neoliberalism. Oxford University Press, USA.

Haultain, S., Kemp, S., \& Chernyshenko, O. S. (2010). The structure of attitudes to student debt. Journal of economic psychology, 31(3), 322-330.

Hayes, C. (2004) War profiteering and you. In Ganz, E. (Ed., 2017). The age of inequality: Corporate America's war on working people. New York: Verso.

Hillman, N. W. (2013). Economic diversity in elite higher education: Do no loan programs impact pell enrollments? Journal of Higher Education, 84(6), 803-833.

Houle, J. N., \& Warner, C. (2017). Into the red and back to the nest? Student debt, college completion, and returning to the parental home among young adults. Sociology of Education, 90(1), 89-108.

Hoxby, C. \& Avery. C. (2013). The missing "one-offs": The hidden supply of highachieving, low-income students. Brookings Papers on Economic Activity, Spring, $1-65$.

Hsu, C. \& Fisher, P.J. (2016). Which US households use education loans? Journal of Student Financial Aid, 43(6), 66-81.

Hunt, J. P. (2020). The development of federal student loan bankruptcy policy. The Journal of College and University Law, 45(1), 85-112.

Indiviglio, D. (2010, September 26). How Americans' love affair with debt has grown. The Atlantic. https://www.theatlantic.com/business/archive/2010/09/howamericans-love-affair-with-debt-has-grown/63552/. 
Jefferson, T. (1803). From Thomas Jefferson to William Henry Harrison, 27 February, 1803. Founders Online, National Archives. retrieved from: https://founders.archives.gov/documents/Jefferson/01-39-02-0500.

Joseph, M. (2014). Debt to society: Accounting for life under capitalism. Minneapolis, MN:University of Minnesota Press.

Joseph, T. (2017). Can't pay for college? FIU offers free tuition. NBC6 South Florida. https://www.nbcmiami.com/news/local/cant-pay-for-college-fiu-offers-freetuition/32440.

Jury, M., Smeding, A., Stephens, N. M., Nelson, J. E., Aelenei, C., \& Darnon, C. (2017). The experience of low-SES students in higher education: Psychological barriers to success and interventions to reduce social-class inequality. Journal of Social Issues, 73(1), 23-41.

Kelchen, R. (2015). Financial need and aid volatility among students with zero expected family contribution. Journal of Student Financial Aid, 44(3).

Keller, R. (2017). The "undue hardship" test: The dangers of a subjective test in determining the dischargeability of student loan debt in bankruptcy. Missouri Law Review, 82, 211-240.

Kezar, A. J., Walpole, M., \& Perna, L. W. (2015). Engaging low-income students. Student engagement in higher education: Theoretical perspectives and practical approaches for diverse populations, 237-255.

Kuh, G. D., Cruce, T. M., Shoup, R., Kinzie, J., \& Gonyea, R. M. (2008). Unmasking the effects of student engagement on first-year college grades and persistence. The Journal of Higher Education, 79(5), 540-563.

Labaree, D. (2018). A perfect mess: The unlikely ascendency of American higher education. Chicago: University of Chicago Press.

Lacayo, J. (2017, Feb 22). FIU's promise to 2017 freshman: As good as gold. FIU News: accessed March 24, 2018.

Lareau, A. (2011). Unequal childhoods: Class, race, and family life. Berkeley, CA: University of California Press.

Lazzarato, M. (2011). The making of the indebted man. Cambridge, MA: Semiotext(e) intervention.

Lazzarato, M. (2015). Governing by debt. Cambridge, MA: Semiotext(e) intervention. 
LeGower, M. \& Walsh, R. (2014). Promise scholarship programs as place-making policy: Evidence from school enrollment and housing prices. NBER Working Paper, No. 20056.

Lightcap, T. L. (2014). Academic governance and democratic processes: The entrepreneurial model and its discontents. New Political Science, 36(4), 474-488.

Lissovoy, N. (2015). Neoliberalism and the contradictions of freedom: Ideology, subjectivity, and critical pedagogy. Texas Education Review, 3(2), p. 44-54.

LoGerfo, L., Christopher, E. M., \& Denton Flanagan, K. (2011). High school longitudinal study of 2009: A first look at fall 2009 ninth-graders' parents, teachers, school counselors, and school administrators. (NCES Publication No. 2011355). Washington: U.S. Government Printing Office.

Looney, A. and Yannelis, C. (2015). A crisis in student loans? How changes in the characteristics of borrowers and in the institutions they attended contributed to rising loan defaults. Brookings Papers on Economic Activity, Fall 2015, 1-89.

Loss, C. P. (2012). Between citizens and the state: The politics of American higher education in the 20th century. Princeton, NJ: Princeton University Press.

Lowenberg, J.S. (1995). Health promotion and the "ideology of choice." Public Health Nursing, 12(5), 319-323.

Lumina Foundation. (2017). A history of federal student aid. Retrieved from: https://lookingback.luminafoundation.org/

Madeloni, B. (2014). From a whisper to a scream: Ethics and resistance in the age of neoliberalism. Learning and Teaching: The International Journal of Higher Education in the Social Sciences, 7(1), p. 79-91.

Malcolm, N. I. (2015). Slaves to the community: Blacks and the rhetoric of "selling out." Journal of African American Studies, 19(2), 120-134.

Mangan, K. (2016). Streamlining the path to program completion. The Chronicle of Higher Education. https://www.chronicle.com/article/Streamlining-the-Pathto/236053.

Mangan, K. (2017). Can 'guided pathways' keep students from being overwhelmed by choice? The Chronicle of Higher Education. https://www.chronicle.com/article/Can-Guided-Pathways-Keep/239886.

Marginson, S. (2011). Higher education and the public good. Higher Education Quarterly, 65(4), p. 411-433. 
Marginson, S. (2016). The worldwide trend to high participation higher education: Dynamics of social stratification in inclusive systems. Higher Education, 72(4), 413-434.

Martin, N. D. (2012). The privilege of ease: Social class and campus life at highly selective, private universities. Research in Higher Education, 53(4), 426-452.

Martineau, J. (2017). Culture in the age of acceleration, hypermodernity, and globalized temporalities. The Journal of Arts, Management, Law, and Society, 47(4), 218229.

Marx, B. M., \& Turner, L. J. (2019). The benefits of borrowing: Evidence on student loan debt and community college attainment. Education Next, 19(1), 70-77.

Maxwell, J. (2013). Qualitative Research Design: An Interactive Approach. Los Angeles, CA:Sage Publications, INC.

Mayhew, M. J., Pascarella, E. T., Bowman, N. A., Rockenbach, A. N., Seifert, T. A., Terenzini, P.T., \& Wolniak, G. C. (2016). How college affects students: 21st century evidence that higher education works (Vol. 3). San Francisco, CA: John Wiley \& Sons.

McNamara, W. (1974). The O'Hara Curriculum. Change, 6(10), 49-50.

McCowan, T. (2017). Higher education, unbundling, and the end of the university as we know it. Oxford Review of Education, 43(6), 733-748.

McDonald, P. (2017). Neoliberalism and the academy. PLG Program Papers, 25 June 2017. Retrieved from: http://www.progressivelibrariansguild.org/PL/PL46/128mcdonald.pdf.

McFarland, J., Hussar, B., Zhang, J., Wang, X., Wang, K., Hein, S.,..\& Barmer, A. (2019). The Condition of Education 2019. NCES 2019-144. National Center for Education Statistics.

Metcalf, S. (2017). Neoliberalism: The idea that swallowed the world. The Guardian. https://www.theguardian.com/news/2017/aug/18/neoliberalism-the-idea-thatchanged-the-world.

Minicozzi, A. (2005). The short term effects of educational debt on job decisions. Economics of Education Review, 24, 417-430. 
Minsky, A. (2019). New lawsuit says the government has failed student loan borrowers. Forbes. https://www.forbes.com/sites/adamminsky/2019/12/03/new-lawsuit-saysthe-government-has-failed-student-loan-borrowers/\#44abfaae232b.

Mitchall, A.M. \& Jaeger, A.J. (2018). Parental influences on low-income, firstgeneration students' motivation on the path to college. The Journal of Higher Education, 89(4), 582-609.

Montgomerie, J. (2008). Spectre of the subprime borrower: Beyond a credit score perspective. CRESC Working Paper Series, No. 58, 2-21.

Muir, D. E., \& Weinstein, E. A. (1962). The social debt: An investigation of lower-class and middle-class norms of social obligation. American Sociological Review, 27(4), 532-539.

Mullen, A. L. (2009). Elite destinations: Pathways to attending an Ivy League university. British Journal of Sociology of Education, 30(1): 15-27.

Nelson, L. A. (2011). Invisible spending on financial aid. Inside Higher Education. https://www.insidehighered.com/news/2011/11/16/tax-credits-tuition-growingrapidly.

Nilsen, E. (2018, Mar 20). Sen. Brian Schatz's ambitious new plan for debt-free college, explained. Vox. Retrieved from:

https://www.vox.com/policy-and-politics/2018/3/20/17124080/brian-schatz-debtfree-college-plan-senate.

Nova, A. (2018, Sep 22). Despite the economic recovery, student debtors' 'monster in the closet' has only worsened. CNBC Personal Finance. https://www.cnbc.com/2018/09/21/the-student-loan-bubble.html.

Nowotny, H. (1994). Time: The modern and postmodern experience. Malden, MA: Polity Press.

O'Meara, K. A. (2007). Striving for what? Exploring the pursuit of prestige. In J.C. Smart (Ed.) Higher education: Handbook of theory and research vol. XXII (pp. 121-179). New York, NY: Springer.

O'Shea, S. (2014). Filling up silences: first in family students, capital and university talk in the home. International Journal of Lifelong Education, 34(2), 139-155.

Office of Hillary Rodham Clinton. (2019). Making college debt-free and taking on student debt. Retrieved from: https://www.hillaryclinton.com/issues/college/.

Olin Wright, E. (2015). Understanding Class. Brooklyn, NY: Verso. 
Olson, J.S. (2014). Opportunities, obstacles, and options: first-generation college graduates and social cognitive career theory. Journal of Career Development, 41(3), 199-217.

Ostry, J.D., Loungani, P., and Furceri, D. (2016). Neoliberalism: Oversold? Finance and Development, 53(2), 38-41.

Padgett Walsh, K. (2018). Transforming usury into finance: Financialization and the ethics of debt. Finance and Society, 4(1), p. 41-59.

Pancer, S.M., Hunsberger, B., Pratt, M.W., \& Alisat, S. (2000). Cognitive complexity of expectations and adjustments to university in the first year. Journal of Adolescent Research, 15(1), p. 38-57.

Patton, M. Q. (2002). Two decades of developments in qualitative inquiry: A personal, experiential perspective. Qualitative social work, 1(3), 261-283.

Peebles, G. (2010). The anthropology of credit and debt. Annual Review of Anthropology, $39,225-240$.

Perkins, L. M. (1983). The impact of the "cult of true womanhood" on the education of black women. Journal of Social Issues, 39(3), 17-28.

Perna, L. W. (2008). Understanding high school students' willingness to borrow to pay college prices. Research in Higher Education, 49(7), 589-606.

Perna, L. W. (2015). Improving college access and completion for low-income and firstgeneration students: The role of college access and success programs.

Retrieved from http://repository.upenn.edu/gse pubs/301.

Perna. L.W. \& Leigh, E.W. (2018). Understanding the promise: A typology of state and localcollege promise programs. Educational Researcher, 47(3), p. 155-180.

Perna, L.W., \& Leigh, E.W. (2019). Database of college promise programs. Philadelphia, PA: University of Pennsylvania, Alliance for Higher Education and Democracy. Retrieved from http://ahead-penn.org/creating-knowledge/college-promise.

Perna, L. W., Kvaal, J., \& Ruiz, R. (2017). An updated look at student loan debt repayment and default. Penn Wharton Public Policy Initiative, 46. Retrieved from: https://publicpolicy.wharton.upenn.edu/live/files/278-a.

Persky, J. (1995). The ethology of homo economicus. The Journal of Economic Perspectives, 9(2), 221-231. 
Pete for America. (2020). The American opportunity agenda: Affordable college, stronger workforce development, and lifelong learning. Retrieved from: https://peteforamerica.com/policies/higher-education/.

Peters. M.A. (2016). Biopolitical economies of debt. Analysis and Metaphysics, 15, 7-19.

Pettus, A. (2007). The “sellout." Harvard Magazine. https://harvardmagazine.com/2007/11/the-sellout.html.

Pew Charitable Trusts. (2011). Economic Mobility Project [Data set]. The Mellman Group and Public Opinion Strategies [Distributor]. Retrieved from:

http://www.pewtrusts.org/ /media/legacy/uploadedfiles/pcs_assets/2011/mellman polldocument-1.pdf.

Phillips, E. D. (2013). Improving advising using technology and data analytics. Change, $45(1), 48-55$.

Polletta, F. \& Tufail, Z. (2014). The moral obligations of some debts. Sociological Forum, 29(1), 1-28.

Poutre, A. \& Voight, M. (2018). The state of free college: Tennessee promise and New York's excelsior scholarship. Institute for Higher Education Policy. Washington, DC. Retrieved From:http://www.ihep.org/research/publications/state-free-collegetennessee-promise-and-new-yorks-excelsior-scholarship.

Protopsaltis, S. \& Parrott, S. (2017). Pell grants - a key tool for expanding college access and economic opportunity - need strengthening, not cuts. Center on Budget and Policy Priorities. https://www.cbpp.org/sites/default/files/atoms/files/7-2717bud.pdf.

Ramos-Sanchez, L. \& Nichols, L. (2007). Self-efficacy of first-generation and non-first-generation college students: the relationship with academic performance and college adjustment. Journal of College Counseling, 10, 6-18.

Robinson, J. \& Gobdey. G. (2005). Business as usual. Social Research, 72(2), 407-426.

Robinson, O.C. (2014). Sampling in interview-based qualitative research: A theoretical and practical guide. Qualitative Research in Psychology, 11(1), 25-41.

Rogers et al. (2015). Trajectories of positive and negative affect across the transition to college: The role of daily interactions with parents and friends. Developmental Psychology, 54(11), p. 2181-2192. 
Rowlands, J. and Rawolle, S. (2013). Neoliberalism is not a theory of everything: a Bourdieuian analysis of illusio in educational research. Critical Studies in Education, 54(3), 260-272.

Rhoden, W.C. (2019). What if top athletes used their leverage to get scholarships for academic stars? One-and-done players could turn their influence into a four-year education for someone else. The Undefeated. Retrieved from: https://theundefeated.com/features/athletes-like-zion-williamson-should-use-theirscholarships-to-educate-others/.

Sacks, P. (2007). Tearing down the gates: Confronting the class divide in American education. Berkeley, CA: Univ of California Press.

Saez, E. (2018). Striking it richer: The evolution of top incomes in the United States (updated with 2017 final estimates). Retrieved from: https://eml.berkeley.edu/ saez/saez-UStopincomes-2017.pdf.

Saldaña, J. (2009). The coding manual for qualitative researchers. Thousand Oaks, CA: Sage Publications Ltd.

Sanders, B. [@BernieSanders] (2019, September 12). Are you truly free [Tweet]. Twitter. https://twitter.com/BernieSanders/status/1172221309025210369.

Saunders, C. B. (1982). Sorry, this commitment may be cancelled: Higher education and Ronald Reagan. Change: The Magazine of Higher Learning, 14(1), 7-9.

Saunders, D. B., \& Blanco Ramirez, G. (2017). Resisting the neoliberalization of higher education: A challenge to commonsensical understandings of commodities and consumption. Cultural Studies $\leftrightarrow$ Critical Methodologies, 17(3), 189-196.

Shirazi, N. and Johnson, A. (2019). The hollow vanity of libertarian "choice" rhetoric. Citations Needed [Audio podcast].

Shure, N. (2019). We don't need choice - we need medicare for all. Jacobin Magazine. https://www.jacobinmag.com/2019/10/donald-trump-medicareadvantage-health-insurance.

Seidman, I. (2013). Interviewing as qualitative research: A guide for researchers in the education and social sciences. New York, NY: Columbia University Press.

Serna, G.R. \& Woulfe, R. (2017). Social reproduction and college access: current evidence, context, and potential alternatives. Critical Questions in Education 8(1), $1-16$. 
Slanger, W. D., Berg, E. A., Fisk, P. S., \& Hanson, M. G. (2015). A longitudinal cohort study of student motivational factors related to academic success and retention using the college student inventory. Journal of College Student Retention: Research, Theory \& Practice, 17(3), 278-302.

Slaughter, S. and Rhoads, G. (2004). Academic capitalism and the new economy: Markets, states, and higher education. Baltimore, MD: Johns Hopkins University Press.

Smith, J.A., Flowers, P., \& Larkin, M. (2009). Interpretive phenomenological analysis: Theory, method, and research. Los Angeles, CA: Sage.

Smithers, L. E. (2018). A molecular sociology of student success in undergraduate education [Unpublished doctoral dissertation]. University of Oregon.

Sollenberger, R. (2019, April 11). The student debt crisis explained: How we got here, why it's getting worse, and how to (maybe) fix it. Paste.

https://www.pastemagazine.com/articles/2019/04/the-student-debt-crisisexplained-how-we-got-here.html.

Soos. P. (2016, Aug 29). Private tax is the great unspoken of neoliberal philosophy. And the rich are winners. The Guardian. Retrieved from: https://www.theguardian.com/commentisfree/2016/aug/30/private-tax-is-thegreat-unspoken-of-neoliberal-philosophy-and-the-rich-are-the-winners.

Soria, K. M., Weiner, B., \& Lu, E. C. (2014). Financial decisions among undergraduate students from low-income and working-class social class backgrounds. Journal of Student Financial Aid, 44(1), 2-23.

Stebleton, M. J., Soria, K. M., \& Huesman Jr, R. L. (2014). First-generation students' sense of belonging, mental health, and use of counseling services at public research universities. Journal of College Counseling, 17(1), 6-20.

State Higher Education Executive Officers. (2016). State higher education finance: FY 2016. Boulder, CO: SHEEO.

Stein, C.H., Wemmerus, V.A., Ward, M., Gaines, M.E., Freeberg, A.L., and Jewell, T.C. (1998). "Because they're my parents": An intergenerational study of felt obligation and parental caregiving. Journal of Marriage and the Family, 60, pp. 611-622.

Steinbeck, J. (1952; 1992). East of eden. New York, NY: Penguin Random House. 
Swanson, E., Watson, A., Ritter, G., and Malachi, N. (2016). Promises fulfilled? A systematic review of the impacts of promise programs. University of Arkansas Working Paper Series, EDRE WP 2016-16.

Sweet, E. (2018). "Like you failed at life": Debt, health, and neoliberal subjectivity. Social Science and Medicine, 212, p. 86-93.

Sweet, E., Nandi, A., Adam, E., \& McDade, T. (2013). The high price of debt: Household financial debt and its impact on mental and physical health. Social Science \& Medicine, 91, 1-16.

Tadair, N.X.M. (2013). Life-times of disposability within global neoliberalism. Social Text, 31(2), 19-48.

Tatham, M. (2019, July 24). Student loan debt climbs to \$1.4 trillion in 2019. Experian. https://www.experian.com/blogs/ask-experian/state-of-student-loan-debt/.

Thompson, L. J., \& Coghlan, J. (2015). Neoliberalism by stealth: Exposing the flaw of neoliberal understandings of 'freedom'. Social Alternatives, 34(3), 60-66.

Tilly, C. (1998). Durable Inequality. Berkeley, CA: University of California Press.

Tinto, V. (2006). Research and practice of student retention: What next? Journal of College Student Retention: Research, Theory \& Practice, 8(1), 1-19.

Tseng, V. (2004). Family interdependence and academic adjustment in college: Youth from immigrant and U.S.-born families. Child Development, 75(3), pp. 966-983.

Tuck, E. (2009). Suspending damage: A letter to communities. Harvard Educational Review, 79(3), 409-427.

United Press International. (1970, February 1). Student loan crisis may block return of many to college. New York Times. https://www.nytimes.com/1970/02/01/archives/student-loan-crisis-may-blockreturn-of-many-to-college.html.

U.S. Department of Education, College Scorecard. (2019). Florida International University. https://collegescorecard.ed.gov/school/?133951-Florida-InternationalUniversity.

U.S. Department of Education, Federal Student Aid (2004). Federal student aid handbook. https://ifap.ed.gov/ilibrary/document-types/federal-student-aidhandbook? award_year=2003-2004\&archive $=1$. 
U.S. Department of Education, Federal Student Aid. (2019). Apply for financial aid. Retrieved from: https://studentaid.gov/h/apply-for-aid.

U.S. Department of Education, National Center for Education Statistics (2015). Integrated Postsecondary Education Data System. Retrieved from: https://nces.ed.gov/ipeds/datacenter/InstitutionByName.aspx.

U.S. Department of Education, National Center for Education Statistics. (2015a). The Condition of Education (NCES Publication No. 2015144). Washington: U.S. Government Printing Office.

U.S. Department of Education, National Center for Education Statistics. (2016). The Condition of Education (NCES Publication No. 2016144). Washington: U.S. Government Printing Office.

U.S. Department of Education, National Center for Education Statistics. (2018). The Condition of Education (NCES Publication No. 2018144). Washington: U.S. Government Printing Office.

U.S. News and World Report. (2019). Florida International University. U.S News and World Report. https://www.usnews.com/best-colleges/fiu-9635.

Valines, F. (2017). Golden promise: Utilizing advanced financial aid packaging to meet strategic goals. Florida College Access. http://floridacollegeaccess.org/wpcontent/uploads/2017/05/Francisco-Valines-FIU-Golden-Promise.pdf.

Wacquant, L. (2012). Three steps to a historical anthropology of actually existing neoliberalism. Social Anthropology, 20(1), 66-79.

Walpole, M. (2003). Socioeconomic status and college: How SES affects college experiences and outcomes. The Review of Higher Education, 27(1), 45-73.

Warren for President. (2020). Affordable higher education for all. Retrieved from: https://elizabethwarren.com/plans/affordable-higher-education.

Welch, L. (2012). Neoliberalism, economic crisis, and the 2008 financial meltdown in the United States. International Review of Modern Sociology, 38(2), 221-257.

William, J. (2006). The pedagogy of debt. College Literature, 33(4), p. 155-169.

Williams, J. R., Masuda, Y. J., \& Tallis, H. (2016). A measure whose time has come: Formalizing time poverty. Social Indicators Research, 128(1), 265-283. 
Wood, J. L., \& Harrison, J. D. (2014). College choice for black males in the community college: Factors influencing institutional selection. Negro Educational Review, 65.

Xue, M., \& Chao, X. (2015). Non-borrowing students' perceptions of student loans and strategies of paying for college. Journal of Student Financial Aid, 45(2), 25-45.

Zerquera, D. D., McGowan, B. L., \& Ferguson, T. L. (2016). Yes, No, Maybe So: College Students' Attitudes Regarding Debt. Journal of College Student Development, 57(5), 609-613.

Zhou, E. \& Mendoza, P. (2017). Financing higher education in the United States: A historical overview of loans in federal financial aid policy. In Hartlep, N.D., Eckrich, L.L.T., \& Hensley, B.O. (Eds.), The neoliberal agenda and the student debt crisis in U.S. higher education: Indebted collegians of the neoliberal American university. New York, NY: Routledge.

Ziol-Guest, K. M., \& McKenna, C. C. (2014). Early childhood housing instability and school readiness. Child Development, 85(1), 103-113.

Zumeta, W., Breneman, D. W., Callan, P. M., \& Finney, J. E. (2012). Financing American higher education in the era of globalization. Cambridge, MA: Harvard Education Press. 


\section{APPENDIX A: SAMPLE PARTICIPATION REQUEST}

Hello <Student $>$,

My name is Michael Ward and I am a doctoral student at Florida International University. I am currently looking to recruit participants for a research study examining students' experiences with the Golden Promise program at FIU. I am emailing to ask if you would be interested in sharing your experiences as a participant in the study. Participation will involve taking part in one interview, with the possibility of a second follow up interview. I estimate that the first interview will last up to 90 minutes and, if necessary, a 45-minute follow up.

Participation in this study is completely voluntary and the information you provide will remain confidential. If you would like additional information about participating, please contact me at mward030@fiu.edu. Requesting additional information does not mean that you are enrolled as a participant in the study. Students who are selected to participate in the study will receive a $\$ 10$ Amazon or Publix gift-card as a token of appreciation for their participation.

This study will provide valuable information about students' experiences in the Golden Promise program and at FIU more broadly and could be very helpful to current and future FIU students. I appreciate your consideration of participating in this research and look forward to hearing from you. Again, if you would like more information or are interested in participating, please contact me at mard030@ fiu.edu and we can set up a time to talk.

Warm regards,

Michael Ward 


\title{
APPENDIX B: INFORMED CONSENT DOCUMENT
}

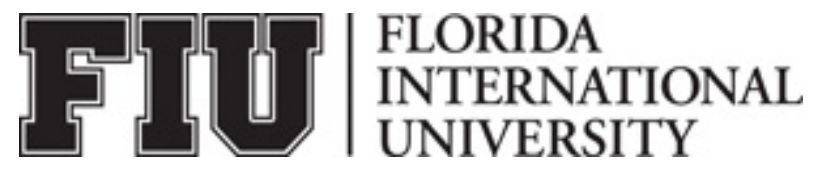

\author{
ADULT CONSENT TO PARTICIPATE IN A RESEARCH STUDY \\ The Promise and (Im)Possibility of the Debt Free Student: A Qualitative Analysis
}

PURPOSE OF THE STUDY

You are being asked to be in a research study. The purpose of this study is explore students' experiences with different forms of debt and the influence debt has on their decision making.

\section{NUMBER OF STUDY PARTICIPANTS}

If you decide to be in this study, you will be one of up to 15 people in this research study.

\section{DURATION OF THE STUDY}

Your participation will require approximately 90 minutes over the course of a single interview session. At a later date, a follow-up interview may be requested by the interviewer or by you.

\section{PROCEDURES}

If you agree to be in the study, you will be asked to respond to a series of open-ended questions and to engage in conversation with the interviewer. The interview will be audio recorded, and a transcript or recording of the interview will be provided to you upon request.

\section{RISKS AND/OR DISCOMFORTS}

There are no known or anticipated risks associated with your participation in this study.

\section{BENEFITS}

There are no known or anticipated benefits associated with your participation in this study.

\section{ALTERNATIVES}

There are no known alternatives available to you other than not taking part in this study. However, any significant new findings developed during the course of the research which may relate to your willingness to continue participation will be provided to you.

\section{CONFIDENTIALITY}

The records of this study will be kept private and will be protected to the fullest extent provided by law. In any sort of report we might publish, we will not include any information that will make it possible to identify a subject. Your responses to interview questions will be coded with a pseudonym or false name. Research records will be stored 
securely in a password protected environment and only the researcher will have access to the records. However, your records may be reviewed for audit purposes by authorized University or other agents who will be bound by the same provisions of confidentiality.

\section{COMPENSATION \& COSTS}

If you are selected to participate in this study, you will receive a $\$ 10$ Visa gift card at the time of your interview. You will not be responsible for any costs to participate in this study.

\section{RIGHT TO DECLINE OR WITHDRAW}

Your participation in this study is voluntary. You are free to participate in the study or withdraw your consent at any time during the study. Your withdrawal or lack of participation will not affect any benefits to which you are otherwise entitled. The researchers reserve the right to remove you without your consent at such time that they feel it is in the best interest.

\section{RESEARCHER CONTACT INFORMATION}

If you have any questions about the purpose, procedures, or any other issues relating to this research study you may contact Michael Ward at mward030@fiu.edu.

\section{IRB CONTACT INFORMATION}

If you would like to talk with someone about your rights of being a subject in this research study or about ethical issues with this research study, you may contact the FIU Office of Research Integrity by phone at (305) 348-2494 or by e-mail at ori @ fiu.edu.

\section{PARTICIPANT AGREEMENT}

I have read the information in this consent form and agree to participate in this study. I have had a chance to ask any questions I have about this study, and they have been answered for me. I understand that I will be given a copy of this form for my records.

Signature of Participant

Printed Name of Participant

Signature of Person Obtaining Consent
Date

Date 


\section{APPENDIX C: INTERVIEW GUIDE}

This semi-structured interview guide includes questions that were used during the research interviews after discussing and completing the informed consent document. Since each participant's experience with debt, choice, and the Golden Promise was different, each interview was approached as a conversation and follow-up questions were asked based on the direction of the student's response. Depending on the direction of each interview, not every question was asked, and additional follow-up questions were utilized where appropriate.

1. Can you provide a brief history of your life up through your decision to come to FIU?

2. Why did you come to college? What made you choose FIU? (How did you come to decide etc)

3. Tell me about how you felt when you found out you received the Golden Promise Scholarship at FIU?

4. What does receiving this scholarship mean to you as an individual and in relation to your family and community?

5. What are some academic related expenses that are not covered by your financial aid, if any?

6. Do you have a job to help cover extra expenses?

7. How many hours per week do you work?

8. What are some of the responsibilities and obligations you feel you have outside of your academics? (Talk to me about some of the obligations you feel beyond studying, academics etc.)

9. What role does family play in your life?

10. Who are some of the people that have been influential in your life?

11. Tell me about a time where you've had to make an important decision regarding your academic future? How did you come to that decision? What were some of the factors that influenced the choice(s) you made?

12. Talk to me about some community spaces that were important in your goals and education?

13. Where do you want to see yourself in 5 or 10 years?

14. What factors do you think might influence the decisions you make?

15. What are your goals/what is beneath those goals?

16. We've talked about all of these things - how are you thinking about this now? Is there anything else you'd like to share? How might you be thinking about debt based on all of the things we've talked about. 
VITA

\section{MICHAEL W. WARD \\ Born, Westwood, NJ}

2010

B.S., Psychology

Fordham University

Bronx, New York

2014

M.A., Counseling

Montclair State University

Montclair, New Jersey

$2015-2019$

Senior Academic Advisor

Florida International University

Miami, Florida

$2019-2020$

Academic Coach

Central New Mexico Community College

Albuquerque, New Mexico

$2015-2020$

Doctoral Candidate, Higher Education

Florida International University

Miami, Florida

\section{PRESENTATIONS}

Ward, M. W. (2018). The Student Activist as Public Intellectual. Presented at the 2018 Association for the Study of Higher Education Annual Conference, Tampa, FL.

Ward, M. W. (2018). Opportunity Hoarding, Cultural Capital, and Elite American Higher Education. Presented at the Southeastern Philosophy of Education Society Annual Meeting, Chattanooga, TN.

Ward, M. W. (2017). Habitus, Cultural Capital and Elite American Higher Education. Presented at the 2017 Association for the Study of Higher Education Annual Conference, Houston, TX. 